\author{
UNIVERSIDADE DE SÃO PAULO \\ FFCLRP - DEPARTAMENTO DE FÍSICA E MATEMÁTICA \\ PROGRAMA DE PÓS- GRADUAÇÃO EM FÍSICA APLICADA À MEDICINA \\ E BIOLOGIA
}

\title{
Dinâmica da alteração perfusional induzida por estado de apnéia utilizando fMRI
}

Kátia Cristine Andrade

Dissertação apresentada à Faculdade de Filosofia, Ciências e Letras de Ribeirão Preto da USP, como parte das exigências para a obtenção do título de Mestre em Ciências, Área: Física Aplicada à Medicina e Biologia.

RIBEIRÃO PRETO - SP 


\section{UNIVERSIDADE DE SÃO PAULO \\ FACULDADE DE FILOSOFIA CIÊNCIAS E LETRAS DE RIBEIRÃO PRETO}

\section{Dinâmica da alteração perfusional induzida por estado de apnéia utilizando fMRI}

\begin{abstract}
Dissertação de Mestrado apresentada à Faculdade de Filosofia Ciências e Letras de Ribeirão Preto da Universidade de São Paulo para obtenção do Título de Mestre em Ciências, área de concentração Física Aplicada à Medicina e Biologia.
\end{abstract}

Aluna: Kátia Cristine Andrade

Orientador: Prof. Dr. Dráulio Barros de Araújo 


\section{FICHA CATALOGRÁFICA}

Preparada pela Biblioteca Central

Do Campus Administrativo de Ribeirão Preto

\section{Andrade, Kátia Cristine}

Dinâmica da alteração Perfusional Induzida por Estado de Apnéia utilizando Fmri. Ribeirão Preto, 2006. 147p.

Dissertação de Mestrado apresentada à Faculdade de Filosofia Ciências e Letras de Ribeirão Preto da Universidade de São Paulo - Área de Concentração: Física Aplicada à Medicina e Biologia.

Orientador: de Araújo, Dráulio Barros.

1. fMRI. 2. Apnéia. 3. BOLD. 4. Perfusão. 
Pra você que merece todo e qualquer elogio que se tece, pra você que é tão...vocêe(!): Leandro Ibiapina Beviláqua. 


\section{Agradecimentos}

Agradeço a Deus, meu guia espiritual e protetor que, através de acasos, coincidências e sorte, sempre me mostra o caminho.

À minha mãe, Auxiliadora, torcedora incondicional, pessoa que admiro e amo. Escutar que sou parecida com ela é um dos melhores elogios que posso receber.

Às minhas irmãs, Cybelle e Fábia, que fizeram e fazem parte do meu aprendizado como pessoa, pelo carinho, pela força e por acreditarem em mim.

Ao meu pai, Andrade, que tem tentado ser mais presente (espero que um dia possamos nos entender de verdade). Agradeço, também, à Madalena, sua esposa, por todo apoio e carinho.

À Danusa, amiga de infância, que apesar dos impropérios da vida, sempre esteve comigo.

Ao prof. Dr. Gil de Aquino Farias, por tudo que aprendi na minha iniciação científica, pela amizade e confiança em meu potencial.

Ao prof. Dr. Erivan Melo, por toda a ajuda que me deu quando decidi fazer meu mestrado em Ribeirão Preto.

Aos meus amigos de graduação, Aristeu, Bruno Abagaro, Bruno Bastos, David, Ednilson, Felipe, Franciné, Leandro, Lucas, Victor, Vladmir, Wagner, que me ajudaram a completar uma fase importante da minha vida.

À Elizete, pessoa generosa que me acolheu em São Carlos.

A todos os amigos que fiz em Ribeirão, Brunão, Catherine, Juliana, Khallil, Nivia, Renata, Sara, Zaira e em especial, aos amigos Fabiana, Hellen, Lincon, Márcio, Paula, Regis e Tiago pelo apoio, incentivo, companhia, por estarem do meu lado (ou ao menos por tentarem) nos momentos difíceis e tornarem ainda mais agradáveis os fáceis.

À Kamillinha, com quem eu tive o prazer de dividir não só o apartamento mas as dificuldades e conquistas, pelos momentos de desabafo e confiança.

Ao prof. Dr. Antônio Adilton Oliveira Carneiro e Ivana Mara Rabello que sempre me ajudaram e apoiaram. 
Ao Dr. Octávio Pontes Neto, pelas discussões sobre o trabalho, por se preocupar comigo e por sempre se mostrar disponível quando precisei.

Aos técnicos da ressonância do HC, Reginaldo, Matheus e Sandra, pela paciência e competência.

Por fim, ao prof. Dr. Dráulio Barros de Araújo, pessoa admirável, que se mostrou igualmente importante nos assuntos mais diversos. Por sua atenção e recepção quando cheguei aqui em Ribeirão e por tudo que aprendi com ele sobre a ciência, sobre as pessoas e sobre a vida de um modo geral. Obrigada, também, pela compreensão, apoio, confiança e críticas. 
"Pesquisar é a vontade de se entender algo e a necessidade de se inserir em alguma coisa." 


\section{REsumo}

O mecanismo de contraste mais utilizado em imagens funcionais por ressonância magnética (functional Magnetic Resonance Imaging, fMRI), também conhecido por sinal BOLD (Blood Oxygenation Level Dependent) mede indiretamente a atividade neural, sendo sensível a mudanças no fluxo cerebral sangüíneo (Cerebral Blood Flow, $\mathrm{CBF}$ ), na taxa cerebral metabólica do oxigênio (Cerebral Metabolic Rate of Oxygen, $\mathrm{CMRO}_{2}$ ) e no volume cerebral sanguíneo (Cerebral Blood Volume, CBV) e, em princípio, ele pode ser utilizado para mapear perfusão cerebral. Desse modo, o objetivo principal deste trabalho foi investigar, quantitativamente, alterações perfusionais no cérebro humano mapeadas pelas mudanças do sinal BOLD em resposta à indução transitória do estado de apnéia. Para isso, imagens por ressonância magnética foram obtidas através de um scanner de 1.5 T Siemens (Magneton Vision) com seqüências do tipo EPI-BOLD. Nesta pesquisa, foi analisada a influência da duração da apnéia no sinal BOLD. Observou-se, também, a diferença ocasionada no sinal em duas situações: apnéia iniciando-se após a inspiração ou após a expiração. Além disso, foi estudada a propagação deste sinal BOLD pelas diferentes regiões cerebrais. Por último, fazendo uso deste sinal BOLD, construiu-se mapas para obter informações a respeito do volume cerebral sangüíneo. Pelos dados obtidos, foi possível analisar o comportamento do sinal BOLD quando na presença de diferentes $\mathrm{PaO}_{2}$ e $\mathrm{PaCO}_{2}$. Observaram-se, também, diferenças regionais na sensibilidade do sinal BOLD ocasionada pelo estado de apnéia induzido. Essa diferença pode estar relacionada à reatividade das artérias que irrigam cada região ou ao volume sangüíneo basal dessas artérias. Além disso, foi possível obter informações a respeito das características temporais da mudança do CBF para diferentes regiões do cérebro em resposta a hipercapnia. Também, foi feita a identificação de áreas corticais responsáveis pelo controle voluntário da respiração. Por fim, os mapas de B-CBV obtidos utilizando o contraste BOLD em resposta à apnéia foram capazes de refletir o volume sangüíneo local, embora, estudos para análise dos outros parâmetros que influenciam o sinal devam ser realizados. 


\begin{abstract}
The BOLD (Blood Oxygenation Level Dependent) signal, is the most used contrast mechanism of the so called functional Magnetic Resonance Imaging (fMRI). Although it indirectly measures neuronal activity, its response is directly related to cerebral blood flow (CBF), Cerebral Metabolic Rate of Oxygen (CMRO2) and Cerebral Blood Volume (CBV) and can be, in principle, used to map cerebral perfusion. Thus, the main purpose of this study was to investigate, quantitatively, some aspects of perfusional alterations in the human brain. These changes were mapped by changes in the BOLD signal as a result of a global and uniform stimulation: hypercapnia induced by breath holding paradigms. Magnetic resonance images were acquired in a $1.5 \mathrm{~T}$ scanner (Siemens, Magneton Vision) with EPI-BOLD fMRI sequences. It was analyzed the BOLD dependency on breath holding duration and differences on the BOLD signal due the employed breath holding techniques: breath holding after expiration or after inspiration. The regional variability of the BOLD signal propagation was also studied. Moreover, the signal was used to construct maps based on CBV information. It was possible to gain information about the BOLD signal behavior that respond to $\mathrm{PaO}_{2}$ and $\mathrm{PaCO}_{2}$ alterations. Besides, it was demonstrated its regional variations sensibility, which can be correlated with arterial reactivity or the rest CBV of this arteries. It was also possible acquire information about the temporal characteristics of CBF changes induced by hypercapnia across brain regions as well as the identification of cortical areas that were responsible to the voluntary breathing. Finally, the B-CBV maps that used the BOLD contrast were able to reflect CBV information, although, it is necessary the study of other parameters that can influence the signal.
\end{abstract}




\section{LiSTA DE ABREVIATURAS}

$\mathrm{AB}$

ACA

$\mathrm{ACM}$

ACP

ACV

AIF

ASL

$\mathrm{BBB}$

BOLD

$\mathrm{CBF}$

CBV

$\mathrm{CMRO}_{2}$

CSF

$\mathrm{dHb}$

DSP

EPI

FID

fMRI

FOV

GLM
Área de Brodmann

Artéria Cerebral Anterior

Artéria Cerebral Média

Artéria Cerebral Posterior

Linha vertical da comissura anterior

Acrônimo do idioma inglês que representa: Arterial Input Function

Acrônimo do idioma inglês que representa: Arterial Spin Labelling

Acrônimo do idioma inglês que representa: Blood Brain Barrier

Acrônimo do idioma inglês que representa: Blood Oxygen Level Dependent

Acrônimo do idioma inglês que representa: Cerebral Blood Flux

Acrônimo do idioma inglês que representa: Cerebral Blood Volume

Acrônimo do idioma inglês que representa: Cerebral Metabolic Rate of Oxygen

Acrônimo do idioma inglês que representa: Cerebral Spinal Fluid

Hemoglobina deoxigenada

Diagramas de seqüências de pulso

Acrônimo do idioma inglês que representa: Eco-Planar Imaging

Free Induction Decay

Acrônimo do idioma inglês que representa: Functional Magnetic Resnoance Imaging

Acrônimo do idioma inglês que representa: , field of view

Acrônimo do idioma inglês que repre- 
Glut-1

$\mathrm{Hb}$

HRF

$\mathrm{JPO}_{2}$

$\mathrm{JSO}_{2}$

MRI

MTT

NMR

$\mathrm{PaCO}_{2}$

$\mathrm{PCSF}_{2}$

PET

$\mathrm{PaO}_{2}$

$\mathrm{RF}$

ROI

$\mathrm{SNC}$

SPECT

TE

TI

TMS

TR

VASO

VOI
Acrônimo do idioma inglês que representa: glucose transporter, isotype 1

Hemoglobina oxigenada

Acrônimo do idioma inglês que representa: hemodinamic response function

Pressão na jugular de $\mathrm{O}_{2}$

Saturação de $\mathrm{O}_{2}$ na jugular

Acrônimo do idioma inglês que representa: Magnetic Resonance Imaging

Acrônimo do idioma inglês que representa: Mean Transit Time

Acrônimo do idioma inglês que representa: Nuclear Magnetic Resonance

Pressão arterial de $\mathrm{CO}_{2}$

Pressão de oxigênio no CSF

Acrônimo do idioma inglês que representa: Positron Emission Tomography

Pressão arterial de $\mathrm{O}_{2}$

Radiofreqüência

Acrônimo do idioma inglês que representa: Region of Interest

Sistema Nervoso Central

Acrônimo do idioma inglês que representa: Single Photon Emission Computer Tomography

Tempo ao Eco

Tempo de inversão

Acrônimo do idioma inglês que representa: Transcranial Magnetic Stimulation

Tempo de Repetição

Acrônimo do idioma inglês que representa: vascular space occupancy

Acrônimo do idioma inglês que representa: Volume of Interest 


\section{ÍNDICE}

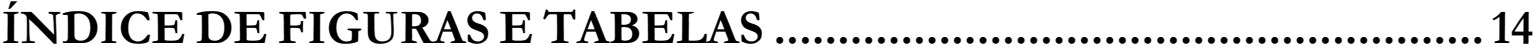

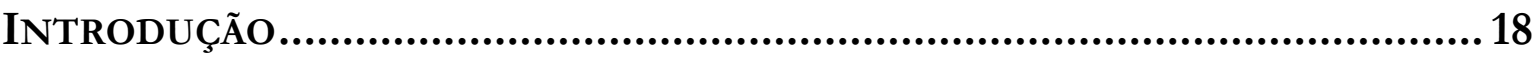

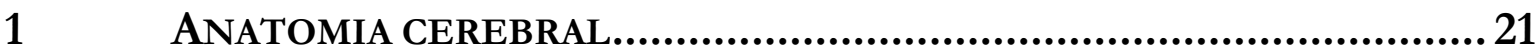

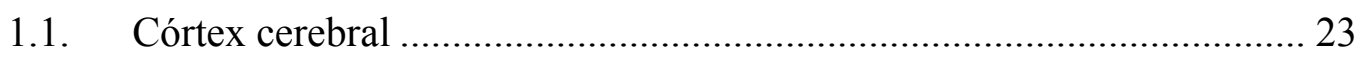

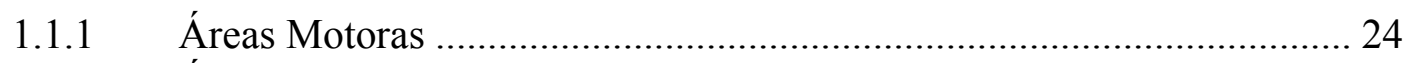

1.1.2 Áreas Sensitivas............................................................................ 25

1.1.3 Áreas de Associação............................................................................. 26

2 CIRCULAÇÃO do SiSTEMA NERVOSO ...........................................29

2.1 Anatomia da circulação cerebral ......................................................... 31

2.2 Os territórios de irrigação arterial............................................................. 35

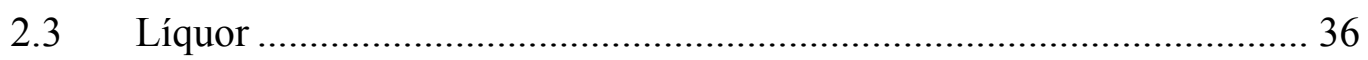

2.4 Barreira hematoencefálica ................................................................... 39

2.5 Vascularização venosa do encéfalo ......................................................... 42

2.5.1 Veias do cérebro ............................................................................... 42

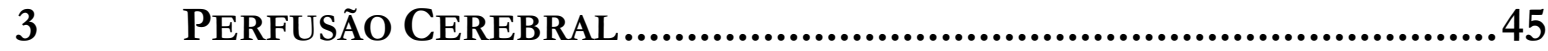

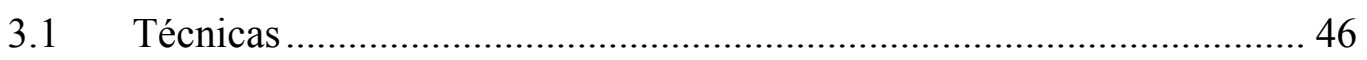

3.1.1 Medidas de perfusão usando DSC.......................................................... 46

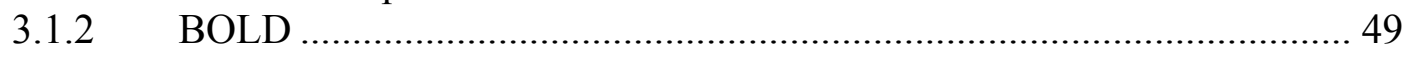

$\rightarrow$ Relações fisiológicas do efeito BOLD ………………………………….... 51

$\rightarrow$ Modelando o efeito BOLD ………………………………………..... 52

$\rightarrow$ Efeito da susceptibilidade magnética e o sinal de MR ............................. 52

$\rightarrow$ Mudanças no sinal BOLD ..................................................................... 54

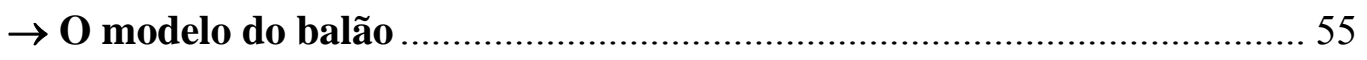

$\rightarrow$ Acoplamento neurovascular ...................................................................... 57

$\rightarrow$ Efeitos da linha de base fisiológica na resposta BOLD ………………..... 57

4 AQUISIÇÃO DAS IMAGENS E PRÉ-PROCESSAMENTO.........................59

$4.1 \quad$ Desenho experimental ..................................................................... 59

4.1.1 Paradigmas em bloco ........................................................................... 60

4.1.2 Paradigmas evento-relacionado ……………………………………..... 62

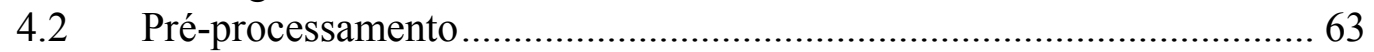

4.2.1 Correção temporal entre fatias............................................................... 63

4.2.2 Correção de movimento ..................................................................... 64

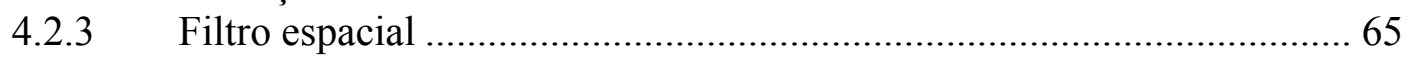

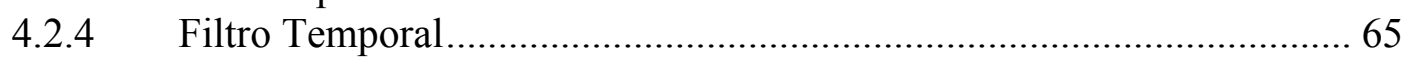

$5 \quad$ ANÁLISE ESTATÍSTICA …........................................................68

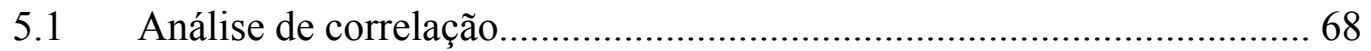

5.2 Modelo Linear Geral (General Linear Model-GLM) .............................. 69 
5.3 Escolhendo um threshold estatístico .................................................... 71

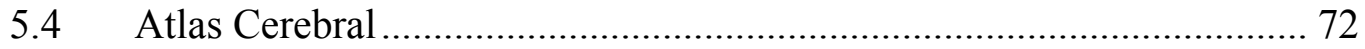

MATERIAL E MÉtodos .............................................................. 75

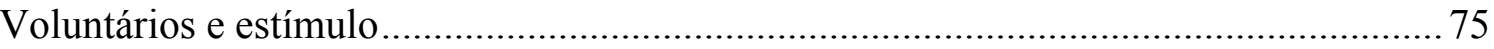

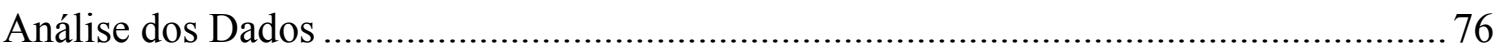



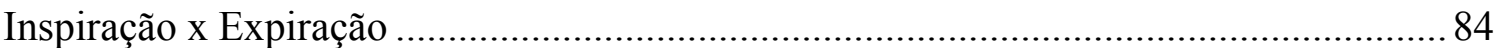

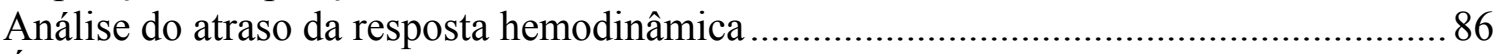



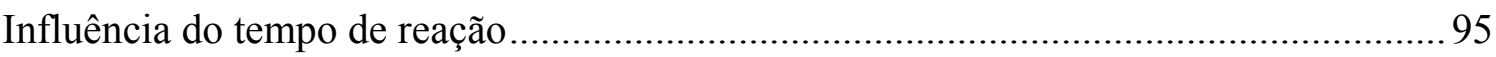

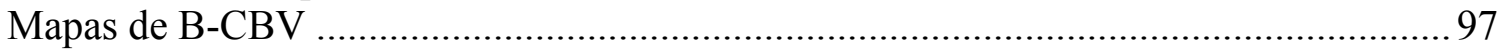

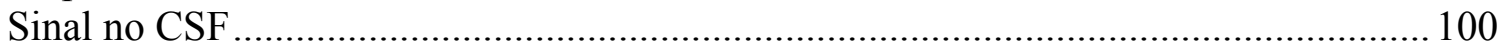

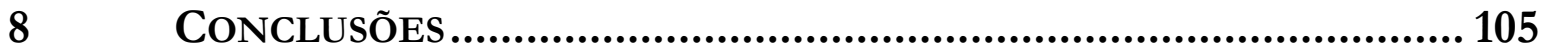

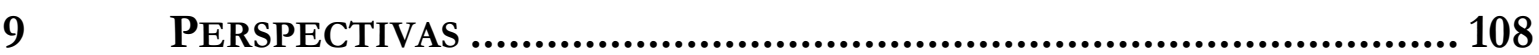

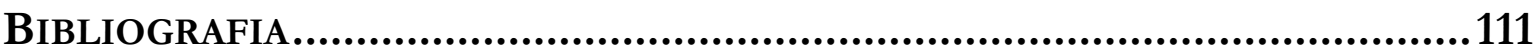

APÊNDICE A .................................................................................. 127

Ressonância Magnética Nuclear (Nuclear Magnetic Resonance -NMR)127

A.1 Teoria quântica da NMR .............................................................. 127

A.2 Modelo clássico da ressonância magnética .......................................... 130

A.3 Processo de relaxação ......................................................................... 134



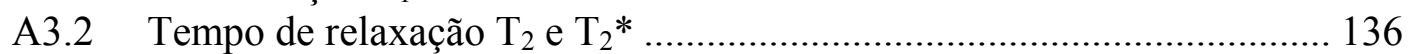

A.4 Free Induction Decay (FID) ....................................................... 137

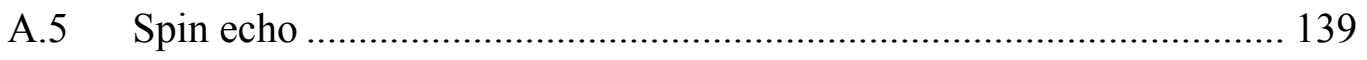

A.6 Localização espacial .......................................................................... 140

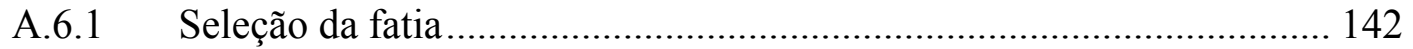

A.6.2 Imageamento de Fourier...................................................................... 142

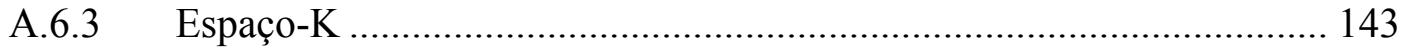

$\rightarrow$ Representação esquemática do espaço $k$.......................................... 145

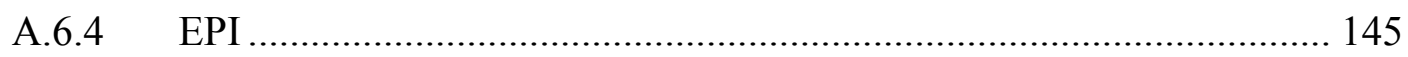




\section{ÍNDICE DE FIGURAS E TABELAS}

Figura 1.1 - Representação dos quatro lobos cerebrais com seus principais sulcos e giros. (Figura tirada de Della Justina, 2005).

Figura 1.2 - Áreas de Brodmann no cérebro humano com atribuição funcional. Figura modificada de http://spot.colorado.edu/ dubin/talks/brodmann/brodmann.html .. 23

Figura 1.3 - Homunculo motor e sensitivo de Penfield. Do lado esquerdo da figura apresenta-se o Homunculo sensitivo e do lado direito o Homunculo motor.......... 25

Tabela 2.1. Principais vias de irrigação Arterial de SNC. (Figura retirada de Lent, 2001).

Figura 2.1. Artérias da base do encéfalo. Círculo arterial do cérebro (polígono de Willis). (Figura tirada do livro Ângelo Machado (1991) Neuroanatomia Funcional. Atheneu, Rio de Janeiro, Brasil).....

Figura 2.2. (a). Artérias da face súpero-lateral do cérebro (b). Artéria da face medial e inferior do cérebro. (Figuras retiradas de Ângelo Machado, 1991) ....................... 36

Tabela 2.2. Composição do Líquor. ............................................................................... 36

Figura 2.3. O plexo coróide é a estrutura que sintetiza o líquor. (a) mostra a posição do plexo coróide no interior dos ventrículos. (b) mostra o aspecto do plexo coróide em um corte parassagital de encéfalo humano, no setor do ventrículo lateral apontado pelas setas em (a) e (b). (Figura modificada de Lent, 2001).

Figura 2.4. O líquor gerado no plexo coróide dentro dos ventrículos emerge através das aberturas do quarto ventrículo (no esquema se vê apenas a abertura mediana) para o espaço subaracnóideo. Dentro do espaço, subaracnóideo o líquor circula em torno da medula e do encéfalo, sendo finalmente reabsorvido nas granulações aracnóideas do seio sagital superior e das raízes medulares (Figura tirada de Lent, 2001).

Figura 2.5. Os quatro tipos de passagem de substâncias através da barreira hematoencefálica. DOPAC=ácido di-hidróxifenilacético; L-DOPA= L-dihidroxifenil-alanina; Glut1 = sistema transportador de glicose, isotipo 1. (Figura tirada de Lent, 2001)...

Figura 2.6. O sistema de drenagem venoso do SNC inclui vasos e seios da dura-máter, e associa a drenagem de sangue à do líquor. Ao final, o sangue venoso do encéfalo desemboca na veia jugular em direção ao coração. (a) é uma vista lateral e (b) é uma vista medial. (Figura tirada de Lent, 2001).

Figura 3.1. Diagrama ilustrativo da resposta hemodinâmica, visualizada em um voxel da imagem. Várias fases compõem o sinal: (a) Linha de base. (b) BOLD negativo anterior. (c) BOLD positivo crescente. (d) Resposta de pico. (e) BOLD positivo decrescente. (f) BOLD negativo posterior. (g) Retorno à linha de base. ................ 56

Tabela 4.1. Vantagens e desvantagens de cada tipo de paradigma de fMRI (Tabela modificada de Huettel et al., 2004) .....

Figura 4.1. (a) Representação do paradigma em bloco. (b) Sinal típico de um voxel durante a realização do paradigma de bloco.

Figura 4.2. (a) Representação do paradigma evento-relacionado. (b) Sinal típico de um pixel durante a realização do paradigma evento-relacionado.

Figura 5.1. Representação, nos planos axial (a), coronal (b) e sagital, das linhas utilizadas para definir o sistema de coordenadas Talairach. (a) Linhas AC vertical e PC vertical. (b) Plano AC-PC. (c) Linhas AC vertical e PC vertical e o plano ACPC. O círculo vermelho indica a localização anatômica da comissura anterior e o círculo branco indica a localização anatômica da comissura posterior. 
Figura 5.2. Representação das linhas utilizadas para definir o sistema de coordenadas Talairach. Também está representada a grade delimitada pelos seis pontos.......... 74

Figura 6.1. Função hemodinâmica para o protocolo de apnéia de (a) 14s; (b)27s; (c) 15s após inspiração/expiração. A linha preta representa a função hemodinâmica preditora utilizada no GLM. A linha branca representa a função hemodinâmica preditora deslocada 4.6s, para o caso da apnéia de 27 e 14 s, e deslocada $2 \mathrm{~s}$ pra o caso de apnéia de $15 \mathrm{~s}$ após inspiração/expiração. As áreas que aparecem em verde representam os períodos em que os voluntários deveriam estar em apnéia, e as áreas em cinza os períodos de repouso............................................................... 78

Figura 6.2. Figura representativa das VOIs dos territórios de irrigação pelas três principais artérias cerebrais. A área em azul representa o território da $\mathrm{ACP}$, a área laranja o território da ACA e a área amarela a da ACM. .................................... 79

Figura 7.1. Mapas temporais da mudança do sinal BOLD durante o paradigma de apnéia de $27 \mathrm{~s}$, mostrando que seu atraso depende da região cerebral. O mapa de cores corresponde a um atraso específico da resposta hemodinâmica: as regiões avermelhadas correspondem àquelas que responderam mais rapidamente, enquanto que as regiões esverdeadas àquelas que responderam mais lentamente................. 82

Figura 7.2. Mapas estatísticos da mudança do sinal BOLD induzida por apnéia, construídos durante o pico de atividade. (a) $14 \mathrm{~s} \mathrm{e} \mathrm{(b)} 27 \mathrm{~s}$. Um aumento global na perfusão cerebral nos dois hemisférios pode ser observado.....

Figura 7.3. Média do sinal BOLD para apnéia de 14s (preto) e 27s (vermelho) para na coordenada Talairach $(20,-74,24)$ para um dos voluntários (Área de Brodmann 31). Quanto maior o tempo de apnéia, maiores o atraso e o aumento da resposta hemodinâmica. As linhas verticais sólida, tracejada e pontilhada, representam o inicio da apnéia, final da apnéia de $14 \mathrm{~s}$, e final da apnéia de $27 \mathrm{~s}$, respectivamente.

Figura 7.4. Evolução temporal da mudança do sinal BOLD em resposta à apnéia, após inspiração (linha vermelha) e expiração (linha preta). As duas retas verticais representam o inicio e o final do período de apnéia, respectivamente.

Figura 7.5. Evolução temporal da área percentual estatisticamente significativa $(\mathrm{p}<$ 0.000109), de cada território arterial, em resposta à apnéia. À esquerda observamos essa variação para a inspiração. À direita, para a expiração respectivamente........ 87

Tabela 7.1. Máxima percentagem de voxels ativos para os 9 voluntários que realizaram apnéia após expiração com um $\mathrm{p}<0.000109$. $\mathrm{O}$ atraso na resposta hemodinâmica para a obtenção dessas percentagens encontra-se na tabela (7.2)......................... 88

Tabela 7.2. Tabelas do tempo para que cada território arterial atinja a maior percentagem ativa para um $\mathrm{p}<0.000109$.

Figura 7.6 Territórios cerebrais, com seus respectivos atrasos ao estímulo de apnéia, após inspiração. (1) 0s; (2) 13s; (3) 15s; (4) 17s; (5) 19s; (6) $21 \mathrm{~s}$; (7) 23s; (8) 25s; (9) 27s; (10) 29s; (11) 31s; (12) 33s. Os territórios irrigados pelas três principais artérias foram destacados (ACA-Laranja, ACM-cinza, ACP-Azul).

Figura 7.7. Número de voxels ativados em áreas que com um $\mathrm{p}<0.000109$, nos voluntários que realizaram o protocolo de apnéia após a expiração. A escala em tons de cinza representa o número de voluntários que ativaram determinada área.93

Figura 7.8. Exemplo de uma função preditora em que foi considerado o tempo real para o voluntário iniciar a apnéia. Os períodos apresentados em cor cinza representam o repouso, enquanto os períodos em verde representam o estado de apnéia. A linha branca representa a convolução entre os períodos de atividade e uma HRF modelo. 
Figura 7.9. Gráfico com o número de pixels ativados. Comparação quando o GLM foi aplicado com a função preditora, considerando o tempo que o voluntário leva pra prender a respiração (cinza claro) e sem considerar esse tempo (cinza escuro)..... 97

Figura 7.10. Mapas de B-CBV gerados a partir do cálculo da área abaixo da curva do contraste BOLD, obtido durante um protocolo de apnéia.

Figura 7.11. Mapas de B-CBV gerados a partir do cálculo da área abaixo da curva do contraste BOLD, obtido durante um protocolo de apnéia após a aplicação de um filtro para retirar o sinal do CSF.

Figura 7.12. Sinal positivo no CSF, em resposta à apnéia (a) após inspiração $(p<0.019040)$, (b) após expiração $(p<0.001847)$. Pode-se ver claramente que o sinal no CSF é mais evidente quando a apnéia é iniciada após expiração.

Figura 9.1 O sinal apresentado em branco é melhor correlacionado com a função preditora apresentada em preto. A função que melhor representa o tempo ao pico do sinal é a função apresentada em vermelho, indicando a necessidade de aplicação de outros métodos para a detecção do atraso da resposta hemodinâmica.

Figura A.1. Diagrama da transição de um próton entre dois estados quânticos através da absorção de um fóton de energia hv.

Figura A.2. Apresentação esquemática do momento magnético em relação a um campo magnético aplicado.

Figura A.3. Apresentação esquemática da magnetização em relação a um campo magnético aplicado.

Figura A.4. Recuperação da magnetização longitudinal $\mathrm{M}_{\mathrm{z}}$ depois de um pulso de $90^{\circ}$. É um processo exponencial, cuja constante de tempo é descrita pela constante de relaxação longitudinal $T_{1}$. A curva mostrada é para o caso de $M_{z}$ em $t=0$.

Figura A.5. Diagrama que representa o sinal detectado por bobinas de indução localizadas sobre o plano x-y em função do tempo. Esse padrão de sinal é conhecido por FID, e retrata o efeito de $\mathrm{T}_{2}{ }^{*}$ na amplitude do sinal detectado..... 138

Figura A.6. Seqüência temporal dos pulsos aplicados e influencia desses sobre o spin. (a) Aplicação do pulso de 900. (b) Precessão em fase. (c) Efeito da relaxação longitudinal. (d) Aplicação do pulso de 1800. (e) Posição dos vetores de magnetização após o pulso. (f) Efeito de eco dos spins. Figura tirada Blinck E. J. MRI principle, 2004)

Figura A.7. Seqüência de pulsos Spin-echo (Método de Carr-Purcell). A aplicação de sucessivos pulsos de 1800 faz aparecerem múltiplos padrões de eco. Observa-se a separação entre T2 (linha verde) e T2* (linha vermelha). TR é o tempo de repetição do pulso excitatório de $90^{0}$.

Figura A.8. Par de bobinas que geram um gradiente de campo que varia na direção do

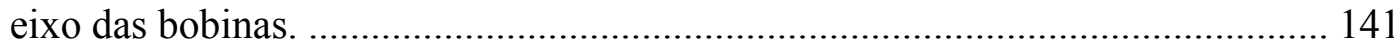

Figura A.9. Relação entre o gradiente e a largura da fatia.

Figura A.10. A curva vermelha é a função $f(x)$ resultante de: $f(x)=5+4$ sen $x+(4 / 3)$ sen $3 x+(4 / 5)$ sen $5 x+(4 / 7)$ sen $7 x+\ldots$ (só com as 5 parcelas explicitadas na equação). Esta série é a representação de uma onda quadrada. Notar que, com 5 parcelas, já ocorre uma certa aproximação. Se infinitas parcelas fossem somadas, o resultado seria uma forma perfeita conforme indicado pela linha tracejada. Para a reconstrução da imagem é necessário que, primeiramente, determine-se os coeficientes de Fourier, como será mostrado a seguir.

Figura A.11. A figura da direita apresenta a transformada de Fourier da imagem da esquerda.

Figura A.12. Representação esquemática de uma seqüência de pulsos EPI, em que se apresenta a varredura das posições através da aplicação dos gradientes. Na linha 
em que se representa o sinal, os quadrados representam o tempo em que se realiza a aquisição.

Figura A.13. Figura de preenchimento do espaço-k para uma seqüência de pulsos simples do tipo eco de spin. A freqüência é codificada na direção $\mathrm{x}$, e a fase, na direção y. 


\section{INTRODUÇÃO}

Nos últimos anos, a ressonância magnética funcional (functional Magnetic Resonance Imaging, fMRI) tem sido utilizada como uma ferramenta não invasiva capaz de gerar imagens a partir dos mapas de sinais associados a funções normais ou patológicas do cérebro. Além de mapear funções cognitivas, um crescente número de estudos indicam que as técnicas de fMRI podem ser úteis no mapeamento précirúrgico (de Araújo et al., 2003).

Uma das descobertas fundamentais para a criação da fMRI foi a de que mudanças no metabolismo cerebral afetam o sinal local de MR, promovendo um mecanismo intrínseco para detecção da atividade cerebral. Esse mecanismo depende do nível de oxigenação do sangue (Blood Oxygenation level dependent, BOLD) e utiliza a característica paramagnética da deoxi-hemoglobina como agente de contraste endógeno. Durante a ativação cerebral, o aumento do fluxo cerebral sangüíneo regional (regional Cerebral Blood Flow, rCBF) aumenta mais do que a taxa cerebral metabólica do oxigênio (Cerebral Metabolic Rate of Oxygen, $\mathrm{CMRO}_{2}$ ). Portanto, a diferença entre a produção e o consumo de oxigênio causa uma redução na concentração de deoxihemoglobina, as distorções magnéticas locais diminuem, e o sinal MR aumenta ligeiramente, mudando, assim, o contraste local das imagens ponderadas em T2*.

Portanto, o sinal BOLD mede indiretamente a atividade neural, sendo sensível a mudanças no $\mathrm{CBF}$, no $\mathrm{CMRO}_{2}$ e no volume cerebral sanguíneo (Cerebral Blood Volume, CBV). Em princípio, ele pode ser utilizado para mapear a perfusão cerebral. Conseqüentemente, esta técnica tem sido utilizada para detectar rCBF através de mudanças no sinal BOLD durante inalação de $\mathrm{CO}_{2}$ ou por injeção de acetazolamida (Lythgoe et al., 1999; Roc et al., 2006). Durante a inalação de $\mathrm{CO}_{2}$, o aumento na $\mathrm{PaCO}_{2}$ provoca vasodilatação e, desta forma, constata-se um aumento no rCBF. Porém, um pequeno, ou nenhum aumento, ocorre na $\mathrm{CMRO}_{2}$, e a atividade metabólica permanece em sua linha de base, referente ao estado de repouso cerebral. Assim, há um decréscimo na concentração de deoxi-hemoglobina, levando a um aumento no sinal de ressonância magnética.

Já a acetazolamida é um inibidor de anidrase carbônica. A anidrase carbônica catalisa a conversão de $\mathrm{CO}_{2}$ para íons bicarbonatos, o que aumenta a capacida- 
de do sangue de retirar $\mathrm{CO}_{2}$. Inibindo essa enzima, há um aumento na concentração de $\mathrm{CO}_{2}$ no cérebro, proporcionando um aumento no $\mathrm{CBF}$.

Essas alterações também podem ser induzidas por estados transitórios de apnéia (Kastrup et al. 1990), e detectadas utilizando técnicas de fMRI. Uma das vantagens de se utilizar um estímulo global, como a apnéia, para estudar a resposta BOLD, é a possibilidade de se avaliar como um estímulo uniforme pode afetar regiões do cérebro de forma diferente. Alguns trabalhos utilizaram a apnéia para analisar diferenças regionais da resposta BOLD (Kastrup et al., 1999b e Thomason et al., 2005), mas esta análise restringiu-se à verificação da intensidade do sinal BOLD e número de pixels ativados em diferentes regiões.

A indução de um estado transitório de apnéia é um paradigma simples para se estudar a resposta hemodinâmica. Uma vez que, possui a vantagem de ser menos invasivo, não necessitando de uma fonte de $\mathrm{CO}_{2}$ ou da injeção de acetazolamida. Por isso, o objetivo principal deste trabalho foi investigar quantitativamente alterações perfusionais no cérebro humano mapeadas pelas mudanças do sinal BOLD em resposta a indução transitória do estado de apnéia, visando, ainda, uma possível aplicação clínica futura.

Nesta pesquisa, foi analisada a influência da duração da apnéia no sinal BOLD, observou-se, também, a diferença ocasionada no sinal em duas situações: apnéia iniciando-se após a inspiração ou após a expiração. Além disso, foi estudada a propagação deste sinal BOLD pelas diferentes regiões cerebrais, tentando correlacionar o atraso da resposta hemodinâmica à apnéia com a reatividade das principais artérias que irrigam o cérebro. Por último, fazendo uso deste sinal BOLD, construiu-se mapas para obter informações a respeito do volume cerebral sangüíneo.

O estudo da perfusão cerebral através da técnica BOLD envolve diferentes conhecimentos de física, neuroanatomia e estatística. Por isso, a fundamentação teórica deste trabalho foi dividida em quatro partes principais. O primeiro capítulo trata dos aspectos anatômicos e fisiológicos, além de descrever brevemente a organização funcional do cérebro humano. O capítulo 2 refere-se à anatomia cerebrovascular, apresentando as principais vias de irrigação arterial do sistema nervoso e suas anastomoses. O capítulo 3 trata das técnicas para avaliação da perfusão cerebral, dando ênfase ao efeito BOLD. No capítulo 4 encontram-se as bases estatísticas utilizadas 
para a análise dos dados. Outras informações teóricas são encontradas no apêndice A, onde são apresentados os princípios físicos da ressonância magnética nuclear e sua utilização para a obtenção de imagens médicas. Por fim, os três últimos capítulos dessa dissertação foram destinados à descrição dos métodos experimentais, aos resultados e discussões e, finalmente, às conclusões e perspectivas do trabalho. 


\section{ANATOMIA CEREBRAL}

Considerando-se princípios anatômicos, o sistema nervoso central dividese em medula espinhal e encéfalo que, por sua vez, tem três partes: cérebro, cerebelo e tronco encefálico. O cérebro, que corresponde à parcela mais importante da cavidade craniana, ocupando cerca de $80 \%$ do seu volume total, é dividido em diencéfalo e telencéfalo.

O diencéfalo compreende as seguintes estruturas: tálamo, hipotálamo, epitálamo e sub-tálamo. Já o telencéfalo é constituído pelos dois hemisférios cerebrais, que encontra na fissura longitudinal suas fronteiras mediais. Anatomicamente, os dois hemisférios são idênticos, possuindo quatro lobos: frontal, parietal, occipital e temporal (figura 1.1). Além desses, existe ainda mais internamente o lobo da ínsula.

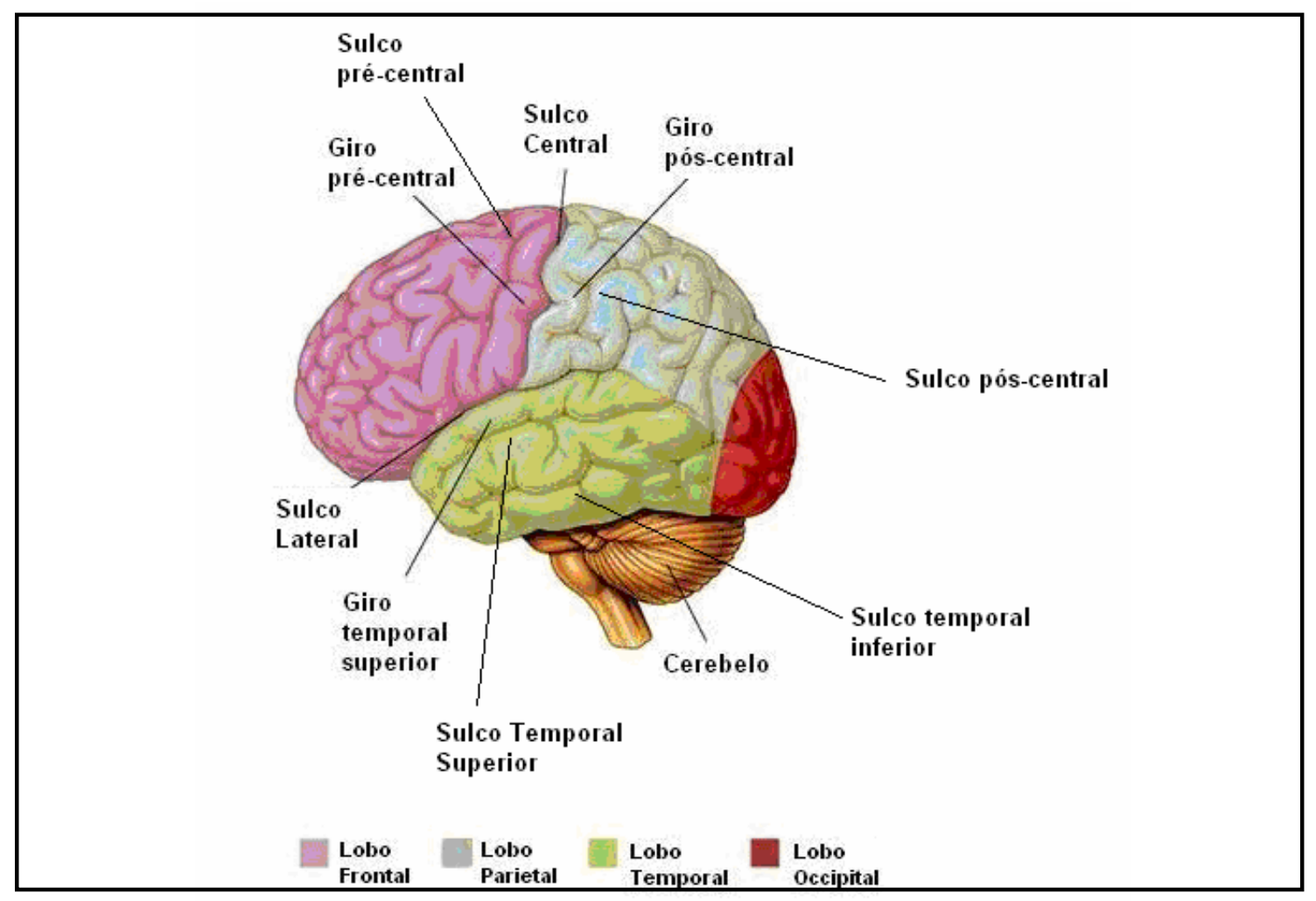

Figura 1.1 - Representação dos quatro lobos cerebrais com seus principais sulcos e giros. (Figura tirada de Della Justina, 2005).

Toda essa superfície é recortada por depressões denominadas sulcos ao longo de todo o volume, delimitando, assim, as regiões elevadas, conhecidas como giros. Os principais sulcos são o sulco lateral (de Sylvius), que separa, em suas por- 
ções anteriores, o lobo frontal do lobo temporal, e o sulco central (de Rolando), que separa o lobo parietal do frontal.

Os diferentes lobos cerebrais também são delimitados por sulcos menores, mas importantes, formando marcas anatômicas que servem na determinação mais detalhada de uma topografia anatômica cerebral.

O lobo frontal é composto por três sulcos principais: pré-central, central superior e central inferior. Os dois últimos recortam o lobo frontal, em porções ântero-posteriores, perpendiculares ao sulco central. O sulco pré-central, por sua vez, é praticamente paralelo ao sulco central, formando entre eles o giro pré-central. Em porções súpero-mediais do sulco frontal superior, delimitado medialmente pela fissura longitudinal, está o giro frontal superior. Entre os sulcos frontal superior e inferior está o giro frontal médio. Por fim, o giro frontal inferior, localizado abaixo do sulco frontal inferior, é dividido em três partes pelos ramos anterior e ascendente do sulco lateral: orbital, triangular e opercular. O lobo temporal é recortado por dois sulcos principais: temporal superior e inferior.

Esses sulcos, juntamente com o sulco lateral, formam os principais giros do lobo temporal, que percorrem porções laterais do cérebro, ântero-posteriormente. O giro temporal superior é delimitado acima pelo sulco lateral e abaixo pelo sulco temporal superior. Entre os sulcos exclusivos do lobo temporal está giro temporal médio. Abaixo do sulco temporal inferior encontra-se o giro temporal inferior. No lobo parietal, encontram-se os giros pós-central, parietal superior e inferior. O sulco pós-central, que segue a topografia do sulco pré-central, paralelo ao sulco central, formando o giro pós-central. O sulco intraparietal forma o giro parietal superior e inferior, sendo o segundo subdividido em supramarginal e angular.

O último lobo, o occipital, não contém nenhum sulco proeminente que sirva para determinação de pontos de referência anatômicos.

É interessante notar que, muito embora a fissura longitudinal divida o cérebro em dois hemisférios, eles não estão isolados. A ligação entre os dois se dá, principalmente, pela projeção de fibras nervosas através de uma comissura conhecida como corpo caloso. Este é localizado em porções mediais inferiores do córtex cerebral. 


\subsection{Córtex cerebral}

O córtex cerebral trata-se de uma das partes mais importantes do sistema nervoso. No córtex cerebral chegam impulsos provenientes de todas as vias da sensibilidade que se tornam conscientes e são interpretadas. Do córtex saem impulsos nervosos que iniciam e comandam os movimentos voluntários e com ele estão relacionados os fenômenos psíquicos.

O córtex cerebral não é homogêneo em toda sua extensão, permitindo a individualização de várias áreas, o que pode ser feito com critérios anatômicos, filogenético, estruturais e funcionais.

O córtex cerebral tem sido objeto de meticulosas investigações histológicas nas quais foram estudados diversos aspectos de sua estrutura, tais como a composição e característica das diversas camadas, espessura total e espessura das camadas, disposição e espessura das raias e estrias etc. Com base nestes estudos o córtex cerebral pode ser dividido em numerosas áreas citoarquiteturais, havendo vários mapas de divisão. Contudo, a divisão mais aceita é a de Brodmann que identificou 52 áreas designadas por números (figura 1.2). As áreas de Brodmann são muito conhecidas e amplamente utilizadas na clínica e na pesquisa médica.

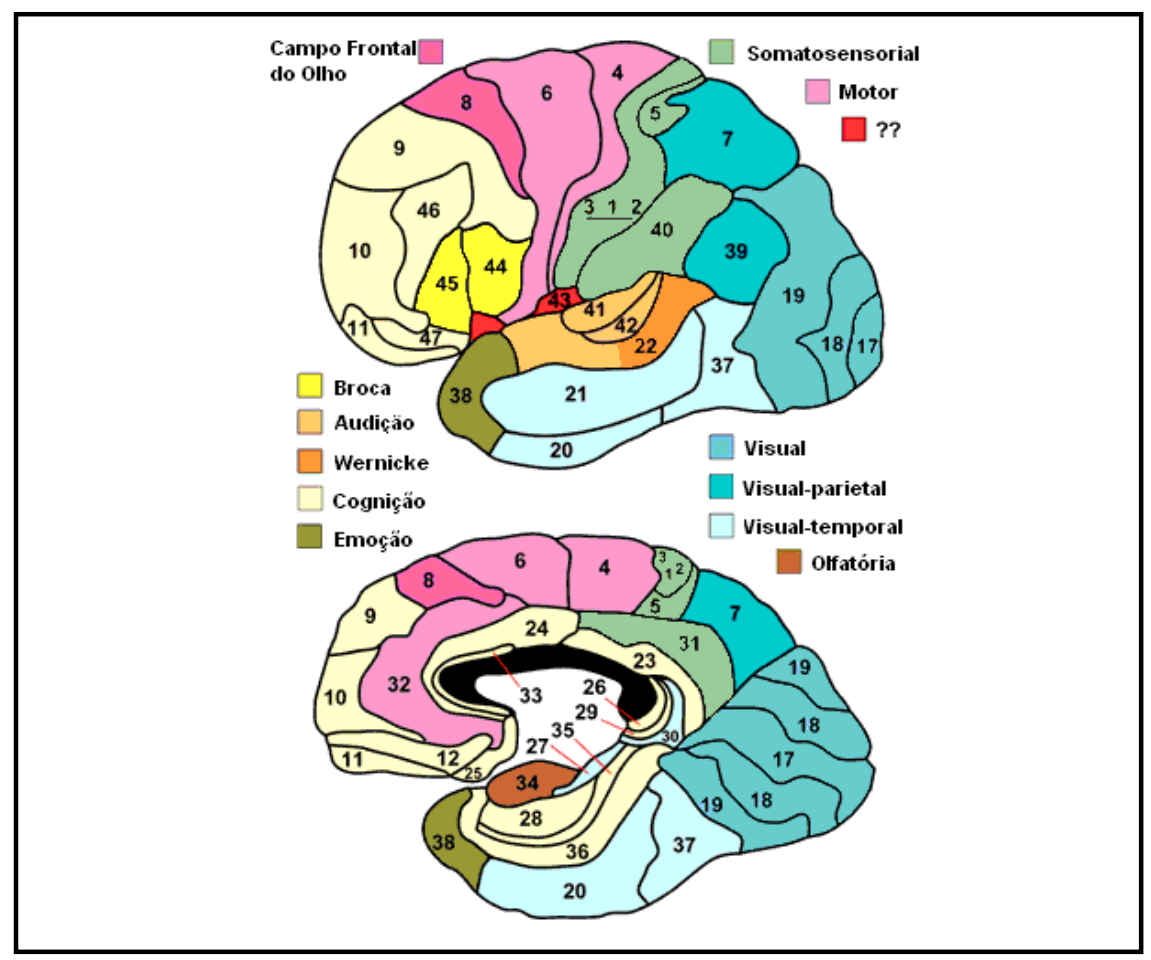

Figura 1.2 - Áreas de Brodmann no cérebro humano com atribuição funcional. Figura modificada de http://spot.colorado.edu/ dubin/talks/brodmann/brodmann.html 
Do ponto de vista funcional as áreas corticais não são homogêneas como se acreditava no início do século XIX. A primeira comprovação deste fato foi feita em 1861 pelo cirurgião francês Broca, que pôde correlacionar lesões em áreas restritas do lobo frontal (área de Broca) com a perda da linguagem falada.

Desde então, a especialização funcional de diferentes áreas cerebrais e a integração dessas regiões, e a determinação de suas conexões físicas, têm despertado grande interesse na comunidade de neurocientistas. Note-se, no entanto, que a localização funcional deve ser percebida como uma especialização de algumas áreas cerebrais, estando elas altamente conectadas umas às outras.

Atualmente, a funcionalidade cerebral é esquematicamente dividida em dois grandes grupos: as áreas de projeção e as de associação. As áreas de projeção são as que recebem ou dão origem a fibras relacionadas diretamente com a sensibilidade e com a motricidade. As demais áreas são consideradas de associação, e de um modo geral, estão relacionadas com funções psíquicas complexas. As áreas de projeção podem ser divididas em dois grandes grupos de função e estrutura diferente: áreas sensitivas e áreas motoras.

A seguir será feito um estudo das principais áreas sensitivas, motoras e de associação do córtex cerebral.

\subsection{1 Áreas Motoras}

A área de projeção motora está localizada sobre o lobo frontal, ocupando porções posteriores do giro pré-central. Essa região é responsável por movimentos de regiões contralaterais do corpo, como pé, mão, lábios, etc.

A área de projeção motora assume uma representação distinta de diferentes partes do corpo em diferentes porções do giro, constituindo, assim, o que é conhecido como mapeamento somatotópico (Penfield e Boldrey, 1937), diagramado de acordo com o Homúnculo Motor de Penfield. Nele, regiões da face e das mãos possuem uma representação cortical bastante extensa (figura 1.3). 


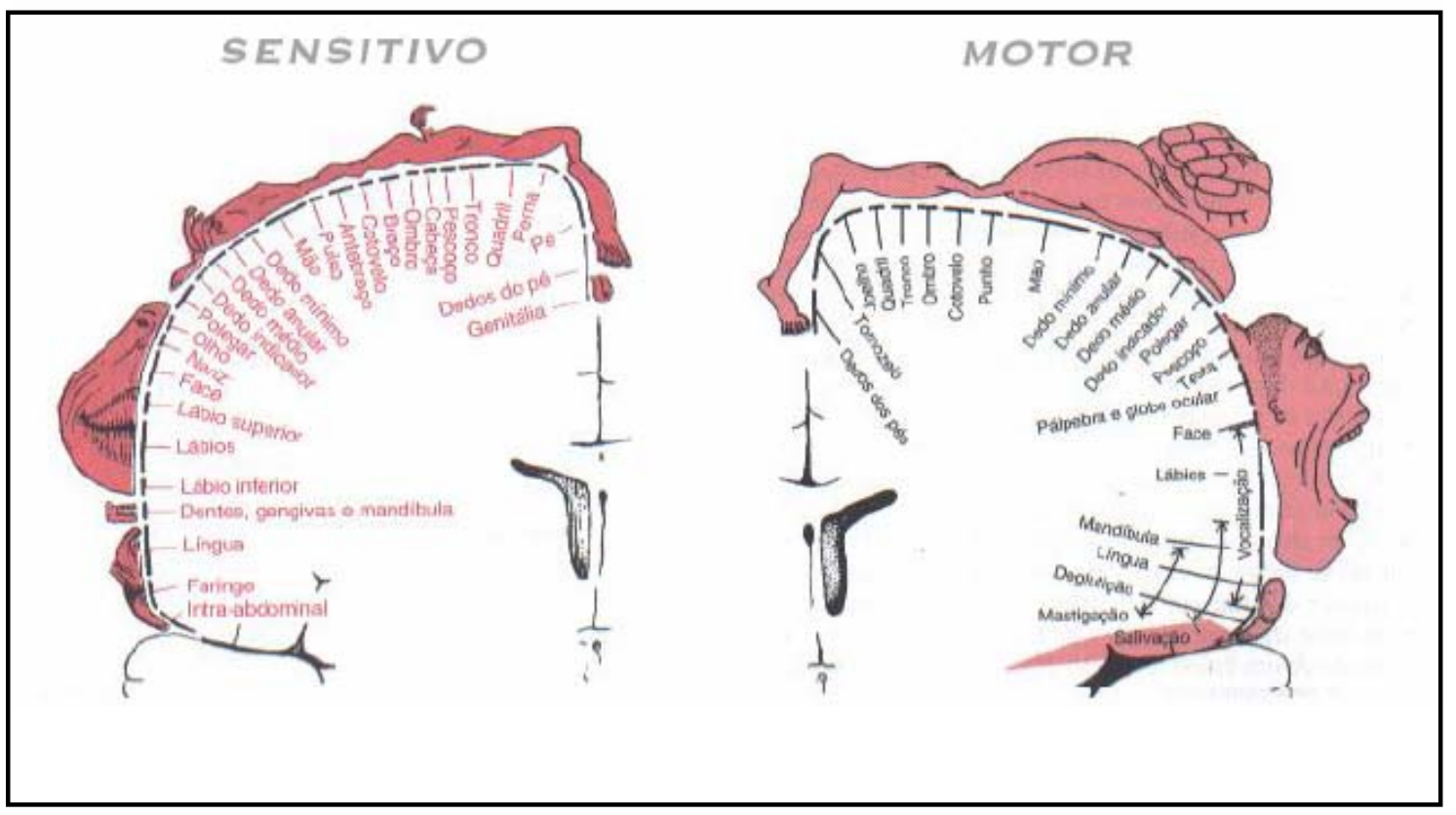

Figura 1.3 - Homunculo motor e sensitivo de Penfield. Do lado esquerdo da figura apresenta-se o Homunculo sensitivo e do lado direito o Homunculo motor.

O córtex motor é dividido adicionalmente em três subáreas, cada uma tendo sua representação de grupos musculares e funções motoras específicas do corpo:

- Córtex motor primário: Localizado na primeira circunvolução dos lobos frontais, anterior ao sulco centra, no giro pré-central. Área 4 na classificação de Brodmann. Compreende áreas musculares da face, boca, mão, braços, troncos, pés e pernas. Envia ordem para realização do movimento.

- Área pré-motora: Localizada anteriormente às porções laterais do córtex motor primário, giro frontal superior e médio. Área 6 de Brodmann, responsável pelo planejamento do movimento.

- Área motora suplementar: Localizada superior à área pré-motora, situando-se sobre o sulco longitudinal, classificação área 6 de Brodmann. Esta área funciona em conjunto com a área pré-motora para provocar movimentos posturais.

\subsection{2 Áreas Sensitivas}

A área somestésica ou área de sensibilidade somática geral está localizada no giro pós-central, que corresponde às áreas 3,2,1 do mapa de Brodmann. A área 3 localiza-se no fundo do sulco central, enquanto as áreas 1 e 2 aparecem na superfície 
do giro pós-central. Aí chegam radiações talâmicas que se originam nos núcleos ventral póstero-lateral e ventral póstero-medial do tálamo e que trazem, por conseguinte, impulsos nervosos relacionados com a temperatura, dor pressão, tato e propriocepção consciente da metade oposta do corpo.

Analogamente ao que foi apresentado para as regiões primárias motoras, também se pode dividir a área de projeção sensitiva levando em consideração sua seletividade na topografia anatômica (Penfield e Boldrey, 1937), formando um Homúnculo Somestésico de Penfield. Novamente, representações das mãos e face ocupam uma área cortical extensa (figura 1.3).

\subsection{3 Áreas de Associação}

Esquematicamente pode-se considerar como áreas de associação do córtex aquelas que não se relacionam diretamente com a motricidade, ou com a sensibilidade. Os efeitos das lesões ou estimulações destas áreas são de avaliação mais difícil, especialmente em animais, pois não resultam em alterações de motricidade ou da sensibilidade. As regiões de associação seguem uma subdivisão proposta pelo pesquisador russo Alexander Luria. Segundo esse modelo, o grau de interação entre uma função cerebral específica e as áreas de projeção indicam o papel destas dentro da hierarquia funcional, caracterizando-as em secundárias e terciárias. As áreas secundárias, também conhecidas como unimodais, receberiam um conjunto de fibras aferentes projetadas de suas respectivas regiões primárias. Portanto, regiões primárias visuais, por exemplo, projetariam um conjunto de fibras em áreas de associação unimodal visual. As áreas terciárias, ou supramodais, não teriam nenhuma conexão física direta com áreas de projeção, sendo responsáveis por processos cognitivos elevados, como memória, emoção, e consciência. As vias de comunicação dessas regiões seriam estabelecidas através de projeções derivadas de áreas unimodais ou outras áreas supramodais.

As regiões unimodais fazem conexões físicas diretas recebendo projeções aferentes de suas respectivas regiões primárias, e desempenham um papel intermediário na hierarquia funcional, participando, por exemplo, de processos de planejamento de movimentos. Elas estão divididas em áreas unimodais motoras e áreas unimodais sensitivas. Essas regiões secundárias localizam-se, geralmente, na periferia 
de seus respectivos centros primários. As áreas de associação sensitivas somestésicas estão localizadas dorsalmente às áreas de projeção somestésicas primárias, i.e., ao longo do giro pós-central. Por outro lado, as regiões auditivas secundárias cercam a área auditiva primária, sobre o giro temporal superior. Já as regiões de associação visuais estão sobre o lobo occipital, anteriores à sua respectiva região primária.

As regiões motoras unimodais são divididas em três subgrupos: motora suplementar, pré-motora e área de Broca. A primeira delas ocupa uma parcela do giro frontal superior, sendo responsável pelo planejamento e execução de tarefas motoras seqüenciais. A segunda, área pré-motora, está relacionada com o controle da musculatura mais robusta, estando localizada em porções laterais, anteriores à área motora primária. Por fim, a região de Broca, envolvida em processos de programação da atividade motora em processos de linguagem, está localizada sobre o lobo frontal, ocupando porções do giro opercular e triangular.

As regiões de associação supramodais recebem projeções de outras áreas de associação, sejam elas unimodais ou supramodais. No córtex pré-frontal encontra-se a habilidade humana de planejamento cognitivo. É o centro responsável pela resolução de problemas complexos, bem como do controle e expressão do comportamento emocional. Outras regiões cerebrais também são importantes na realização de tarefas funcionais complexas. As áreas contidas no lobo parietal, por exemplo, controlam, dentre outras coisas, a orientação espacial. Aparentemente, essa área tem papel fundamental nas habilidades de orientação espacial. Ainda no lobo parietal, uma região anatômica importante diz respeito às estruturas temporoparietais. Essa área está localizada entre as regiões secundárias auditivas, visuais e somestésicas, especulandose, portando, uma possível estrutura de integração desses três estímulos.

Outra estrutura importante em processos cognitivos elevados é o sistema límbico. Ele é constituído pela parte média que contorna regiões entre hemisférios, e tem um papel muito antigo na evolução cerebral, mantendo conexões importantes com outras regiões cerebrais, e tendo acesso às informações processadas em elementos funcionais de hierarquia inferior. Esse sistema, dada mais uma vez sua importância, está dividido em várias outras estruturas: hipocampo, parahipocampo, amígdala, septo, dentre outras, com participações importantes em processos emocionais e de memória. 
Muito estudada hoje em dia, uma das estruturas do sistema límbico, o hipocampo, tem participação em vários processos cognitivos elevados. Trata-se de uma estrutura da região sub-cortical, em forma de "U" . Como parte do sistema límbico, está localizada no lobo temporal, desempenhando papel fundamental em processos de memória, de emoção e comportamento sexual. Além disso, participa, aparentemente, de processos de mapeamento e de posicionamento. Estaria, sobretudo, juntamente com o giro parahipocampal envolvida em processos de orientação espacial. Danos dessa região resultam, por exemplo, em dificuldades de lembrar-se de paisagens. Mais que isso, pacientes com derrame cerebral, que apresentam dificuldades de orientação espacial, invariavelmente sofreram danos em uma região intimamente ligada ao hipocampo, o giro parahipocampal. Estudos realizados em julho de 1997, por Vargha (Vargha-Khadem, et al., 1997), indicam que a memória semântica (memória relacionada a construções lógicas, sem nenhum tipo de contextualização) e a memória episódica (memória de eventos temporal e espacialmente localizados) manifestam suas características em diferentes regiões cerebrais. Aparentemente, o hipocampo está diretamente relacionado ao armazenamento da memória episódica, mas nada tem a ver com a memória semântica, sendo um caminho necessário por onde novas informações passam a fim de formar novas memórias.

Em geral, os processos cognitivos elevados não ocorrem em uma estrutura singular. Como exemplo, em 1937 o neuroanatomista James Papez demonstraria que emoções não são função de uma região específica, de um único centro cerebral, mas sim de um circuito envolvendo quatro estruturas: o hipotálamo, o núcleo talâmico anterior, o giro do cíngulo e o hipocampo. Atualmente conhecido como circuito de Papez, sabe-se que esse sistema desempenha papel fundamental em processos emocionais. 


\section{Circulação do Sistema Nervoso}

O sistema nervoso central (SNC) flutua em um ambiente líquido especial que o protege mecanicamente e favorece trocas metabólicas. Esse ambiente líquido é delimitado externamente pelas meninges (dura-máter, aracnóide e pia-máter). Abaixo da aracnóide fica o espaço subaracnóideo, que se comunica com as cavidades internas do SNC (ventrículos e canais). Estruturas especializadas chamadas plexos coróides produzem o líquor ou líquido cefalorraquidiano, líquido que preenche os compartimentos desse sistema. A partir dos plexos coróides, o líquor circula pelos ventrículos, passa ao espaço subaracnóideo e é finalmente drenado para o sangue venoso.

O ambiente líquido que banha o exterior do sistema nervoso e o interior de suas cavidades não é suficiente para garantir sua nutrição e o aporte de oxigênio para o tecido nervoso. Para isso é necessária uma rede vascular bastante ramificada e extensa, que tem nos vasos suas estrutura básica. Os vasos que partem do coração e vão à periferia do corpo se chamam artérias; aqueles que seguem o percurso inverso, isto é, da periferia se dirigem ao coração, se chamam veias. Assim, as artérias carregam sangue rico em oxigênio e em substâncias nutritivas para os vários tecidos do organismo, já nas veias corre um sangue rico em anidrido carbônico e substâncias de rejeição. As substâncias de rejeição serão depois eliminadas pelos rins, que têm justamente a tarefa de filtrar o sangue. A eliminação de anidrido carbônico e a absorção de oxigênio, têm lugar nos pulmões, por efeito da respiração.

As artérias, à medida que chegam à periferia do corpo humano, vão reduzindo seu diâmetro, se transformando em arteríolas, até que o seu calibre se torna microscópico: é a este nível que têm lugar a troca entre sangue e células. Estes vasos microscópicos, chamados capilares, formam nos órgãos e nos tecidos uma vasta rede. Os capilares confluem para pequenas veias (vênulas) que aos poucos vão se unindo umas com outras, tornam-se veias verdadeiras e trazem de volta o sangue ao coração. Do coração partem duas grandes artérias: a artéria pulmonar e a artéria aorta. 
A artéria pulmonar tem a tarefa de levar o sangue aos pulmões. Depois de ter cedido o anidrido carbônico e de ter se carregado de oxigênio, o sangue volta ao coração pelas veias pulmonares. Todo esse conjunto constitui a pequena circulação. A artéria aorta leva o sangue ao resto do organismo e os seus numerosos ramos acabam formando a rede capilar de todos os órgãos. O sangue é trazido de volta ao coração pelas veias, que se reúnem, enfim, em dois grossos troncos: as veias cavas, que chegam à aurícula direita. Todo esse conjunto constitui a grande circulação. Da mesma forma, no sistema nervoso, as artérias que levam o sangue para o encéfalo e a medula se abrem em vasos cada vez mais finos, que por fim se ramificam em uma extensa rede de capilar capaz de irrigar todas as regiões neurais, levando-lhes o oxigênio e os nutrientes de que precisam para o seu funcionamento. No entanto, a rede vascular do sistema nervoso tem particularidades morfológicas e funcionais que se distinguem da circulação sistêmica. O que era de se esperar, pois o sistema nervoso é formado por estruturas nobres e altamente especializadas, que exigem para seu metabolismo um suprimento permanente e elevado de glicose e oxigênio. O encéfalo representa apenas cerca de $2 \%$ da massa corporal de uma pessoa, mas recebe 15\% do fluxo sanguíneo e consome aproximadamente $20 \%$ do oxigênio disponível na circulação. Refletindo, assim, uma alta taxa metabólica do tecido nervoso. A glicose também é intensamente consumida pelos neurônios, que a utilizam como fonte anaeróbica de energia. Como o tecido nervoso não armazena nem glicose nem oxigênio, é necessário que haja um fluxo continuo desses componentes através do sangue arterial. Quando ocorre anóxia ou isquemia de poucos segundos, o indivíduo pode apresentar sintomas neurológicos que dependem da região atingida, e se essas ocorrências se prolongarem por alguns minutos, ocorre morte cerebral irreversível. Em contrapartida, em circunstâncias normais o metabolismo dos neurônios se intensifica muito quando estes se tornam mais ativos, e, quanto mais ativos, mais sangue precisam receber pela circulação.

Assim, a circulação sanguínea do SNC deve apresentar características especiais que dêem conta da delicada relação entre atividade funcional, metabolismo e fluxo sanguíneo no tecido nervoso.

Uma característica importante das arteríolas do sistema nervoso é a sua capacidade de mudar localmente seu diâmetro, seja para manter o fluxo sanguíneo 
constante, seja para mudá-lo, em resposta às necessidades funcionais. Ainda não se conhece o mecanismo, mas sabe-se que o diâmetro responde a variações na pressão sistêmica, na faixa entre 60 e $150 \mathrm{mmHg}$, e a sutis alterações da concentrarão sanguínea dos gases respiratórios $\left(\mathrm{O}_{2}\right.$ e $\left.\mathrm{CO}_{2}\right)$.

Quando há uma queda na pressão arterial no organismo de um indivíduo, geralmente há uma diminuição do fluxo ocasionada pela vasoconstrição sistêmica, provocada pela ação de regiões do tronco encefálico e do sistema nervoso autônomo. Porém, no sistema nervoso é prioritário controlar o fluxo, até porque as variações de pressão sanguínea encefálica teriam pouca influência sobre a pressão sistêmica. Portanto, o mecanismo de auto-regulação do diâmetro vascular no sistema nervoso atua no sentido inverso, dentro da faixa mencionada de 60 e $150 \mathrm{mmHg}$, ao invés de ocorrer vasoconstrição, ocorre vasodilatação. Assim, a vasoconstrição sistêmica é compensada pela vasodilatação neural, fazendo com que o fluxo no encéfalo e na medula permaneça constante. Quando há elevação da pressão sistêmica, ocorre vasodilatação sistêmica e vasoconstrição neural. Deste modo, o aporte de sangue para o encéfalo e a medula pode ser mantido constante independente das variações sistêmicas. Fora dessa faixa de 60 e $150 \mathrm{mmHg}$, entretanto, a pressão e o fluxo no SNC acompanham as variações sistêmicas. Porém, há certas condições que fazem com que o fluxo sanguíneo cerebral sofra grandes alterações. Um exemplo é quando a concentração relativa de oxigênio cai (ou cresce a de $\mathrm{CO}_{2}$ ). A inalação de ar com 7\% de $\mathrm{CO}_{2}$ (o ar atmosférico tem geralmente apenas cerca de $0.04 \%$ ) é capaz de duplicar o fluxo sanguíneo do sistema nervoso.

\subsection{Anatomia da circulação cerebral}

O sistema de irrigação arterial do SNC possui três vias de entrada (Ver tabela 2.1): (1) a via anterior ou carotídea, que irriga os hemisférios cerebrais e o tronco encefálico; (2) a via posterior ou vértebro-basilar, que compartilha com as caróti- 


\begin{tabular}{|c|c|c|c|}
\hline \multicolumn{4}{|c|}{ Principais vias de irrigação Arterial de SNC } \\
\hline & \multicolumn{2}{|l|}{ Principais Ramos } & Principais territórios \\
\hline \multirow{4}{*}{$\begin{array}{l}\text { Via an- } \\
\text { terior }\end{array}$} & \multirow{4}{*}{$\begin{array}{l}\text { Carótida interna (par } \\
\text { bilateral) }\end{array}$} & $\begin{array}{l}\text { Cerebral anterior (par } \\
\text { bilateral) }\end{array}$ & $\begin{array}{l}\text { Regiões mediais dos lobos frontal e parietal, } \\
\text { cápsula interna }\end{array}$ \\
\hline & & $\begin{array}{l}\text { Comunicante posterior } \\
\text { (par bilateral) }\end{array}$ & Anastomose com a via posterior \\
\hline & & Oftálmica (par bilateral) & Nervo ótico e retina \\
\hline & & $\begin{array}{l}\text { Coróidea anterior (par } \\
\text { bilateral) }\end{array}$ & Hipocampo, diencéfalo e núcleos da base \\
\hline \multirow{4}{*}{$\begin{array}{l}\text { Via Pos- } \\
\text { terior }\end{array}$} & \multirow{4}{*}{ Basilar (única, mediana) } & $\begin{array}{l}\text { Cerebelar inferior ante- } \\
\text { rior (par bilateral) }\end{array}$ & Regiões inferiores e rostrais do cerebelo \\
\hline & & $\begin{array}{l}\text { Pontinas (várias bilate- } \\
\text { rais) }\end{array}$ & Ponte \\
\hline & & $\begin{array}{l}\text { Cerebelar superior (par } \\
\text { bilateral) }\end{array}$ & Regiões superiores do cerebelo \\
\hline & & $\begin{array}{l}\text { Cerebral posterior (par } \\
\text { bilateral) }\end{array}$ & Regiões mediais e laterais do lobo occipital \\
\hline \multirow{4}{*}{$\begin{array}{l}\text { Via Sis- } \\
\text { têmica }\end{array}$} & $\begin{array}{l}\text { Cerebelar inferior pos- } \\
\text { terior (par bilateral) }\end{array}$ & & Regiões inferiores e caudais do cerebelo \\
\hline & $\begin{array}{l}\text { Espinhal anterior (úni- } \\
\text { ca, mediana) }\end{array}$ & & Região anterior da medula \\
\hline & $\begin{array}{l}\text { Espinhal posterior (par } \\
\text { bilateral) }\end{array}$ & & Região posterior da medula \\
\hline & $\begin{array}{l}\text { Radiculares (muitas, } \\
\text { bilaterais) }\end{array}$ & & Anastomose com a via posterior \\
\hline
\end{tabular}

Tabela 2.1. Principais vias de irrigação Arterial de SNC. (tabela retirada de Lent, 2001).

das a irrigação do tronco encefálico e se encarrega também da medula espinhal; e (3) a via sistêmica, que irriga a medula por anastomose com a via posterior. As grandes 
artérias que formam essas três vias possuem trajetos bastante semelhantes entre indivíduos e ao longo desses trajetos originam-se numerosos ramos que podem ser superficiais (cobrem a superfície externa do encéfalo e da medula, gerando arteríola penetrantes que se aprofundam no tecido e se abrem na rede capilar) ou profundos (orientando-se para estruturas internas do encéfalo, como os núcleos da base, o diencéfalo e outras).

As vias de irrigação arterial do sistema nervoso apresentam poucas anastomoses, em relação às que ocorrem em outros órgãos. Estas poucas anastomoses representam as únicas alternativas para manter irrigada uma região, mesmo que apenas parcialmente, quando sua artéria principal sofre algum tipo de obstrução. A principal estrutura de anastomose é o círculo arterial do cérebro ou polígono de Willis.

O polígono de Willis está situado na base do cérebro, onde circunda o quiasma óptico e o tuber cinéreo, relacionando-se ainda com a fossa interpeduncular e a substância perfurada anterior (figura 2.1). O polígono de Willis é formado pelas porções próximas das artérias cerebrais anterior, média e posterior, pela artéria comunicante anterior e pelas artérias comunicantes posteriores direita e esquerda. A artéria comunicante anterior é pequena e liga as duas artérias cerebrais anteriores, adiante do quiasma óptico. As artérias comunicantes posteriores unem, de cada lado, as carótidas internas às cerebrais correspondentes. Assim, elas formam uma anastomose entre o sistema carotídeo interno e o sistema vertebral. Porém, esta anastomose é apenas potencial, já que, em condições normais não há passagem de sangue do sistema vertebral para o carotídeo interno ou vice-versa. Do mesmo modo, praticamente não existe troca de sangue entre a metade direita e esquerda do polígono de Willis. Existem evidências de que, mesmo na artéria basilar, que é única e formada pela junção das duas artérias vertebrais, há certa independência no fluxo sangüíneo proveniente de cada artéria vertebral (Machado, 1991). O polígono de Willis, em alguns casos, permite a manutenção de um fluxo sangüíneo adequado em todo o cérebro, em caso de obstrução de uma ou mais das quatro artérias que o irrigam. Pode-se ver que a obstrução, por exemplo, da carótida direita provoca uma baixa de pressão em seu território, o que faz com que o sangue flua para aí através da artéria comunicante posterior direita. 


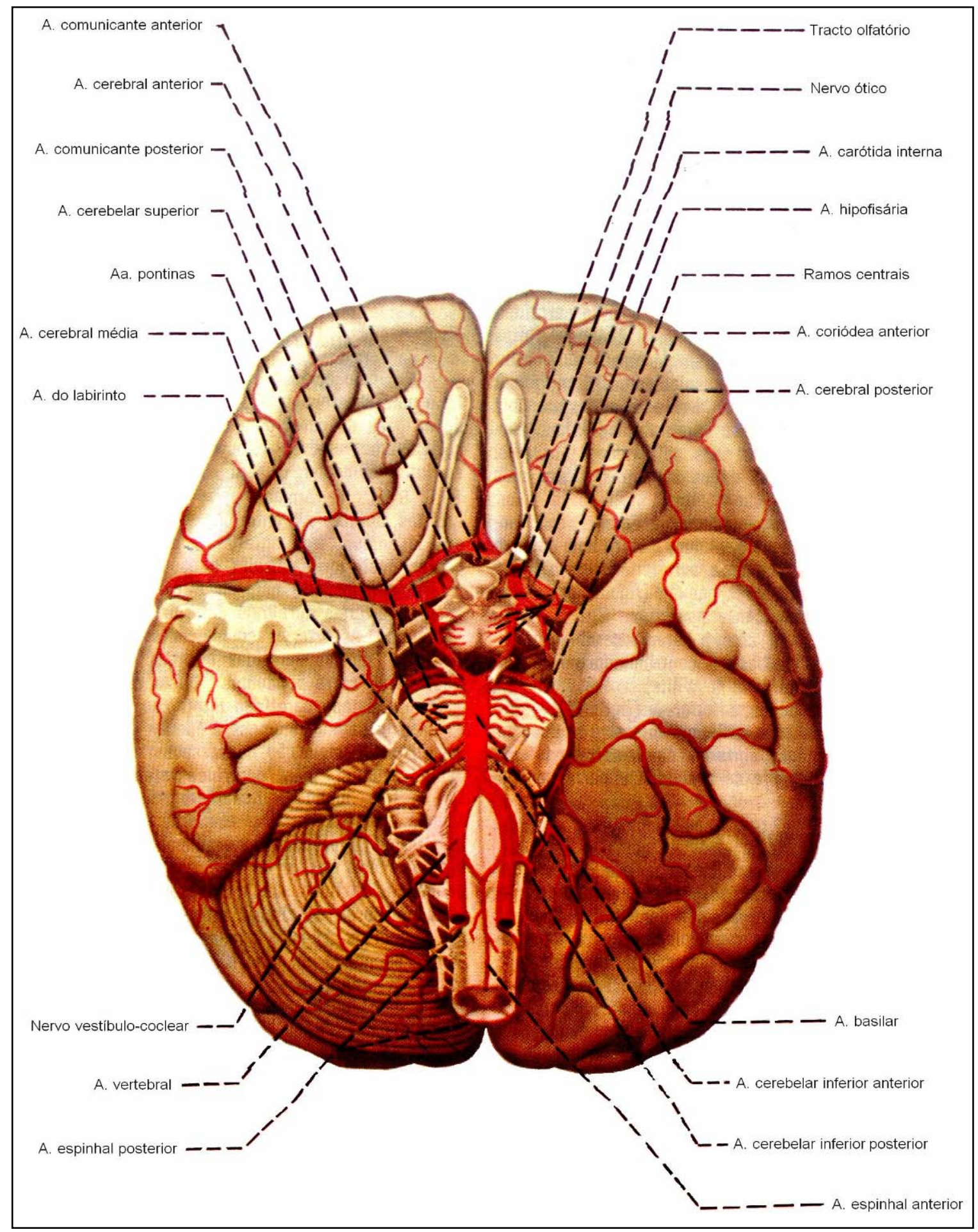

Figura 2.1. Artérias da base do encéfalo. Círculo arterial do cérebro (polígono de Willis). (Figura tirada do livro Ângelo Machado (1991) Neuroanatomia Funcional. Atheneu, Rio de Janeiro, Brasil).

Porém, o polígono de Willis possui muitas variações, que tornam imprevisível o comportamento diante de um determinado quadro de obstrução vascular. Em muitos indivíduos, o círculo é incompleto, faltando uma ou mais artérias comunicantes. Apesar disso, não há qualquer prejuízo funcional. Além do mais, o estabe- 
lecimento de uma circulação colateral adequada, tanto no cérebro como em outras áreas, depende de vários fatores, tais como a rapidez com que se instala o processo obstrutivo e o estado da parede arterial, o qual, por sua vez, depende da idade do paciente.

\subsection{Os territórios de irrigação arterial}

O conhecimento detalhado dos territórios de irrigação das principais artérias do SNC é importante, já que doenças agudas e crônicas desses vasos podem provocar sintomas muito específicos, que dependem da área do tecido nervoso irrigada por cada uma delas. Na tabela 2.1 encontram-se os princípios gerais de organização dos territórios arteriais.

Os hemisférios cerebrais são irrigados pelas artérias cerebrais (anteriores, médias e posteriores, figura 2.2). Em cada lado, a cerebral anterior emerge da carótida interna em direção rostral, próximo à linha média. Insere-se no sulco interhemisférico e contorna o joelho do corpo caloso para trás, deixando no trajeto vários ramos que irrigam a face medial e dorsal do córtex cerebral (figura 2.2.b). Já a artéria cerebral média emerge da carótida interna em sentido lateral (figura 2.2.b), e se aloja no sulco lateral, reaparecendo lateralmente na superfície externa do encéfalo (figura 2.2.a), onde se ramifica para baixo e para cima irrigando toda a face lateral do lobo temporal, a face dorso-lateral dos lobos frontal e parietal e o lobo da ínsula. Por último, a artéria cerebral posterior se origina da basilar, contorna o tronco encefálico e se ramifica profundamente por toda a superfície medial e lateral do lobo occipital (figuras 2.2).

Os núcleos da base e o diencéfalo são irrigados pelos ramos profundos das três artérias cerebrais e por um ramo que emerge diretamente da carótida interna, a artéria coróidea anterior, que também irriga parte do hipocampo. Outro ramo da carótida e a artéria oftálmica irrigam a retina e o nervo óptico. A alimentação do mesencéfalo e do tronco encefálico é feita pelas artérias que constituem a via posterior. 


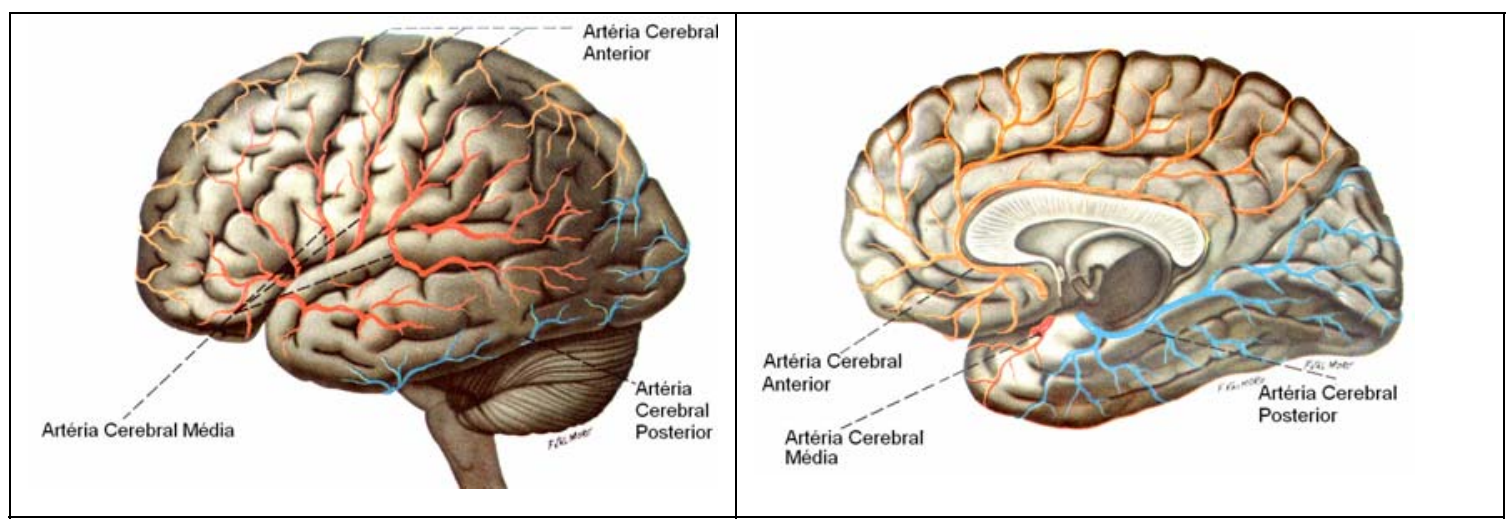

Figura 2.2. (a). Artérias da face súpero-lateral do cérebro (b). Artéria da face medial e inferior do cérebro. (Figuras retiradas de Ângelo Machado, 1991)

\subsection{Líquor}

O Fluido que preenche o espaço subaracnóideo e as cavidades internas do SNC, como já foi visto, é o líquido cefalorraquidiano ou líquor, Cerebral Spinal Fluid (CSF) que desempenha funções essenciais para a proteção e a homeostasia do tecido nervoso.

\begin{tabular}{|l|l|}
\hline \multicolumn{2}{|c|}{ Composição do Liquor } \\
\hline Água $(\%)$ & 99 \\
\hline Proteína (mg/dl) & 35 \\
\hline Glicose $(\mathrm{mg} / \mathrm{dl})$ & 60 \\
\hline Osmolaridade (mOsm/l) & 295 \\
\hline $\mathrm{Na}^{+}(\mathrm{mEq} / \mathrm{l})$ & 138 \\
\hline $\mathrm{K}^{+}(\mathrm{mEq} / \mathrm{l})$ & 2,8 \\
\hline $\mathrm{Ca}^{++}(\mathrm{mEq} / \mathrm{l})$ & 2,1 \\
\hline $\mathrm{Mg}^{++}(\mathrm{mEq} / \mathrm{l})$ & 0,3 \\
\hline $\mathrm{Cl}^{-}(\mathrm{mEq} / \mathrm{l})$ & 119 \\
\hline$p H$ & 7,33 \\
\hline
\end{tabular}

Tabela 2.2. Composição do Líquor. 
(a)

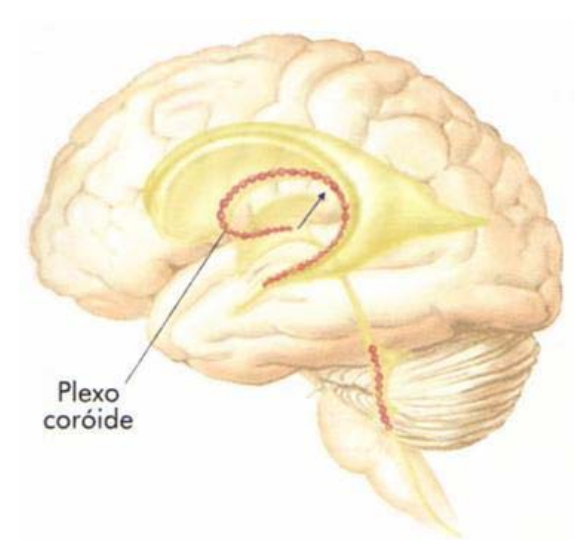

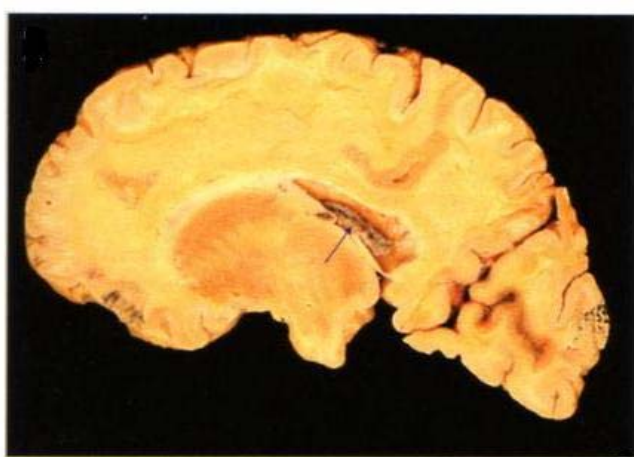

(b)

Figura 2.3. O plexo coróide é a estrutura que sintetiza o líquor. (a) mostra a posição do plexo coróide no interior dos ventrículos. (b) mostra o aspecto do plexo coróide em um corte parassagital de encéfalo humano, no setor do ventrículo lateral apontado pelas setas em (a) e (b). (Figura modificada de Lent, 2001).

O líquor é produzido pelo plexo coróide (figura 2.3), uma estrutura altamente vascularizada situada nos ventrículos, e em menor quantidade pelas células ependimárias que recobrem as cavidades. O plexo retira do sangue os componentes necessários para formar o líquor (tabela 2.2).

Há plexos coróides nos quatro ventrículos, e células ependimárias recobrindo todas as cavidades. Em conjunto, essas estruturas produzem cerca de $500 \mathrm{ml}$ de líquor por dia. Como o volume liquórico total nas cavidades e no espaço subaracnóideo é de aproximadamente $150 \mathrm{ml}$, isso significa que o volume total do líquor é renovado de três a quatro vezes por dia. Pela lógica, então, deve-se supor que haja um processo de absorção (ou eliminação) do líquor que compense a taxa de secreção e mantenha o volume constante. Além disso, se o líquor é secretado nos ventrículos e absorvido em outro lugar, pode-se imaginar a existência de um fluxo circulatório.

De fato, fisiologistas demonstraram que a circulação de líquor é unidirecional e pulsátil, dos ventrículos laterais para o terceiro e o quarto ventrículos, e deste último para o espaço subaracnóide através de duas aberturas laterais e uma mediana (figura 2.4) (Czosnyka et al., 2004). No espaço subaracnóideo, o líquor circula em torno da medula espinhal e do encéfalo até atingir as regiões de drenagem no topo do encéfalo e ao longo da medula. Esse movimento do líquor pode ser visto em seres humanos utilizando técnicas de imagens por ressonância magnética (Hofmann et al., 1995). Na passagem do líquor pelas cavidades ventriculares, e pelo espaço suba- 
racnóideo, intensas trocas ocorrem através do epêndima com o líquido intersticial e como sangue, tanto no plexo coróide como nas paredes ventriculares e especialmente nos espaços periventriculares.

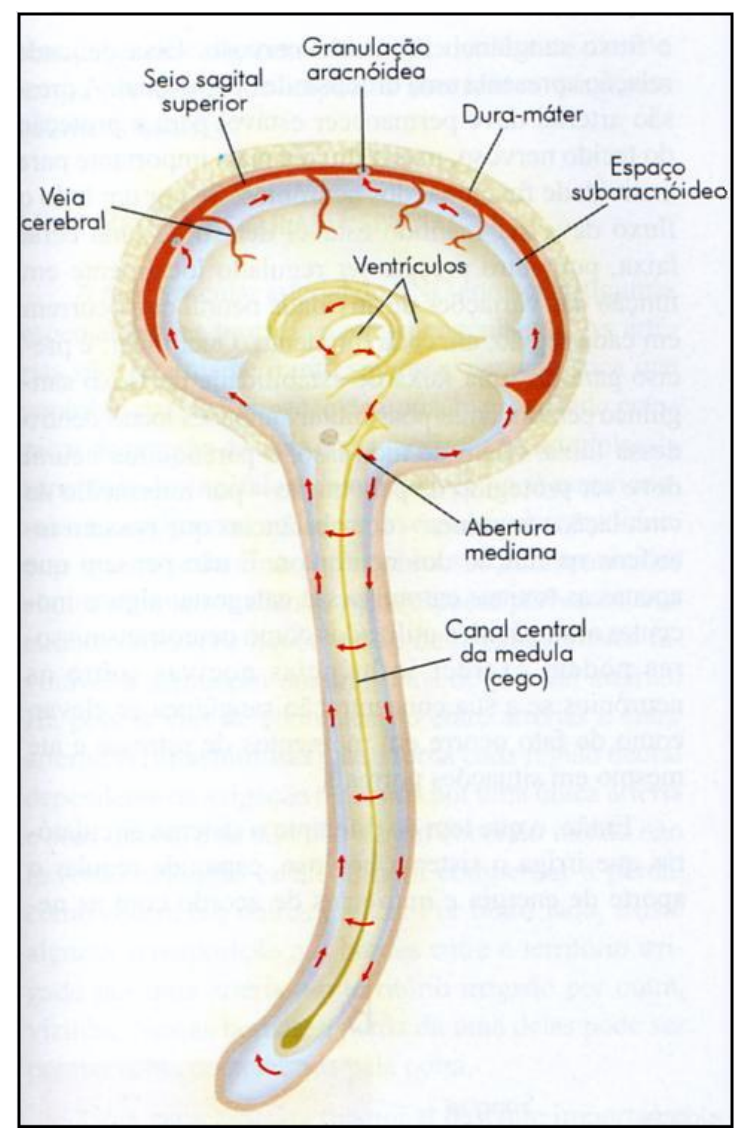

Figura 2.4. $O$ líquor gerado no plexo coróide dentro dos ventrículos emerge através das aberturas do quarto ventrículo (no esquema se vê apenas a abertura mediana) para o espaço subaracnóideo. Dentro do espaço, subaracnóideo o líquor circula em torno da medula e do encéfalo, sendo finalmente reabsorvido nas granulações aracnóideas do seio sagital superior e das raízes medulares (Figura tirada de Lent, 2001).

Geralmente, com a vasodilatação cerebral, a conformação espacial do CSF diminui. Efeitos semelhantes foram confirmados com o aumento de edemas no cérebro, inflação de um balão extradural e outras lesões com expansões de massa (Schettini e Walsh 1988, 1993). No entanto, nenhuma mudança significativa foi observada no coeficiente de elasticidade cerebral $^{2}$ durante a hipotensão arterial (Czosnyka et al., 1999). Em contrapartida, durante a hipercapnia o coeficiente de elasticidade cerebral aumenta, significando um aumento na rigidez do cérebro. Estes

\footnotetext{
${ }^{2} \mathrm{O}$ coeficiente de elasticidade (unidade $\mathrm{ml}^{-1}$ ) é inversamente associado com a resistência ao afluxo do CSF (tans e Poortvliet 1989).
} 
dados sugerem que, durante a hipercapnia, quando as arteríolas parênquimais dilatam, o coeficiente de elasticidade cerebral diminui similarmente ao observado durante edemas experimentais do cérebro ou nos pacientes que sofrem de hipertensão intracraniana benigna. O mais intrigante neste estudo é a mudança na resistência ao afluxo do CSF, observado durante diferentes manobras vasodilatatorias cerebrais. A reabsorção ou afluxo do CSF diminui com hipotensão, mas aumenta com hipercapnia.

\subsection{Barreira hematoencefálica}

A rede capilar do tecido nervoso é especial pois possui uma barreira chamada de barreira hematoencefálica. Por essa barreira deve passar o oxigênio e nutrientes, mas não substância que possam causar dano à função dos neurônios. Através dela, deve haver, também um fluxo inverso das substâncias secretadas pelo sistema nervoso.

Enquanto a camada celular que constitui a parede dos capilares sistêmicos é formada por células endoteliais dispostas lado a lado, entre as quais existem amplos espaços ou poros (fenestrações), por onde passam livremente inúmeros componentes do sangue, até mesmo moléculas relativamente grandes, nos capilares do sistema nervoso as células endoteliais são perfeitamente justapostas, sem fenestrações, e entre elas existe junções oclusivas que impedem a passagem de moléculas entre o compartimento sangüíneo e o intersticial.

Assim, nos capilares, a passagem de moléculas do sangue para o compartimento intersticial só pode ocorrer através das células endoteliais, isto é, passando por dentro delas. Esse caminho de transmembrana ou transcelular força uma seleção entre as moléculas capazes de passar e as que não conseguem fazê-lo.

\subsubsection{Mecanismo seletivo da barreira}

Fisiologistas verificaram que há quatro tipos de passagem de substâncias através da barreira (figura 2.5): (1) difusão livre; (2) transporte mediado por receptores a favor do gradiente de concentração (difusão facilitada); (3) transporte mediado por receptores contra o gradiente de concentração (transporte ativo); e (4) passagem por canais iônicos (Betz et al., 1986). 
Devido à barreira, a difusão livre só é possível para substâncias lipossolúveis, ou seja, aquelas que por suas características físico-químicas são capazes de dissolverem-se nos lipídios, que constituem a membrana plasmática. Substâncias desse tipo atravessam facilmente a parede endotelial impulsionadas pelo gradiente químico. $\mathrm{O} \mathrm{O}_{2}$ e o $\mathrm{CO}_{2}$, os gases da respiração, estão nesse caso, atravessado livremente a barreira do sangue para o parênquima neural.

A glicose é o principal exemplo do segundo tipo de passagem pela barreira hematoencefálica, que é a difusão facilitada, um transporte mediado por receptores e a favor do gradiente químico (figura 2.5). O transportador da glicose trata-se de uma proteína de cerca de 500 aminoácidos, fortemente encravada na membrana endotelial, e conhecida pela sigla Glut-1 (glucose transporter, isotype 1). O Glut-1 existe tanto na membrana luminal como na abluminal, o que garante que a glicose seja transportada do sangue para o citoplasma endotelial, e depois deste para o tecido nervoso. Alguns aminoácidos grandes e neutros são transportados desse modo também por meio de um transportador chamado "sistema L". É o caso da valina e da leucina e também da L-DOPA. A difusão facilitada não depende de energia e apenas favorece a passagem transmembrana dessas substâncias, carreada pela diferença de concentração, que é geralmente maior no sangue do que na célula endotelial e no tecido nervoso.

Outros aminoácidos, pequenos e neutros, como a glicina, a alanina e a serina, são carreados por sistemas transportadores dependentes de energia, que os levam de um compartimento a outro, contra seu gradiente de concentração (transporte ativo, figura 2.5). Esses transportadores são peculiares porque se encontram apenas na membrana abluminal do endotélio e atuam do meio intersticial do tecido nervoso para dentro da célula endotelial. No caso da glicina, um neurotransmissor inibitório particularmente abundante na medula espinhal, esse parece ser um mecanismo importante para remover o excesso resultante da ativação das vias inibitórias.

A energia necessária para o transporte contra o gradiente químico é fornecida por uma enzima que hidrolisa o ATP, chamada $\mathrm{Na}^{+}-\mathrm{K}^{+}$-ATPase ou bomba de $\mathrm{Na}^{+} / \mathrm{K}^{+}$, que atua como transportador iônico (figura 2.5). 


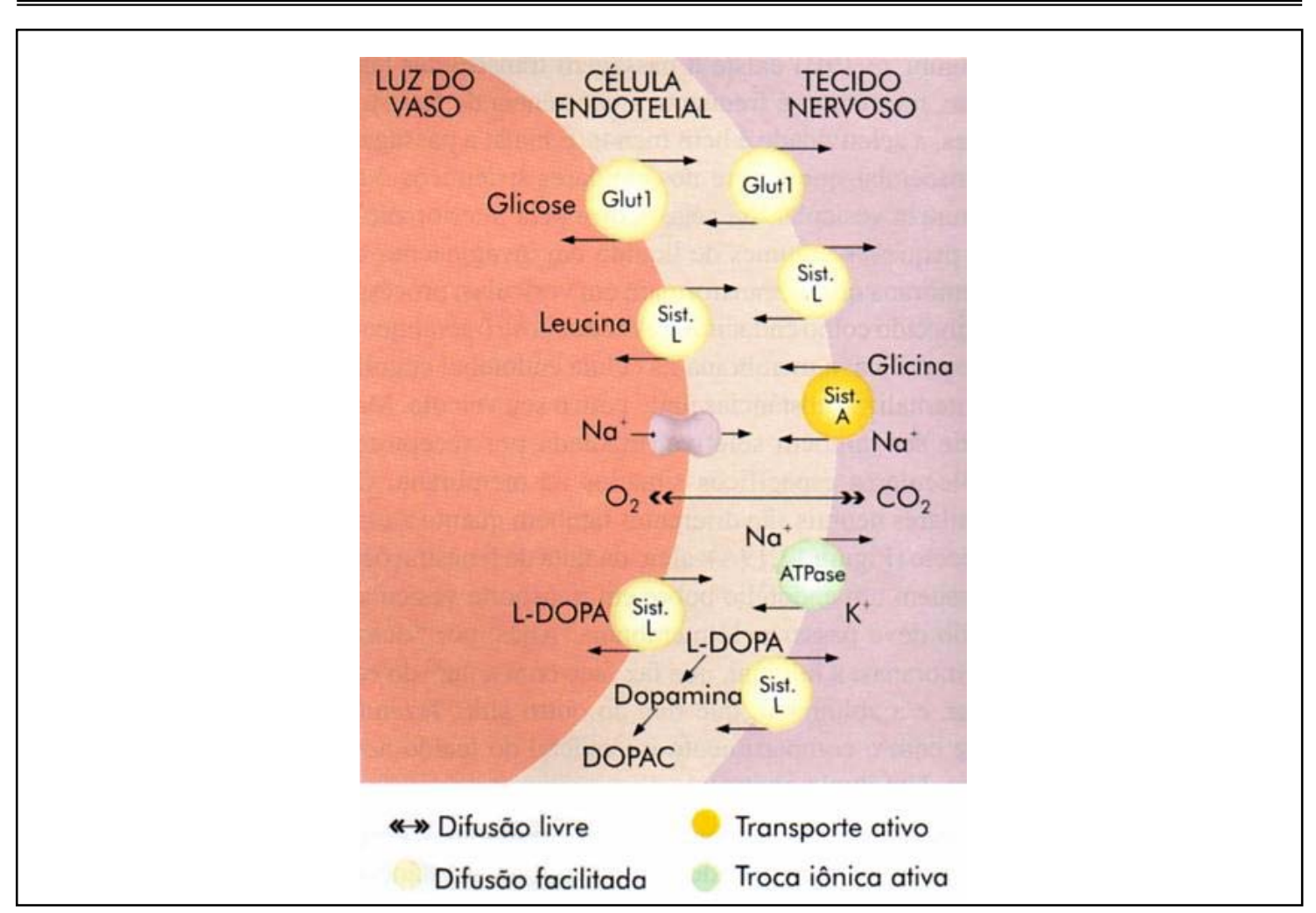

Figura 2.5. Os quatro tipos de passagem de substâncias através da barreira hematoencefálica. DOPAC=ácido di-hidróxifenilacético; L-DOPA= L-di-hidroxifenil-alanina; Glut1= sistema transportador de glicose, isotipo 1. (Figura tirada de Lent, 2001).

Por último, a membrana endotelial apresenta canais iônicos, que permitem a passagem de diversos íons. Canais desse tipo foram identificados na face luminal (Figura 2.5), permitindo a passagem de íons $\mathrm{Na}^{+}$e $\mathrm{K}^{+}\left(\mathrm{Na}^{+}\right.$para dentro e $\mathrm{K}^{+}$para fora). Para completar o transporte para o meio intersticial e no sentido contrário (em ambos os casos contra o gradiente químico), esses íons são carregados pela bomba de $\mathrm{Na}^{+} / \mathrm{K}^{+}$. Desse modo, o sangue fornece o $\mathrm{Na}^{+}$extracelular necessário à atividade elétrica dos neurônios e remove o $\mathrm{K}^{+}$que se acumula no meio intersticial como resultado dela.

Assim, as principais funções da barreira hematoencefálica são: garantir o equilíbrio iônico do compartimento intersticial do tecido nervoso, mediar a entrada controlada de substâncias de importância fisiológicas, possibilitar a saída de substâncias que se acumulem no tecido nervoso com risco potencial de neurotoxidade. A barreira hematoencefálica existe em quase todas as regiões do SNC, exceto algumas que desempenham funções neurossecretoras ou quimioreceptoras. Essas regiões situam-se geralmente próximas à parede dos ventrículos, sendo, por isso, chamadas de órgãos circunventriculares. Em algumas dessas regiões os capilares são fenestra- 
dos, em outras as células endoteliais apresentam abundante transporte vesicular inespecífico.

\subsection{Vascularização venosa do encéfalo}

As veias do encéfalo são maiores e mais calibrosas do que as artérias. Drenam para os seios da dura-máter ${ }^{3}$ de onde o sangue converge para as veias jugulares internas que recebem praticamente todo o sangue venoso encefálico. As paredes das veias encefálicas são muito finas e praticamente desprovidas de musculatura. Faltam, assim, os elementos necessários a uma regulação ativa venosa. Esta se faz principalmente sob a ação de três forças:

a) aspiração da cavidade torácica, determinada pelas pressões subatmosférica da cavidade torácica, mais evidente, no início da inspiração;

b) força da gravidade, notando-se que o retorno sanguíneo do encéfalo é feito a favor da gravidade, o que torna desnecessário a existência de válvulas nas veias cerebrais;

c) pulsação das artérias, cuja eficácia é aumentada pelo fato de que se faz em uma cavidade fechada. Este fator é mais eficiente no seio cavernoso, cujo sangue recebe diretamente a força expansiva da carótida interna que o atravessa.

O leito venoso do encéfalo é muito maior que o arterial, conseqüentemente a circulação venosa é muito mais lenta. A pressão venosa no encéfalo é muito baixa e varia muito pouco devido à grande distensibilidade das veias e seios.

\subsubsection{Veias do cérebro}

As veias do cérebro dispõem-se em dois sistemas: o sistema venoso superficial e o sistema venoso profundo. Embora anatomicamente distintos, estes dois sistemas são unidos por numerosas anastomoses.

3 Seios da dura-máter são canais venosos revestidos de endotélio situados entre os dois folhetos que compõem a dura-máter encefálica. Os seios dispõem-se principalmente ao longo da inserção das pregas da duramáter, distinguindo-se seios em relação com a abóbada (seio sagital superior, sagital inferior, reto, transverso, sigmóide, hospital) e com a base do crânio (seios cavernosos, intercavernosos, esfenoparietal, petroso superior e basilar). 
- Sistema venoso superficial

É constituído por veias que drenam o córtex e a substância branca subjacente, formam anastomoses na superfície do cérebro onde ocorrem grandes troncos venosos, as veias cerebrais superficiais, que desembocam nos seios da dura-máter. Há dois tipos de veias cerebrais superficiais, as inferiores e as superiores.

As veias cerebrais superficiais superiores provem da face medial e da metade superior da face súpero-lateral de cada hemisfério e de sua face inferior, terminando nos seios da base (petroso superior e cavernoso) e no seio transverso. A principal veia superficial inferior é a veia cerebral média superficial, que percorre o sulco lateral e termina, em geral, no seio cavernoso. Esta, geralmente, liga-se à veia anastomótica superior, tributária do seio sagital superior constituindo, assim, importante via de anastomose entre os seios venosos da abóbada e da base do crânio. A anastomose com as veias tributárias do seio transverso é feita através da veia anastomótica inferior.

- Sistema venoso profundo

É formado pelas veias que drenam o sangue de regiões profundas do cérebro, tais como: o corpo estriado, a cápsula interna, o diencéfalo e grande parte do centro branco medular do cérebro. A mais importante veia deste sistema é a veia cerebral magna ou veia de Galeno, para a qual converge quase todo o sangue do sistema venoso profundo do cérebro. A veia cerebral magna, de paredes muito finas, é um curto tronco venoso ímpar e mediano formado pela confluência das veias cerebrais internas logo abaixo do esplênio do corpo caloso, desembocando no seio reto.

A figura 2.6 apresenta um esquema do sistema de drenagem do SNC. 


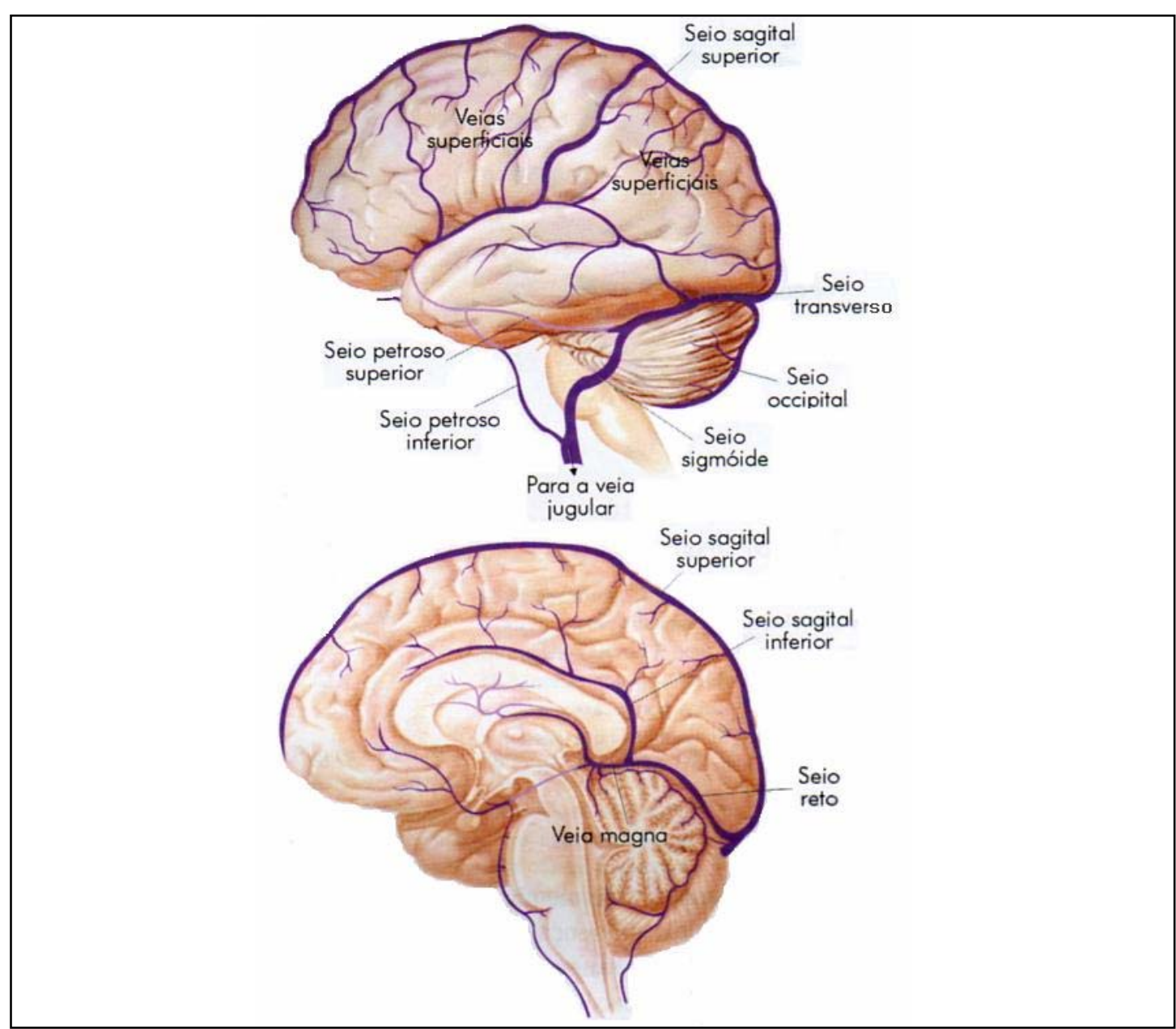

Figura 2.6. O sistema de drenagem venoso do SNC inclui vasos e seios da dura-máter, e associa a drenagem de sangue à do líquor. Ao final, o sangue venoso do encéfalo desemboca na veia jugular em direção ao coração. (a) é uma vista lateral e (b) é uma vista medial. (Figura tirada de Lent, 2001). 


\section{Perfusão Cerebral}

Imagem por ressonância magnética, Magnetic Resonance Imaging (MRI) é uma técnica não invasiva baseada nos conceitos da ressonância magnética nuclear $(\mathrm{N}$ MR). Ela é principalmente usada no contexto médico podendo adquirir imagens de tecido e órgãos com alta resolução espacial e temporal (Apêndice A).

A MRI foi inicialmente usada para adquirir imagens morfológicas de vários tecidos para a identificação de alterações estruturais. Nos últimos anos, contudo, ela evoluiu e várias informações fisiológicas têm sido obtidas através de técnicas modernas de aquisição de imagens, como, por exemplo, a perfusão e o volume sanguíneo.

A perfusão é o fluxo sanguíneo através dos capilares por unidade de massa do tecido, sendo medida em unidades de volume sanguíneo/massa de tecido/tempo, tipicamente $\mathrm{ml} / 100 \mathrm{~g} / \mathrm{min}$ ou $\mathrm{ml} / \mathrm{g} / \mathrm{s}$. No cérebro, essa quantidade é, freqüentemente, referida como fluxo cerebral sanguíneo, Cerebral Blood Flow (CBF). Por outro lado, o volume sanguíneo cerebral, Cerebral Blood Volume (CBV) pode ser definido como o volume total dentro de um voxel dividido pela massa do voxel e é medido em unidades de volume de sangue/massa de tecido, usualmente $\mathrm{ml} / 100 \mathrm{~g}$. O volume sanguíneo é, tipicamente, dividido em volume sanguíneo arterial, capilar e venoso. A maior parte do sangue dentro de um voxel é venoso ou venular.

A perfusão regional foi inicialmente medida com traçadores radioativos através de técnicas como a tomografia computadorizada por emissão de fóton único, Single Photon Emission Computer Tomography (SPECT) e tomografia por emissão de pósitron, Positron Emission Tomography (PET). A primeira tentativa para se medir perfusão usando MRI envolvia a injeção de traçadores marcados com $19 \mathrm{~F}$ e $2 \mathrm{H}$, como uma aproximação das medidas de perfusão com traçadores radioativos (Thomas et al., 1992). No entanto, imagens obtidas usando estes traçadores eram complicadas, devido as suas baixas concentrações, e conseqüente baixo sinal. Atualmente, medidas de perfusão por MRI são baseadas em prótons $(1 \mathrm{H})$ e é medida usando-se traçadores capazes de alterar os tempos de relaxação de tecidos subjacentes. 
Medidas de perfusão podem, geralmente, ser usadas como ferramenta diagnóstica, em especial sobre distúrbios na microvasculatura tecidual (DelaTorre, 1997). Em pesquisas, as medida de perfusão são uma poderosa técnica para investigar a cinética do fluxo sanguíneo. Por exemplo, estas medidas desenvolvem um papel crucial no modelo do consumo de oxigênio durante a ativação cerebral ( $\mathrm{Gu}$ et al., 2005).

\subsection{Técnicas}

Atualmente dois tipos de contrastes, os exógenos e os endógenos, podem ser usados para se avaliar a perfusão cerebral. No caso de mecanismos endógenos admite-se que o traçador se difunde livremente do compartimento intra para extravascular. Para tanto, as duas técnicas mais conhecidas são: o ASL (Arterial Spin Labelling), e o BOLD (Blood Oxygenation Level Dependent).

Por outro lado, a utilização de um mecanismo exógeno, também conhecido como Dynamic Susceptibility Contrast (DSC), se faz a partir de substâncias paramagnéticas injetadas na circulação sangüínea, que permanece restrito ao compartimento intravascular e não se difunde para o espaço extravascular.

Nas próximas seções será discutida apenas a técnica DSC, por ter servido de motivação para a proposta de criação de mapas de CBV deste trabalho, e a BOLD que foi utilizada nos experimentos aqui apresentados.

\subsubsection{Medidas de perfusão usando DSC}

Esta técnica envolve a injeção de um traçador paramagnético em bolus por via intravenosa, geralmente o Gd-DTPA, dose $0.1 \mathrm{mmol} / \mathrm{kg}$. A passagem pela rede de capilares desse bolus promove alterações no campo magnético do tecido cerebral, que podem ser medidas através de variações na intensidade de sinal (diminuição de $\mathrm{T}_{1}$ e $\mathrm{T}_{2}$ ), e que podem ser mapeadas pela utilização de seqüências rápidas, como a EPI (Apêndice A). Ou seja, imagens vão sendo adquiridas enquanto o bolus passa pela rede de capilares. Varias imagens de uma mesma região cerebral são adquiridas no tempo e, desta forma, pode-se capturar a dinâmica deste bolus (variação da concentração do traçador em cada região, no tempo). 
A concentração, dependente do tempo, $\mathrm{C}_{\mathrm{vol}}(\mathrm{t})$ do traçador em um dado volume de interesse (VOI) pode ser descrita em termos de três funções:

Função transporte, $\mathrm{h}(\mathrm{t})$ : densidade de probabilidade do tempo de trânsito t através de um VOI após a injeção instantânea do bolus. Reflete a distribuição do tempo de trânsito através do voxel, no qual é dependente da estrutura vascular e do fluxo.

Função resíduo, $\mathrm{R}(\mathrm{t})$ : fração do traçador injetado que ainda está presente no VOI, no tempo t, após a injeção instantânea do bolus, no tempo $\mathrm{t}=0$. Por definição:

$$
R(t)=1-\int_{0}^{t} h(t) d \tau
$$

O termo da integral representa a fração que deixou o VOI, e $\mathrm{R}(\mathrm{t}=0)=1$, isto é, todo o traçador está presente no VOI no tempo $\mathrm{t}=0$.

- $\quad$ Função de entrada arterial (Arterial Input Function, AIF), Ca(t): concentração do agente de contraste entrando no VOI no tempo t.

Desse modo, a concentração, $\mathrm{CVII}_{\mathrm{V}(\mathrm{t})}$, pode ser escrita em termos de uma convolução da função resíduo e a AIF (Ostergaad et al., 1996b):

$$
C_{V O I}(t)=\left(\frac{\rho}{k_{H}}\right) F_{V O I}\left(C_{a}(t) \otimes R(t)\right)=\left(\frac{\rho}{k_{H}}\right) F_{V O I} \int_{0}^{t} C_{a}(t) R(t-\tau) d \tau .
$$

Em que $\mathrm{F}_{\mathrm{VOI}}$ é o $\mathrm{CBF}$ no VOI, $\rho$ é a densidade do tecido do cérebro e $\mathrm{k}_{\mathrm{H}}=(1$ Hart)/(1-Hcap) dá a diferença de hematrócitos $\mathrm{H}$ (volume percentual de hemácias presentes na amostra de sangue total) entre capilares e vasos grandes.

Essa expressão pode ser interpretada considerando a AIF como sendo uma superposição de consecutivos bolus, $\mathrm{Ca}(\tau) \mathrm{d} \tau$, injetados em um tempo $\tau$. Para cada bolus, a concentração ainda presente no VOI, no tempo t, será proporcional à $C_{a}(t) R(t-\tau) d \tau$. A concentração $C_{\mathrm{VOI}}(\mathrm{t})$ será dada pela integral de todas estas contribuições. Para calcular o CBF, a equação (3.2) deve ser deconvoluida de modo a isolar $\mathrm{F}_{\mathrm{VOI}} \mathrm{R}(\mathrm{t})$. 
Respeitando as condições impostas pela barreira hematoencefálica, Blood Brain Barrier (BBB), o CBV é proporcional à quantidade total de traçador normalizada:

$$
C B V=\left(\frac{k_{H}}{\rho}\right) \frac{\int C_{V O I}(t) d t}{\int C_{a}(t) d t} .
$$

Pode-se observar, pela equação (3.3), que o CBV é dado pela área embaixo da curva de concentração normalizada pela a AIF. A normalização do AIF diz que, independente do $\mathrm{CBV}$, se mais traçador é injetado, uma maior concentração chegará ao VOI.

O terceiro parâmetro fisiológico que pode ser calculado, o MTT (Mean Transit Time), que é o tempo médio para que qualquer partícula de traçador passe através do tecido, considerado uma injeção instantânea. Seu valor é obtido pela relação existente entre o CBF, MTT e CBF, a partir do teorema do volume central:

$$
M T T=\frac{C B V}{F_{V O I}} .
$$

Em um exame de perfusão por MRI, o valor de $C(\mathrm{t})$ não é medido diretamente. Logo, para que se possa fazer uso dos dados obtidos com a MRI, é necessário que se converta a variação da intensidade do sinal MR em concentração do agente de contraste. Foi mostrado, empiricamente (Villriger et al 1988, Rosen et al 1990, Hedehus et al 1997) e usando simulação de Monte Carlo (Weisskoff et al 1994, Boxerman et al 1995, Kennan et al 1994), que a concentração do traçador é proporcional às mudanças nas taxas de relaxação $\mathrm{R}_{2}=1 / \mathrm{T}_{2}\left(\right.$ ou $\mathrm{R}_{2}{ }^{*}$ ). A mudança na taxa de relaxação $\left(\Delta \mathrm{R}_{2}\right)$ pode ser obtida através da variação na intensidade do sinal a partir de um sinal base $\left(\mathrm{S}_{0}\right)$, antes da administração do contraste:

$$
C_{V O I}(t)=k_{V O I} \Delta R_{2}=-\frac{k_{V O I}}{T E} \ln \left(\frac{S_{V O I}(t)}{S_{0}}\right)
$$

SVOI $(\mathrm{t})$ é a intensidade do sinal medido em um VOI no tempo t, e TE é o tempo de eco da seqüência de pulso. A constante de proporcionalidade kvor depende do teci- 
do, do agente de contraste, da intensidade do campo aplicado e os parâmetros da seqüência de pulso.

Várias considerações devem ser feitas para que se possa fazer uso do método descrito acima: primeiro, o fluxo sanguíneo deve permanecer estável durante a medida, segundo o agente de contraste deve possuir volume desprezível e não afetar a CBF; terceiro, a mudança do tempo de relaxação $\mathrm{T}_{1}$ ser desprezível; quarto, a recirculação do sangue é negligenciada ou eliminada. Para eliminar a contribuição dos efeitos de recirculação do agente de contraste pode ser feito um ajuste da curva com uma função gama variável. (para maiores detalhes ver Starmer et al., 1970 e Berninger et al., 1981)

\subsubsection{BOLD}

Uma das grandes descobertas em MRI foi a de que mudanças no metabolismo do cérebro afetam o sinal local de MR promovendo, assim, um mecanismo intrínseco para detecção da atividade cerebral.

A origem desse efeito está nas características magnéticas da hemoglobina (Hb): ela é diamagnética quando oxigenada e paramagnética quando desoxigenada. A presença da deoxi-hemoglobina afeta a susceptibilidade magnética local, criando distorções no campo magnético. Essa inomogeneidade de campo produz uma ligeira alteração no sinal local de MR.

Aumentando-se a atividade cerebral, o fluxo cerebral sanguíneo aumenta bem mais que a razão metabólica cerebral de oxigênio (cerebral metabolic rate of oxygen, $\mathrm{CMRO}_{2}$ ), e, como conseqüência a fração de extração local de oxigênio (E) diminui com a ativação (Fox e Raichle,1986). Devido ao fato do sangue local ser mais oxigenado, há menos deoxi-hemoglobina presente, as distorções magnéticas diminuem, e o sinal MR aumenta ligeiramente. Essa pequena mudança de sinal devido à dependência no nível de oxigenação é conhecida por contraste BOLD, e é, atualmente, o principal mecanismo de contraste utilizado para mapear regiões de atividade cerebral diante de diferentes estímulos, conhecido por imagem funcional por ressonância magnética, Functional Magnetic Resonance Imaging (fMRI).

O sinal BOLD não mede diretamente a atividade neural. Ao invés disso, os seus mecanismos são sensíveis a mudanças do $\mathrm{CBF}, \mathrm{CMRO}_{2}$ e $\mathrm{CBV}$, e esse conjun- 
to de respostas fisiológicas é referido coletivamente como resposta hemodinâmica à ativação.

Além de mapear função cerebral, um crescente número de estudos indica que técnicas de fMRI podem se tornar úteis em avaliações da perfusão cerebral. Nos últimos anos, essas técnicas têm sido usadas para mapear a intensidade do sinal BOLD e mudanças no CBF durante a inalação de $\mathrm{CO}_{2}$ ou injeção de acetazolamida (Lythgoe et al., 1999; Rostrup et al., 1994). Embora a capacidade de reserva cerebrovascular possa ser medida através de PET e SPECT, esses métodos têm grandes desvantagens como a necessidade do uso de radioisótopos, além da sua baixa resolução espaço-temporal.

A propriedade de vasodilatação do $\mathrm{CO}_{2}$, quando inalado, provoca um aumento de fluxo sanguíneo e como não há um aumento no $\mathrm{CMRO}_{2}$, produz uma redução no E e na quantidade total de deoxi-hemoglobina presente em um voxel, levando a um aumento no sinal MR. A acetazolamida, por sua vez, é um inibidor de anidrase carbônica (Brown et al., 2003), que catalisa a conversão de $\mathrm{CO}_{2}$ para íons bicarbonatos, o que aumenta a capacidade do sangue de retirar $\mathrm{CO}_{2}$. Inibindo essa enzima, há um aumento na concentração de $\mathrm{CO}_{2}$ no cérebro, levando a um aumento de CBF.

Recentemente, foi demonstrado que o CBF e mudanças de oxigenação durante a indução de um estado transitório de apnéia (Kastrup et al., 1990) podem ser detectados utilizando técnicas de fMRI. Enquanto estudos precedentes geralmente usam a inalação de $\mathrm{CO}_{2}$ ou a injeção de acetazolamida, para acessar a reatividade cerebrovascular, a indução de um estado transitório de apnéia, que é causada quando o indivíduo prende a respiração por alguns segundos, tem a vantagem de ser menos invasiva por não ter a necessidade de uma fonte de $\mathrm{CO}_{2}$ ou a injeção de acetazolamida.

Além disso, esse tipo de teste pode trazer informações clínicas interessantes. Experiências através de Doppler Transcraniano sugerem que testes utilizando a indução do estado transitório de apnéia podem ser úteis para se obter informações funcionais de pacientes com doenças na artéria carótida (Silvestrini et al., 1996). 
A compreensão das possíveis aplicações clínicas desse método passa pelo melhor entendimento da relação do sinal BOLD com os efeitos fisiológicos neurovasculares causados por alterações da concentração de $\mathrm{CO}_{2}$ sangüíneo.

\section{$\rightarrow$ Relações fisiológicas do efeito BOLD}

$\mathrm{O}$ aumento do $\mathrm{CBF}$ associado à atividade neural é desencadeado pela relaxação do músculo liso das paredes das arteríolas. As arteríolas promovem a maior parte da resistência na árvore vascular e são capazes de diminuí-la por um processo de relaxação dessas fibras. Quando a resistência das arteríolas baixa, a pressão através dos vasos também decresce, aumentando a pressão nos capilares e veias. Os vasos também podem expandir devido ao aumento de pressão, aumentando o CBV.

Estudos experimentais, através de cintilografia, (Grubb et al., 1974) têm mostrado que a relação no estado de repouso do $\mathrm{CBV}$ e do $\mathrm{CBF}$ pode ser descrita como uma lei de potência:

$$
\frac{C B V}{C B V_{0}}=\left(\frac{C B F}{C B F_{0}}\right)^{\alpha},
$$

em que o expoente é, $\alpha=0.4$, e o subscrito " 0 " denota o valor na linha de base. Essa relação empírica aplica-se a todo volume sanguíneo.

Por outro lado, o $\mathrm{CBF}$ e o $\mathrm{CMRO}_{2}$ também estão relacionados pela concentração arterial de oxigênio, $C_{a}$, e pela fração líquida da extração do oxigênio, $E$ (Buxton et al., 2004):

$$
\mathrm{CMRO}_{2}=\mathrm{E} \cdot \mathrm{C} \cdot \mathrm{CBF} \text {. }
$$

Para pequenas mudanças em torno da linha de base, experimentos sugerem que a relação entre as mudanças de $\mathrm{CBF}$ e o $\mathrm{CMRO}_{2}$ é linear, com inclinação n, definida por:

$$
n=\frac{\Delta C B F / C B F_{0}}{\Delta C M R O_{2} / \mathrm{CMRO}_{20}},
$$

o subscrito " 0 " denota o valor na linha de base. Medidas experimentais encontraram n=2-3 (Davis et al., 1998; Hoge et al., 1999; Kastrup et al., 2002; Marrett and Gjedde, 
1997; Seitz e Roland, 1992), no entanto, valores maiores também têm sido registrados (Fox e Raichle, 1986; Kuwabara et al., 1992).

$O$ fato de $n>1$ implica em um aumento de $E$ com a ativação, sendo essa a fonte fisiológica do efeito BOLD, originalmente descrita como o desacoplamento do $\mathrm{CBF}$ e $\mathrm{CMRO}_{2}$, no trabalho de Fox e Raichle (1986).

Através do estudo dessas relações fisiológicas alguns modelos para o efeito BOLD foram propostos.

\section{$\rightarrow$ Modelando o efeito BOLD}

O efeito BOLD é primeiramente devido a mudanças locais no índice de deoxi-hemoglobina. Mas deve-se levar em conta que há duas fontes de mudança de sinal que devem ser modeladas: os sinais intravasculares e os extravasculares (Boxerman et al., 1995a; Ogawa et al., 1993). Embora o sinal intrínseco intravascular seja muito menor que o sinal extravascular, a sensibilidade do sinal intravascular à oxigenação do sangue é muito maior. O resultado é que a contribuição intravascular é responsável por metade ou mais da mudança de sinal observada. O índice de deoxihemoglobina total pode ser mudado, também, pela alteração da fração de extração de oxigênio ou do volume de sangue venoso. Então, o papel da mudança de volume deve ser incluído (Boxerman et al., 1995b; Ogawa et al., 1993 Yablonsky a Haacke, 1994). Finalmente, para os vasos menores, o efeito de difusão pode ser importante. Assim, modelar o efeito BOLD depende não só do modelo biofísico pelos quais diferenças de susceptibilidade intravascular alteram o sinal, mas também modelos fisiológicos para o qual CBF, $\mathrm{CBV}$ e $\mathrm{CMRO}_{2}$ mudam com a ativação. A mudança relativa no $\mathrm{CBF}$ e $\mathrm{CMRO}_{2}$ determina o nível de oxigenação do sangue, o CBV determina a quantidade total de sangue, e, assim, o total de deoxi-hemoglobina presente no voxel.

\section{$\rightarrow$ Efeito da susceptibilidade magnética e o sinal de MR}

Ogawa et al. (1993) introduziu um modelo biofísico para o efeito BOLD e Davis et al. (1998) estendeu esse modelo baseado em aproximações razoáveis e em resultados de simulação numérica. Pela simplicidade, o modelo tem provado ser 
uma ferramenta útil para entender o efeito BOLD de um modo quantitativo e fornece um modo de calibrar o sinal BOLD e medir as mudanças de $\mathrm{CMRO}_{2}$.

O sinal de MR, para uma aquisição típica, é modelado por uma dependência exponencial com o tempo de eco (TE), e pode ser escrito como:

$$
\begin{gathered}
S=S_{\max } \cdot e^{-T E \cdot R_{2}^{*}}, \\
R_{2}^{*}=R_{2}^{*}(0)+R,
\end{gathered}
$$

sendo $S_{\max }$ o efeito da densidade de spin, que refletiria o sinal medido caso TE pudesse ser reduzido a zero. A constante da taxa de relaxação transversal, $R_{2}{ }^{*}$, é descrita como a soma de dois termos: $R_{2}^{*}(0)$ é o valor de $R_{2}^{*}$ se nenhuma deoxihemoglobina estivesse presente, e $\mathrm{R}$ descreve a relaxação adicional produzida pela deoxi-hemoglobina. $R_{2}^{*}(0)$ é muito maior que $R$, isto é, o $T_{2}^{*}$ que descreve o decaimento do sinal é mais fortemente determinado pelo $\mathrm{T}_{2}$ intrínseco e pelo gradiente de campo no voxel, que pelo efeito adicional da deoxi-hemoglobina. Por esta razão, a mudança de sinal devido ao efeito BOLD é pequena, mas mensurável.

Buxton et al. (Buxton et al., 2004), tentando modelar o sinal BOLD, consideraram que, durante a ativação, $R$ é o único parâmetro que muda. Desta forma, o sinal BOLD durante a ativação ficaria:

$$
\begin{gathered}
\frac{\Delta S}{S_{0}}=-e^{-\Delta R_{2}^{*} \cdot T E}-1 \approx-\Delta R_{2}^{*} \cdot T E, \\
\Delta R_{2}^{*}=R_{a c t}-R_{0} .
\end{gathered}
$$

O subscrito " 0 " denota o valor no estado de repouso e "act" denota os valores em estados de atividade e $\Delta S=S_{\text {act }} S_{0}$. A magnitude da distorção do campo próxima ao vaso magnetizado é proporcional à diferença de susceptibilidade magnética entre o sangue e o espaço extravascular ao redor. Experimentos indicam que a diferença de susceptibilidade pode ser modelada por uma dependência linear com a concentração local de deoxi-hemoglobina no sangue, que pode ser expressa em termos da mudança na fração de extração de oxigênio.

No entanto, como spins evoluem em um campo inhomogêneo, há uma distribuição dos ângulos de fase, e essa dispersão da fase na coleção de dados no tempo é que determina $R$. Em particular, a difusão das moléculas de água suaviza a 
distribuição do campo para criar uma menor propagação das fases. Para modelar isso de uma forma aproximada, David et al. (1998) supuseram uma relação de lei de potência entre $R$ e a magnitude da distorção do campo, $\Delta B: R \propto \Delta B^{\beta}$. Simulações numéricas (Boxerman et al., 1995a, b; Ogawa et al., 1993) e análises teóricas (Yablonsky e Haacke, 1994) sugerem que quando a difusão não é importante $\beta \approx 1$, mas que $\beta \approx 2$ descreve melhor a região próxima aos pequenos vasos, onde o efeito de difusão é importante. Simulações numéricas de uma mistura de vasos de diversos tamanhos sugerem que $\beta=1.5$ é uma boa aproximação para 1.5-3T, mas em campos maiores $\beta$ deve se aproximar de 1 .

Além da mudança de E com a ativação, a mudança no volume sangüíneo também afeta $R$. Por exemplo, mesmo que a oxigenação do sangue não mude mas o volume venoso sangüíneo aumente, a quantidade total de deoxi-hemoglobina irá aumentar, e é de se esperar que isso faça com que $R$ aumente e o sinal de MR diminua. Simulações numéricas sugerem que uma aproximação razoável é considerar $\mathrm{R}$ proporcional a $V$, volume sangüíneo venoso. Combinado essa dependência, a contribuição da deoxi-hemoglobina na taxa de relaxação (Buxton et al., 2004):

$$
R \propto V E^{\beta} .
$$

\section{$\rightarrow$ Mudanças no sinal BOLD}

A evolução temporal do sinal BOLD é conhecida como função resposta hemodinâmica, hemodinamic response function (HRF). A figura 3.1 ilustra a HRF em uma região cerebral. A forma da HRF varia com as propriedades do estimulo evocado e com a atividade neural subjacente. A altura do patamar está associada ao grau de atividade neural. Se ocorrer aumento da taxa de atividade neural, pode-se esperar um aumento da amplitude da HRF e, da mesma maneira, se a duração da atividade neural for aumentada, a largura da HRF também poderá aumentar. A relação exata entre os eventos neurais que provocam a HRF e sua forma ainda não estão bem claros. Sabe-se, no entanto, que as respostas neurais corticais, que ocorrem dentro de aproximadamente $10 \mathrm{~ms}$, só promovem as primeiras mudanças observáveis da HRF em torno de 1 ou 2 segundos depois do estímulo. 
Geralmente, a HRF para uma área de atividade neural específica, como, por exemplo, a área visual, é composta por sete fases distintas: (i) antes da apresentação do estímulo, o sinal encontra-se em uma linha de base; (ii) em seguida, geralmente logo após a apresentação do estímulo, a resposta decresce por um breve intervalo de tempo. Esse padrão foi atribuído devido à extração de oxigênio inicial antes do aumento do fluxo sanguíneo e aumento transiente na concentração da $\mathrm{dHb}$, mas esse efeito não é sempre visto, sendo com mais freqüência em estímulo visual; (iii) após a depressão do sinal, ele inicia uma etapa de derivada positiva (BOLD positivo anterior), atingindo um máximo, usualmente após 7-10 segundos do estímulo. Este máximo é conhecido como o pico da HRF (figura. 3.1). (iv) o sinal permanece em um platô por poucos segundos. Se a atividade neural é estendida através de um bloco de eventos no tempo, o pico pode ser estendido dentro de um platô; (v) em seguida, ele passa a decrescer, formando um efeito de BOLD positivo posterior; (vi) esse decréscimo é seguido por uma nova depressão do sinal, negativo com respeito à linha de base, conhecido como undershoot, uma vez que, seguindo o término da atividade neural, o fluxo sanguíneo diminui mais rapidamente que o volume sanguíneo. Se o volume permanece acima do nível da linha de base, enquanto o fluxo estava na linha de base, então uma maior quantidade de dHb estará presente, fazendo com que o sinal de MR seja levado a valores abaixo da linha de base. (vii) como o volume sanguíneo retorna lentamente para níveis normais, o sinal fMRI aumentará, gradativamente, voltando para a linha de base.

\section{$\rightarrow$ O modelo do balão}

O modelo do balão (Buxton et al., 1998a) foi motivado pela observação em estudos com animais (Mandeville et al., 1998) no qual o CBV voltava à linha de base mais lentamente que o CBF após o estímulo, e pela idéia que esse efeito pudesse explicar a queda freqüentemente observada do sinal BOLD, abaixo da linha de base, logo após o estímulo.

O modelo é capaz de produzir a queda do sinal BOLD abaixo da linha de base após o estímulo, e tem boa correlação com os dados experimentais. No entanto, a premissa central do modelo, que essa queda ocorre quando o CBV retorna len- 
tamente para a linha de base, não foi definitivamente estabelecida e testes experimentais são necessários para responder essas questões (Mandeville et al., 1999a.; Toronov et al., 2003).

A resposta rápida correspondendo à queda inicial do sinal BOLD foi primeiro detectada em estudos ópticos medindo as mudanças de deoxi-hemoglobina e oxi-hemoglobina, e foi interpretada como um aumento rápido de E. No entanto, esta interpretação não é completamente consistente com os estudos mais recentes, os quais encontraram que o período de resposta rápida corresponde a um aumento da deoxi-hemoglobina mas nenhuma mudança na oxi-hemoglobina (Jones et al., 2001; Malonek e Grinvald, 1996), sugerindo uma mudança combinada no CBV e E (Buxton, 2001). Na versão original do modelo do balão (Buxton et al., 1998a), foi notado que a queda inicial do sinal BOLD também poderia resultar de um rápido aumento no volume sangüíneo com nenhuma mudança em E. Um estudo mais recente, no entanto, encontrou uma queda inicial correspondente na oxi-hemoglobina em conjunto com um aumento na deoxi-hemoglobina, mais claramente sugerindo uma mudança no E (Devor et al., 2003), fazendo com que Buxton et al. (2004) em seu novo modelo atribuíssem a queda inicial à essa mudança.

O modelo do balão tem sido aprimorado e comparado a dados experimentais (Feng et al., 2000; Friston 2002; Friston et al. 2000; Mildner et al., 2001; Obata et al., 2004; Toronov et al., 2003), e alguns erros na estimativa dos parâmetros originais foram recentemente corrigidos (Obata et al., 2004).



Figura 3.1. Diagrama ilustrativo da resposta hemodinâmica, visualizada em um voxel da imagem. Várias fases compõem o sinal: (a) Linha de base. (b) BOLD negativo anterior. (c) BOLD positivo crescente. (d) Resposta de pico. (e) BOLD positivo decrescente. (f) BOLD negativo posterior. (g) Retorno à linha de base. 


\section{$\rightarrow$ Acoplamento neurovascular}

Atualmente, não se tem um entendimento quantitativo do mecanismo que acopla a atividade neural ao $\mathrm{CBF}$ e à $\mathrm{CMRO}_{2}$. De fato, não há consenso sobre qual aspecto da atividade neural comanda a resposta hemodinâmica e isso ainda é alvo de pesquisa.

Friston et al. (2000) introduziu um modelo de acoplamento neurovascular no qual a taxa de mudança do CBF é proporcional à concentração de agentes vasoativos liberados pela atividade neural. Nesse modelo, a resposta CBF é uma transformação linear da atividade neural.

Uma das finalidades de se modelar a resposta hemodinâmica é entender a origem da não linearidade da resposta, e para este propósito, é útil ter um modelo que inclua a transformação não linear do padrão de estímulo para a resposta do CBF. Tal não-linearidade pode surgir do estímulo para a resposta neural, por exemplo, na adaptação. Além disso, a não linearidade pode ocorrer da atividade neural para a resposta $\mathrm{CBF}$, por exemplo, o $\mathrm{CBF}$ atingir um platô.

Buxton et al. (2004) propuseram que a não linearidade acontece do estímulo para a atividade neural. Nele, a resposta neural governa, independentemente, a resposta $\mathrm{CBF}$ e $\mathrm{CMRO}_{2}$, sendo essas convoluções lineares de uma função da resposta impulso $\mathrm{h}(\mathrm{t})$ com a atividade neural, $\mathrm{N}(\mathrm{t})$

Uma forma plausível para essa função impulso é o modelo proposto por Friston em 1998 (Friston et al., 1998), que consiste da diferença de duas funções gama:

$$
h(t)=\left(\frac{t}{d}\right)^{a} \exp \left(-\frac{t-d}{b}\right)-c\left(\frac{t}{d^{\prime}}\right)^{a^{\prime}} \exp \left(-\frac{t-d^{\prime}}{b^{\prime}}\right)
$$

Sendo t o tempo, $d=$ ab, o tempo para o pico, e d' = a'b', o tempo para o undershoot.

\section{$\rightarrow$ Efeitos da linha de base fisiológica na resposta BOLD}

Crescentes evidências sugerem que a linha de base do CBF pode ter um grande efeito na magnitude da resposta BOLD para um mesmo estímulo (Corfield et al., 2001; Davis et al, 1998; Hoge at al., 1999; Kastrup et al, 2002; Kim et al., 1999; Li 
et al., 1999). Por exemplo, se a linha de base do CBF for aumentada pela inalação de $\mathrm{CO}_{2}$, a resposta BOLD para uma mesma tarefa é reduzida substancialmente. No entanto, a mudança no $\mathrm{CBF}(\triangle \mathrm{CBF})$ parece ser a mesma, independente da mudança na linha de base (Ances et al., 2001; Kastrup et al., 2002; Li et al, 1999, 2000). Resultados similares têm sido encontrados com injeção de acetazolamida.

Embora se saiba que a linha de base do CBF pode afetar a resposta BOLD, não se sabe o que determina a linha de base CBF. Uma teoria recente, não muito bem estabelecida, afirma que o CBF é regulado para manter constante a relação entre $\mathrm{O}_{2}$ e $\mathrm{CO}_{2}$ na mitocôndria para preservar a energia termodinâmica livre do metabolismo oxidativo da glucose (Buxton, 2004).

A concentração de $\mathrm{O}_{2}$ nas mitocôndrias $\left(\left[\mathrm{O}_{2}\right]\right)$ é determinada por $E$, assim aumentar o fluxo difusivo do $\mathrm{O}_{2}$ dos capilares para mitocôndria, a fim de manter $\left[\mathrm{O}_{2}\right]$, requer que $E$ diminua com ativação. Além disso, o aumento do $\mathrm{CO}_{2}$ no sangue diminui a relação [O2]/[CO2], e, para que isso seja restaurado, diminui-se E novamente. Assim, o modelo prediz que $\mathrm{CBF}$ deve aumentar com $\mathrm{CO}_{2}$, e esse aumento adicional é requerido pela necessidade de aumento do $\mathrm{CMRO}_{2}$. Pelo modelo proposto por Buxton (2004), a mudança de $\mathrm{CBF}$ devido à ativação e ao $\mathrm{CO}_{2}$ é um caso especial de mudanças induzidas na linha de base do $\mathrm{CO}_{2}$. Porém, experiências futuras são necessárias para testar se este fenômeno ocorre também quando a linha de base CBF é alterada por outros meios.

Imagens que podem trazer, por exemplo, informações perfusionais ou funcionais, de uma dada região cerebral podem ser adquiridas fazendo uso das relações fisiológicas descritas anteriormente. Nas próximas seções será descrito como estas imagens são obtidas e analisadas para que se possam tirar informações destes dados obtidos no ambiente da ressonância. 


\section{AQUISIÇÃO DAS IMAGENS E PRÉ-PROCESSAMENTO}

Um exame típico de fMRI é dividido, basicamente, em duas partes. Em um primeiro momento, são adquiridas as imagens que resultam nas localizações de difusão, perfusão ou ativação funcional para uma região cerebral específica, através do cálculo de mapas estatísticos. Neste trabalho, para esta primeira parte, foi obtida imagens de alterações perfusional no cérebro humano mapeadas pelas mudanças da resposta do sinal BOLD pela indução transitória do estado de apnéia utilizando a seqüência de pulso do tipo EPI.

Como já discutido (Apêndice A), seqüências de pulso EPI possuem boa resolução temporal, mas baixa resolução espacial. Portanto, após a aquisição dessa primeira série de imagens, um segundo conjunto de imagens é obtido com o objetivo de servir de substrato para a apresentação dos resultados estatísticos, uma vez que apresentam uma boa resolução anatômica, com voxels de $1,0 \mathrm{~mm}^{3}$. No caso do presente estudo, esse segundo conjunto é formado por seqüências ponderadas em $\mathrm{T}_{1}$, do tipo MPR, orientadas no plano sagital, e cobrindo os dois hemisférios cerebrais.

Para o pesquisador saber se uma determinada área é ativada, ou não, devido a um determinado estímulo, ou determinar a difusão e perfusão de uma determinada área, é necessário estabelecer uma forma para o experimento, também conhecido por paradigma.

\subsection{Desenho experimental}

Paradigmas em fMRI correspondem à série de tarefas apresentadas ou a serem apresentadas aos indivíduos a fim de se observar áreas de atividade cerebral (Clare, 1998). O seu planejamento é fundamental na obtenção de bons resultados, que reflitam a atividade de regiões específicas de interesse, devendo engajar uma circuitaria neural bastante restrita.

Os paradigmas são, então, desenhados a partir de estímulos, enquadrados em três grupos: 
- Discretos, ou paradigmas em bloco: alternam-se períodos de atividade com períodos de repouso, de, aproximadamente, mesma duração;

- Contínuos ou paramétricos: os estímulos são apresentados continuamente, em geral de forma aleatória;

- Evento-relacionados ou evento-único: estímulos curtos são intercalados com longos períodos de repouso.

Cada tipo de paradigma possui vantagens e desvantagens (tabela 4.1).

\begin{tabular}{|c|c|c|}
\hline & VANTAGENS & DESVANTAGENS \\
\hline Bloco & $\begin{array}{l}\text { Excelente poder de detecção; } \\
\text { útil para examinar estados tran- } \\
\text { sitórios; Fácil de analisar. }\end{array}$ & $\begin{array}{l}\text { Pouco poder de estimativa; } \\
\text { Insensível a forma da resposta } \\
\text { hemodinâmica; problemas em } \\
\text { selecionar condições. }\end{array}$ \\
\hline paramétricos & $\begin{array}{l}\text { Bom poder de detecção; Per- } \\
\text { mite a determinação de mu- } \\
\text { danças a partir da linha de ba- } \\
\text { se; estratégias de análise muito } \\
\text { flexíveis; melhor para a classifi- } \\
\text { cação experimental post-hoc. }\end{array}$ & $\begin{array}{l}\text { Pode ter o poder de detecção } \\
\text { reduzido; Susceptível a erros na } \\
\text { função hemodinâmica predito- } \\
\text { ra; Efeitos refratários podem } \\
\text { influenciar as análises. }\end{array}$ \\
\hline Evento-relacionado & $\begin{array}{l}\text { Melhor combinação entre de- } \\
\text { tecção e estimativa; Capaz de } \\
\text { dissociar componentes transi- } \\
\text { ente e sustentado de atividade. }\end{array}$ & $\begin{array}{l}\text { O mais complicado de analisar; } \\
\text { Requer a suposição de lineari- } \\
\text { dade. }\end{array}$ \\
\hline
\end{tabular}

Tabela 4.1. Vantagens e desvantagens de cada tipo de paradigma de fMRI (Tabela modificada de Huettel et al., 2004)

Dado que neste trabalho foram utilizados os paradigmas em bloco e evento-relacionado serão detalhados, a seguir, alguns aspectos importantes de ambos.

\subsubsection{Paradigmas em bloco}

Esses paradigmas consistem de várias épocas discretas, que alternam períodos com e sem a presença de estímulos, gerando um padrão tipo ligado e desligado. Por exemplo, imagine que se queira investigar e mapear a atividade cerebral associada ao movimento voluntário das mãos. Em um primeiro instante, para formar a li- 
nha de base, o voluntário/paciente deve se encontrar em uma condição de repouso, neste caso, não deve estar movimentando os dedos. Posteriormente, o voluntário passa para a situação ativa, sendo neste caso a movimentação dos dedos. Assim, os períodos de repouso e atividade são intercalados e repetidos até que um número suficiente de imagens seja obtido, formando um padrão semelhante ao da figura 4.1a. Enquanto o paciente realiza esse protocolo as imagens funcionais são adquiridas.

Como resultado, voxels da imagem presentes em regiões corticais ativas são seguidos de alterações no contraste da imagem. Como esses estados de atividade são intercalados com estados de repouso, o sinal proveniente dessa região forma um padrão topográfico semelhante àquele mostrado na figura 4.1b. Ou seja, como foi visto na seção 3.1.2, quando uma área cerebral é ativa, observa-se um aumento do sinal BOLD, como o protocolo intercalou períodos de repouso e atividade, esperase que as áreas que responderam a esses estímulos apresentem um aumento de sinal nos períodos em que a atividade (aqui, movimento das mãos) estava sendo realizada. Em contrapartida, regiões que não responderam à tarefa apresentarão um padrão de ruído, simplesmente.

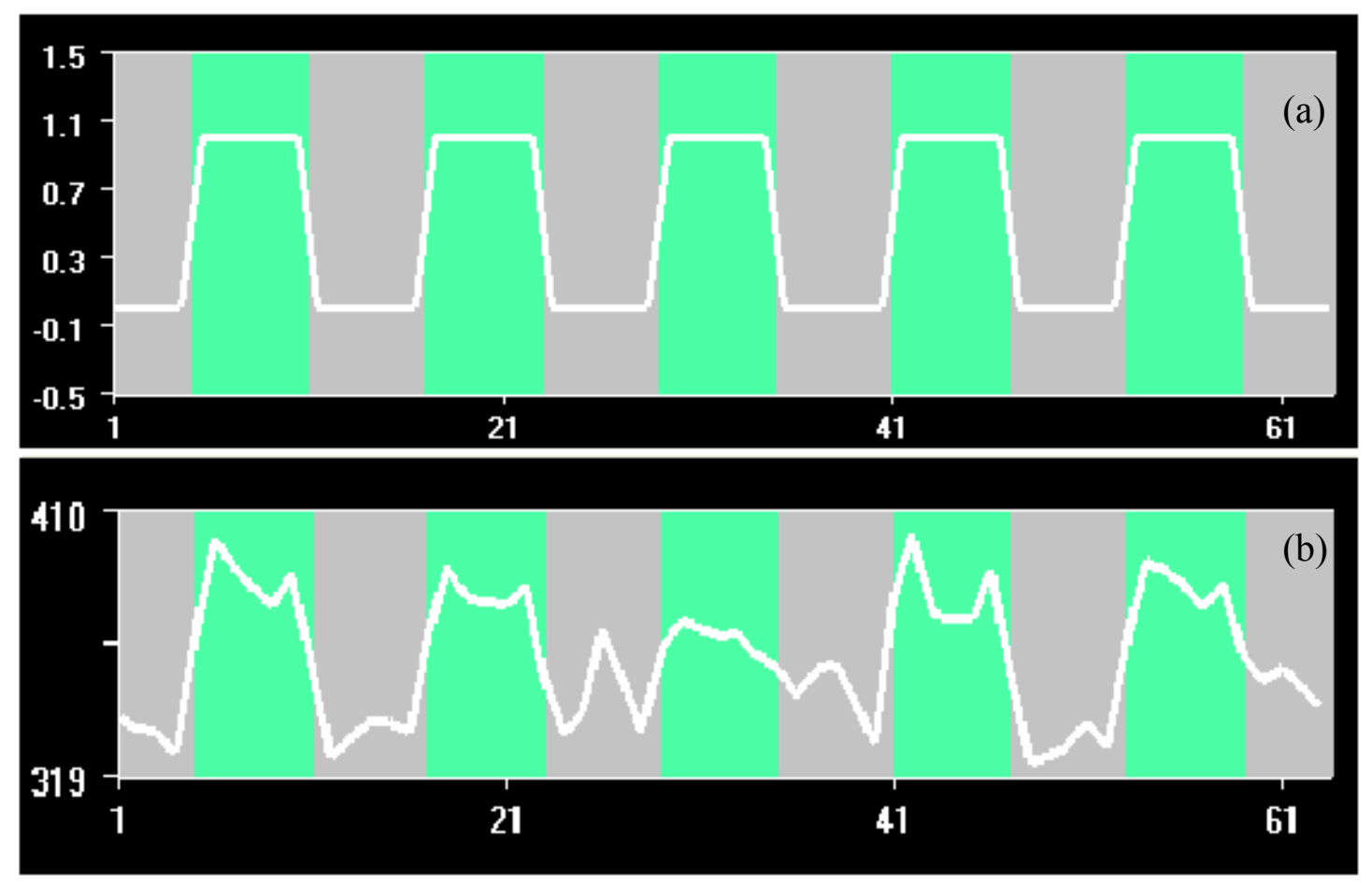

Figura 4.1. (a) Representação do paradigma em bloco. (b) Sinal típico de um voxel durante a realização do paradigma de bloco. 
A idéia central do paradigma em bloco é manter a função BOLD em seu máximo por um tempo relativamente longo, para que a amostra seja comparada com a amostra proveniente da linha de base.

Embora, como já foi apresentado na tabela 4.1, seja mais fácil a análise dos dados adquiridos por esse paradigma, uma vez que a resposta pode ser representada por uma função simples, a informação relativa à função de resposta hemodinâmica de uma única ativação não poder ser obtida, pois respostas individuais são perdidas devido ao longo período de ativação. Por isso, para analisar e inferir melhor certos aspectos da função de resposta hemodinâmica é interessante a utilização de paradigmas o evento-relacionados.

\subsubsection{Paradigmas evento-relacionado}

Os paradigmas evento-relacionado associam processos cerebrais a eventos discretos pela apresentação do estímulo por um período de tempo relativamente curto enquanto que o repouso é relativamente longo. A figura 4.2a apresenta um esquema do estímulo e também da função resposta hemodinâmica para um paradigma evento relacionado.

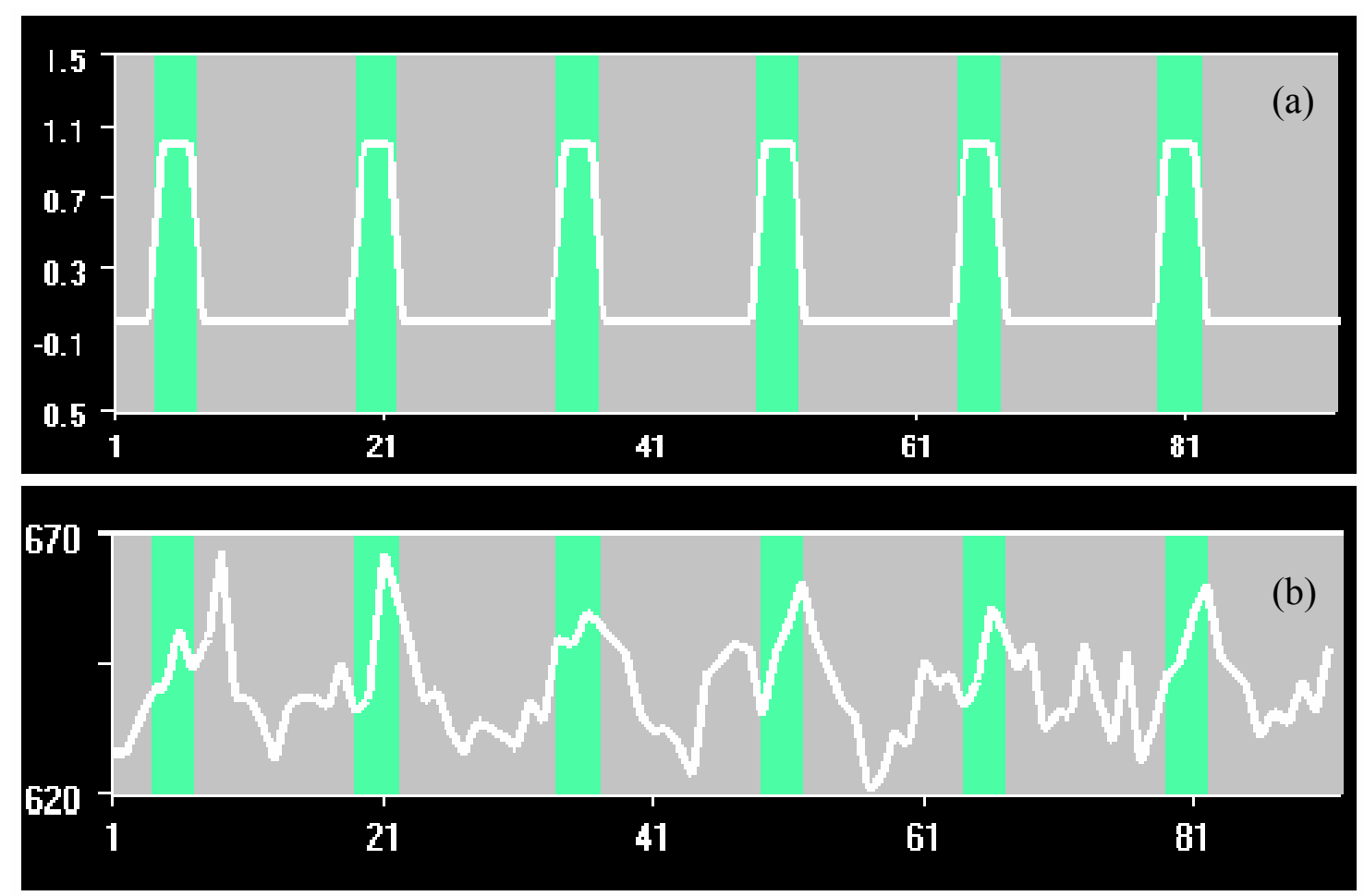

Figura 4.2. (a) Representação do paradigma evento-relacionado. (b) Sinal típico de um pixel durante a realização do paradigma evento-relacionado. 


\subsection{Pré-processamento}

Uma vez adquiridos os dados, eles devem ser analisados por métodos estatísticos. Uma forma direta de se fazer tal analise é extrair as informações temporais de cada voxel e comparar cada uma dessas informações com alguma hipótese usando um teste de significância. Embora essa aproximação forme a base da análise dos dados fMRI, ela possui várias suposições embutidas. Por exemplo, é necessário considerar que cada voxel representa uma única e invariável localização no cérebro e que a amostragem do voxel ocorre em uma razão regular e conhecida. Essa suposição, embora aparentemente plausível, é quase sempre errada. Todos os dados de fMRI sofrem variações espacial e temporal causadas por movimentos da cabeça do voluntário, oscilações fisiológicas como batimento cardíaco e respiração, inomogeneidade do campo estático e diferenças no tempo de aquisição das imagens.

Dessa forma, é necessária a aplicação uma série de procedimentos computacionais, conhecidos como pré-processamento, para auxiliar na eliminação de alguns artefatos e maximizar a sensibilidade de análises estatísticas posteriores.

O propósito do pré-processamento é diminuir a variabilidade dos dados que não está associada ao experimento, com o intuito de maximizar a sensibilidade de análises estatísticas posteriores, e também, em algumas situações, aumentar a validade estatística. Nas próximas seções, será descrito uma série de procedimentos computacionais utilizados no pré-processamento, podendo-se citar: a correção temporal entre fatias, a correção de movimento e a aplicação de filtros espaciais e temporais.

\subsubsection{Correção temporal entre fatias}

Em exames de fMRI, as fatias que compõem os volumes são adquiridas em instantes ligeiramente defasados no tempo. Desse modo, devem-se corrigir as séries temporais tornando-as alinhadas, em fase. Para corrigir esses erros, algumas análises experimentais modificam a resposta hemodinâmica preditora. Assim, cada fatia é comparada a uma função da resposta hemodinâmica com tempos ligeiramente diferentes. Porém, o método mais utilizado na correção temporal entre fatias é a interpolação temporal. Essa utiliza a informação dos pontos temporais vizinhos para estimar a amplitude do sinal de MR. Várias estratégias para interpolação são usadas em fMRI, incluindo linear, spline e sinc. A eficiência da interpolação depende de dois fa- 
tores: a variabilidade dos dados experimentais e a taxa de amostragem. Se a mudança nos dados experimentais acontece mais rapidamente no tempo se comparado à taxa de amostragem, a interpolação será incapaz de capturar mudanças entre os dados. Caso contrário, se mudanças nos dados ocorrerem mais lentamente se comparadas à taxa de amostragem, a interpolação será mais eficiente (Huettel et al., 2004).

\subsubsection{Correção de movimento}

Para que a análise dos dados seja bem sucedida, deve-se supor que os voxels permanecem espacialmente invariantes ao longo de toda a aquisição das imagens. Qualquer tipo de movimento viola esse princípio e, portanto, deve ser evitado.

Vários fatores podem gerar artefatos de movimento como, por exemplo, as flutuações internas provenientes do movimento dos tecidos intracranianos, processos fisiológicos como respiração e batimento cardíaco. Além de provocarem o movimento dos tecidos, esses ritmos fisiológicos fazem aparecer uma inomogeneidade de campo local. Ainda, pode ocorrer movimento involuntário da cabeça do indivíduo causando, também, alterações nos sinais MR. Esse movimento é mais facilmente detectável e de mais fácil controle (Friston et al. 1996).

Para restringir o nível de contaminação nos exames de fMRI, é aconselhável planejar experiências que minimizem o movimento do indivíduo e ter certeza de que ele esteja confortavelmente acomodado no interior do tomógrafo. Contudo, correções posteriores também podem ser feitas (Woods et al. 1992). Nesse processo, a primeira imagem da série é tomada como referência. A fim de simplificar os cálculos, supõe-se que o cérebro é um corpo rígido que pode mover-se com seis graus de liberdade, isto é, que a cabeça muda sua posição e orientação, mas não se submete a mudanças de forma.

Para as correções de movimento, as matrizes de rotação e de translação, $\vec{R}$ e $\vec{T}$, são definidas com respeito ao volume de referência, comumente escolhido como o primeiro volume da imagem nas séries temporais de fMRI, de modo que:

$$
\vec{x}^{(2)}=\stackrel{\Rightarrow}{R} \vec{x}^{(1)}+\vec{T},
$$

em que $\vec{x}^{(1)}$ e $\vec{x}^{(2)}$ são as posições dos vetores dos voxels antes e depois das transformações de rotação e translação, respectivamente. Essa operação é realizada até 
que a soma dos quadrados da diferença entre pixels de duas imagens subseqüentes seja minimizada. Fazendo com que o volume a ser corrigido esteja ajustado ao volume de referência.

\subsubsection{Filtro espacial}

O papel principal da filtragem espacial nos dados de fMRI é reduzir o nível de ruído enquanto mantém o sinal subjacente. Além disso, etapas estatísticas procedentes certamente podem requerer que as imagens funcionais sejam espacialmente suavizadas.

Os filtros geralmente utilizados são do tipo Gaussiano, em que é realizada a convolução das imagens EPIs com funções do tipo (de Araújo, 2002):

$$
f(x, y, z)=\exp \left\{-\left[\frac{x^{2}}{2 s_{x}^{2}}+\frac{y^{2}}{2 s_{y}^{2}}+\frac{z^{2}}{2 s_{z}^{2}}\right]\right\},
$$

sendo $x, y$ e $z$ às posições geométricas das imagens, e $s_{x}, s_{y}$ e $s_{z}$ são os desvios padrão da função, definida pelo usuário. As características do filtro são bem definidas pelo parâmetro FWHM, que determina a forma de atuação do filtro sobre a imagem. Não existe uma forma direta de determinação dos melhores parâmetros dos filtros a serem utilizados nas análises, uma vez que uma melhoria da relação sinalruído implica na redução da resolução espacial, mas é comum utilizar uma largura entre 3 a 10 mm FWHM para imagens de fMRI.

Como o filtro é efetivamente uma média local então o valor do ruído na vizinhança local irá tender a cancelar um ao outro. A fim de que o sinal subjacente não seja reduzido junto com o ruído, é necessário que o tamanho da máscara do filtro não seja maior do que o tamanho da região ativada.

\subsubsection{Filtro Temporal}

A filtragem temporal tem como objetivo remover componentes indesejáveis da série temporal sem, é claro, danificar o sinal de interesse. Por exemplo, se uma estimulação é aplicada durante 30s, seguida por 30s de repouso, e esse padrão é repetido várias vezes, o sinal de interesse será próximo a uma onda quadrada de período 60s. O filtro temporal buscará remover as componentes na série temporal que 
variam mais lentamente do que o sinal de período 60s (filtro passa alta), como por exemplo, perturbações provenientes de efeitos fisiológicos, como batimento cardíaco e respiração, ou devido a flutuações associadas ao tomógrafo, e também remover componentes que variam mais rapidamente (filtro passa baixa).

A filtragem temporal, ao invés de trabalhar com cada volume separadamente, como o filtro espacial, trabalha com cada série temporal de voxels separadamente. Devido à maioria das bases de análises estatísticas operarem diretamente nas séries temporais dos voxels, de regra, a realização dessa etapa é realizada após todos os estágios de pré-processamento descritos anteriormente. 


\section{ANÁLISE ESTATÍSTICA}

Nos exames de fMRI o que se deseja não é apenas descrever as observações feitas e sim fazer inferências sobre o que está por trás dos processos que geraram os dados e assim, determinar características da população baseadas em dados obtido de uma amostra pequena. Isso pode ser feito fazendo uso da inferência estatística.

Todos os experimentos são desenhados para se distinguir entre duas hipóteses possíveis, a hipótese de que a diferença entre as condições (neste caso, ativa e repouso) possuir efeito nos dados $\left(\mathrm{H}_{1}\right)$ e a de que a diferença entre as condições não afeta os dados, sendo esta última chamada de nula $\left(\mathrm{H}_{0}\right)$. Ou seja,

$$
\begin{aligned}
& \mathrm{H}_{1} \text { : repouso } \neq \text { ativo; } \\
& \mathrm{H}_{0} \text { : repouso=ativo. }
\end{aligned}
$$

O processo que avalia se a hipótese nula é verdadeira é chamado de teste de hipótese. Nas próximas seções, serão explorados diferentes testes de hipótese para os dados de fMRI. Esses testes diferem nas suas suposições e objetivos, mas possuem algumas características semelhantes:

o Todos eles expressam a significância como a probabilidade do resultado ocorrer sobre a hipótese nula;

o O mapa de cores que forma a base de muitas figuras de fMRI quase sempre expressa essa probabilidade, geralmente com as cores escuras representando alta probabilidade de que as diferenças observadas sejam devido a mudança de estado;

o Os voxels nos quais as probabilidades estejam abaixo do limiar estatístico, conhecido como valor alfa, são ditos significantes, enquanto que voxels cuja probabilidade é maior que o limiar estatístico são ditos não-significantes. O valor alfa diz qual a probabilidade de ocorrer o erro do tipo I, ou seja, a probabilidade de decidir que a hipótese nula é falsa quando na verdade ela é verdadeira. Nos dados de fMRI, isso que dizer que o erro do tipo I ocorre quando se considera que o voxel é ativo quando na verdade não é (falsos positivos). Os 
o dados de fMRI envolvem testes estatísticos de milhares de voxels, sendo, portanto, difícil de decidir um valor alfa apropriado. Pode-se, ainda, ter um erro do tipo II. Esse erro ocorre quando se aceita a hipótese nula quando na verdade ela é falsa (falsos negativos).

Logo, o método estatístico mais apropriado para cada experimento depende da natureza do desenho experimental, da hipótese a ser testada, e o tipo do erro a ser minimizado. Ao avaliar se um voxel tem a média do sinal diferente em duas condições experimentais, o teste-t é o mais apropriado. Se a hipótese faz predições específicas sobre a forma da mudança ocasionada pela atividade, como quando se usa um modelo para a resposta hemodinâmica esperada, o teste de correlação é mais indicado. Para paradigmas periódicos, que alternam blocos de atividade e repouso, a análise de fourier é útil para identificar mudanças regulares nos dados de fMRI que tenham a mesma freqüência do estímulo. Para uma comparação mais complexa, o modelo linear geral (GLM-General Linear Moded) pode ser usado. Nas próximas seções apenas o GLM e o teste de correlação serão descritos, por terem sido utilizados no presente trabalho.

\subsection{Análise de correlação}

Enquanto o teste-t não dá, nem requer, nenhuma informação sobre a forma da resposta hemodinâmica, a análise de correlação pode quantificar a correspondência entre uma função hemodinâmica prevista e os dados adquiridos. Em 1993, a análise de correlação foi primeiramente aplicada a fMRI por Bandettini e colaboradores e, desde então, tem sido uma ferramenta importante em análise de fMRI (Iidaka et al., 2006). A análise de correlação é feita a partir da relação:

$$
r=\frac{1}{n-1} \frac{\sum(x-\bar{x})(y-\bar{y})}{\sigma_{x} \sigma_{y}} .
$$

Pela relação acima, pode-se ver que a correlação varia ente 1 e -1, ou seja, de uma correlação perfeitamente positiva a uma correlação perfeitamente negativa. Quando $\mathrm{r}=0$, os dados experimentais não são correlacionados com a função de referência. A 
significância do coeficiente de correlação pode ser avaliada usando uma tabela estatística baseada nos graus de liberdade; uma correlação de 0.5 é muito mais significativa se baseada em 1000 dados do que apenas em 10. Essa correlação é, então, calculada para cada voxel no cérebro para criar um mapa de cores da atividade estatisticamente significante.

A análise de correlação é geralmente feita sobre a média do sinal, mas, em principio, poderia ser feita comparando-se toda a série temporal com uma função de referência composta por várias respostas hemodinâmicas individuais. De fato, essa é a idéia básica do modelo linear geral, descrito mais adiante. Porém, se os dados possuírem mudanças de baixa freqüência, como, por exemplo, provenientes de vibrações do scanner, então, a correlação entre os dados e a função de referência pode ser fortemente reduzida. Portanto, realizar a média dos dados antes de fazer a análise de correlação pode diminuir a influência dessas mudanças de baixa freqüência.

Uma das limitações da análise de correlação é que a resposta hemodinâmica varia entre sujeitos, regiões do cérebro e estímulo e, assim, essas variações podem diminuir a significância do teste de correlação. Várias estratégias são utilizadas para diminuir esse problema. Dentre essas, pode-se gerar uma resposta hemodinâmica para cada sujeito, baseada na seleção de dados parciais ou de regiões de interesse.

\subsection{Modelo Linear Geral (General Linear Model-GLM)}

A idéia central do GLM é de que os dados observados (y) são iguais a uma combinação ponderada de funções de referência, ditas preditoras, $\left(\mathrm{x}_{\mathrm{i}}\right)$ mais um erro adicional (e), definida por:

$$
y=\beta_{0}+\beta_{1} x_{1}+\beta_{2} x_{2}+\ldots+\beta_{n} x_{n}+e .
$$

O parâmetro de peso $\left(\beta_{i}\right)$ indica quanto cada fator contribui para todos os dados. $\mathrm{O}$ termo $\left(\beta_{0}\right)$ reflete a contribuição de todos os fatores que permanecem constantes durante todo o experimento, como, por exemplo, os valores brutos de $\mathrm{T}_{2}{ }^{*}$ de um voxel particular na ausência da ativação BOLD. Quando há apenas uma variável dependente, a equação (5.2) é conhecida como um modelo de regressão múltipla univariada. Mas a mesma equação pode ser estendida para incluir um grande número de 
variáveis dependentes, como os vários pontos temporais de um estudo fMRI, por meio do GLM. Escrevendo a equação (5.2) para cada dado observado, yi, tem-se:

$$
\begin{aligned}
& y_{1}=\beta_{0}+\beta_{1} x_{11}+\beta_{2} x_{1 l}+\ldots+\beta_{L} x_{1 L}+e_{1} \\
& y_{2}=\beta_{0}+\beta_{1} x_{21}+\beta_{2} x_{2 l}+\ldots+\beta_{L} x_{2 L}+e_{2} \\
& \vdots \\
& y_{J}=\beta_{0}+\beta_{1} x_{J 1}+\beta_{2} x_{J 2}+\ldots+\beta_{L} x_{J L}+e_{J} .
\end{aligned}
$$

Escrevendo na forma matricial:

$$
\begin{gathered}
\left(\begin{array}{c}
y_{1} \\
\vdots \\
y_{J}
\end{array}\right)=\left(\begin{array}{ccc}
x_{11} & \cdots & x_{1 L} \\
\vdots & \ddots & \vdots \\
x_{J 1} & \cdots & x_{J L}
\end{array}\right)\left(\begin{array}{c}
\beta_{1} \\
\vdots \\
\beta_{L}
\end{array}\right)+\left(\begin{array}{c}
e_{1} \\
\vdots \\
e_{J}
\end{array}\right) . \\
\mathrm{Y}=\quad \mathrm{X} \times \beta+\boldsymbol{e} .
\end{gathered}
$$

Y é o vetor coluna das observações, $\boldsymbol{e}$ é o vetor coluna dos erros e $\beta$ o vetor coluna dos parâmetros $\beta_{i}$. A matriz X com JxL elementos é a matriz de referência. Essa matriz possui uma linha por observação e uma coluna por função preditora. A matriz de referência consiste de um ou mais fatores que representam possíveis contribuições no tempo de curso da fMRI. A consideração básica desta matriz é que a resposta BOLD pode ser estimada convoluindo a resposta hemodinâmica com os tempos de apresentação dos estímulos. Embora muitas vezes isso seja apropriado, a matriz, desta forma, testa hipóteses sobre a atividade hemodinâmica e não sobre o estímulo. Antes de criar a matriz de referência para um experimento, deve-se pensar cuidadosamente sobre os diferentes tipos de processos cerebrais que são recrutados no experimento, levando em conta seus ritmos e a durações.

Geralmente, as equações mostradas em (5.3) não podem ser simultaneamente e perfeitamente resolvidas (isto é, $\boldsymbol{e}=0$ ). Então, o que se procura é achar uma solução que minimize a soma dos quadrados dos resíduos.

Sejam os parâmetros estimados por $\widetilde{\beta}=\left(\widetilde{\beta}_{1}, \ldots, \widetilde{\beta}_{L}\right)$. Esses parâmetros ajustam os valores $\tilde{Y}=\left(\widetilde{Y}_{1}, \ldots, \widetilde{Y}_{J}\right)=X \widetilde{\beta}$, dando um erro residual de $e=\left(e_{1}, \ldots, e_{J}\right)=Y-\widetilde{Y}=Y-X \widetilde{\beta}$. A soma residual dos quadrados $S=\sum_{j=1}^{J} e_{j}^{2}=e^{\mathrm{T}} e$ é a soma dos quadrados das diferenças entre os dados reais e os valores ajustados. O 
método dos mínimos quadrados estima os valores $\hat{\beta}$ que minimizam a soma residual dos quadrados, ou seja:

$$
S=\sum_{j=1}^{J}\left(Y_{j}-x_{j 1} \widetilde{\beta}_{1}-\ldots-x_{j L} \widetilde{\beta}_{L}\right)^{2}
$$

$S$ terá seu valor mínimo quando:

$$
\frac{\partial S}{\partial \widetilde{\beta}_{l}}=2 \sum_{j=1}^{J}\left(-x_{j l}\right)\left(Y_{j}-x_{j 1} \widetilde{\beta}_{1}-\ldots-x_{j L} \widetilde{\beta}_{L}\right)=0
$$

Essa equação é simplesmente a j-ésima linha de $X^{\mathrm{T}} Y=\left(X^{\mathrm{T}} X\right) \widetilde{\beta}$. Assim, o valor $\hat{\beta}$ estimado pelos mínimos quadrados satisfaz a equação:

$$
X^{\mathrm{T}} Y=\left(X^{\mathrm{T}} X\right) \hat{\beta}
$$

Se $X^{\mathrm{T}} X$ tiver inversa, e isso é verdade se e somente se a matriz $\mathrm{X}$ for de rank completo, então:

$$
\hat{\beta}=\left(X^{\mathrm{T}} X\right)^{-1} X^{\mathrm{T}} Y
$$

Se a matriz X não for de rank completo (isto é, possuir colunas linearmente dependentes), então, haverá várias soluções para $\hat{\beta}$ que satisfazem a equação (5.5).

Para testar a significância de uma função preditora, sobre um dado voxel, a amplitude do parâmetro associado é dividida pelo erro residual. Sobre a hipótese nula, essa quantidade deve seguir a distribuição $F$ e assim, essa significância pode ser avaliada como uma função dos graus de liberdades avaliados.

\subsection{Escolhendo um threshold estatístico}

Existem dois fatores que influenciam diretamente a habilidade de detectar efeitos: a relação sinal ruído e o número de observações (isto é, o número de estímulos e o número de participantes no estudo).

Uma maneira de otimizar o baixo sinal é usar paradigmas em bloco (como discutido na seção 4.1). Aumentar o tamanho da amostra também aumenta o poder estatístico, por exemplo, coletando vários exames do mesmo participante e aumentando o número de voluntários. No entanto, scanners são muito caros, fazendo com que poucas máquinas estejam disponíveis para estes tipos de exames. Além disso, testar pessoas por tempos longos pode induzir fadiga e, com isso, piorar a qualidade 
dos exames. Por fim, outra forma de influenciar no poder estatístico é ajustar os critérios, com relação ao nível alfa.

Um problema inerente da aplicação de métodos estatísticos a dados com ruído é a de cometer erros baseados nos testes de hipótese. Por exemplo, ajustandose um nível do alfa com $\mathrm{p}<0,1$ promove a detecção de efeitos reais, embora $10 \%$ dos resultados sejam falsos. Por outro lado, ajustando-se um alfa mais conservador, de $\mathrm{p}<0,001$, a taxa de falsos positivos abaixa (uma em mil), mas perdem-se efeitos reais. Uma consideração muito importante para os dados de neuroimagem é o fato de se fazer um teste estatístico para cada voxel na imagem. Um cérebro normal tem um volume aproximadamente de $2500 \mathrm{~cm}^{3}$, ou seja, será feito quase 100.000 testes se os voxels forem 3x3x3mm (ou 300.000 testes se os dados tiverem definição de $2 \times 2 \times 2 \mathrm{~mm})$. Se 100.000 voxels forem testados com um nível alfa de 5\%, então, espera-se que 5000 voxels sejam erroneamente ditos como ativos. Em outras palavras, a chance de se cometer um erro é grande. Uma maneira de corrigir esses falsos positivos é pela aplicação a correção de Bonferroni. Na correção de Bonferroni, o threshold é dividido pelo número de testes. O alfa do exemplo acima ficaria, então, $0.05 / 1000000=0.0000005 \%$. Em princípio, a correção de Bonferroni diminui o erro do tipo I, mas o decréscimo do erro tipo I, também aumenta a probabilidade de ocorrer o erro do tipo II e muitas vezes o aumento desse erro pode ser problemático. Por exemplo, no caso em que o exame de fMRI é utilizado como exame précirúrgico para detectar áreas eloqüentes. Um alfa muito restritivo pode ocasionar em perda de voxels verdadeiramente ativos. Nesta situação, o erro do tipo II pode levar a ressecção de um tecido funcional e isso terá conseqüências reais no estado final do paciente.

\subsection{Atlas Cerebral}

Até então, focou-se em identificar áreas ativas em um único voluntário. Porém alguns dos experimentos de fMRI coletam dados de vários sujeitos. Muitas vezes, então, aparece a necessidade da normalização dos resultados. Atualmente, a forma mais utilizadas é o Atlas Talairach (Talairach e Tournoux 1988), o qual estabelece um padrão espacial. Esse sistema de coordenadas normalizado, além de facili- 
tar a comparação direta entre resultados de localização funcional, também serve como uma ferramenta de correção das variações anatômicas cerebrais entre indivíduos.

O sistema de coordenadas Talairach está baseado no plano entre duas formações anatômicas típicas: a comissura anterior (AC) e a comissura posterior (PC), o qual é chamado plano AC-PC. Após a definição do novo plano de coordenadas são geradas quatro linhas de referências que formam o sistema de grade Talairach: a linha AC-PC, a linha AC vertical (ACV), a linha PC vertical (PCV) e a linha média (figura 5.1).

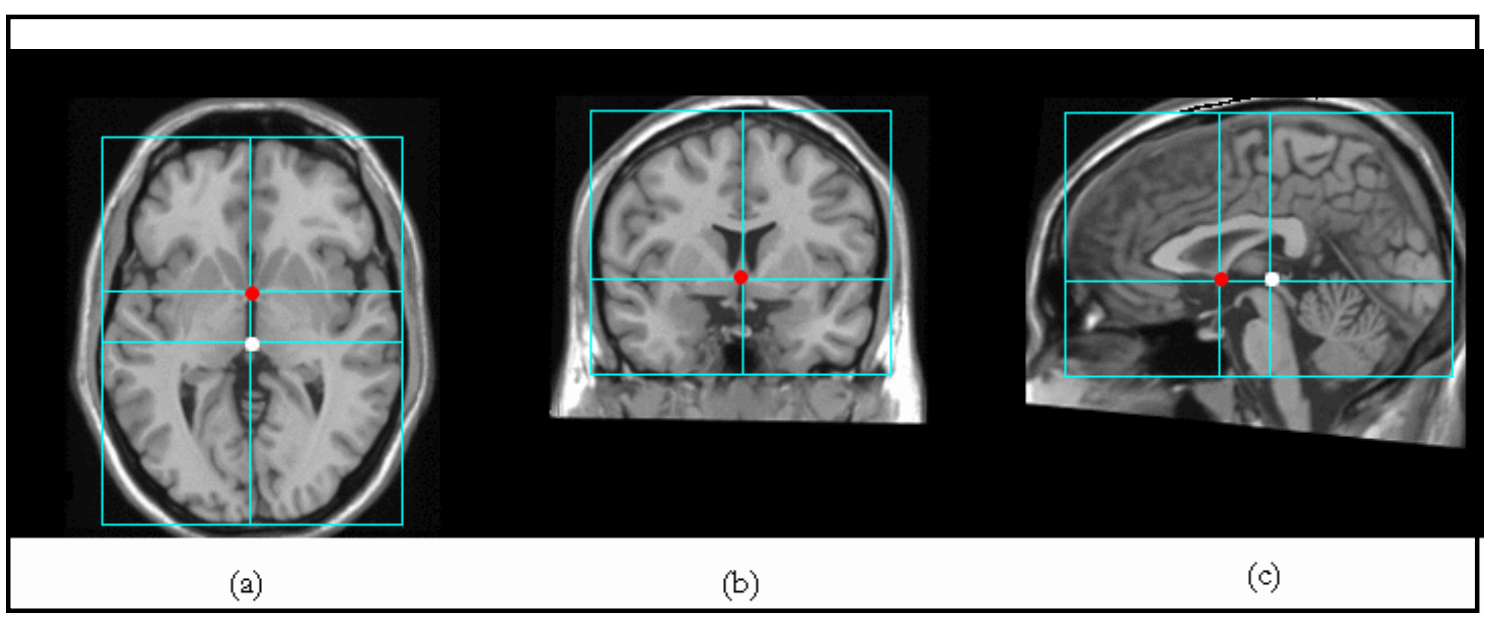

Figura 5.1. Representação, nos planos axial (a), coronal (b) e sagital, das linhas utilizadas para definir o sistema de coordenadas Talairach. (a) Linhas AC vertical e PC vertical. (b) Plano AC-PC. (c) Linhas AC vertical e PC vertical e o plano AC-PC. O círculo vermelho indica a localização anatômica da comissura anterior e o círculo branco indica a localização anatômica da comissura posterior.

As definições seguintes são utilizadas para delimitar o sistema de coordenadas: 1. A linha AC-PC passa pela borda superior da comissura anterior e pela borda inferior da comissura posterior. 2. A ACV é uma linha vertical perpendicular a linha AC-PC que atravessa a margem posterior da comissura anterior. 3. A PCV é uma linha que atravessa a margem anterior da comissura posterior é, também, perpendicular a linha AC-PC. 4. A linha média é a fissura interhemisférica. O sistema de grade Talairach é estabelecido baseado nas máximas dimensões do cérebro. O passo seguinte, de demarcação, é utilizado para definir a periferia cortical, no qual são definidos 6 pontos: o ponto mais superior do córtex parietal, a porção mais posterior do córtex occipital, o ponto mais inferior do córtex temporal, o ponto mais anterior 
do lobo frontal, e os pontos mais laterais (direito e esquerdo) do córtex parietotemporal (Figura 5.2).

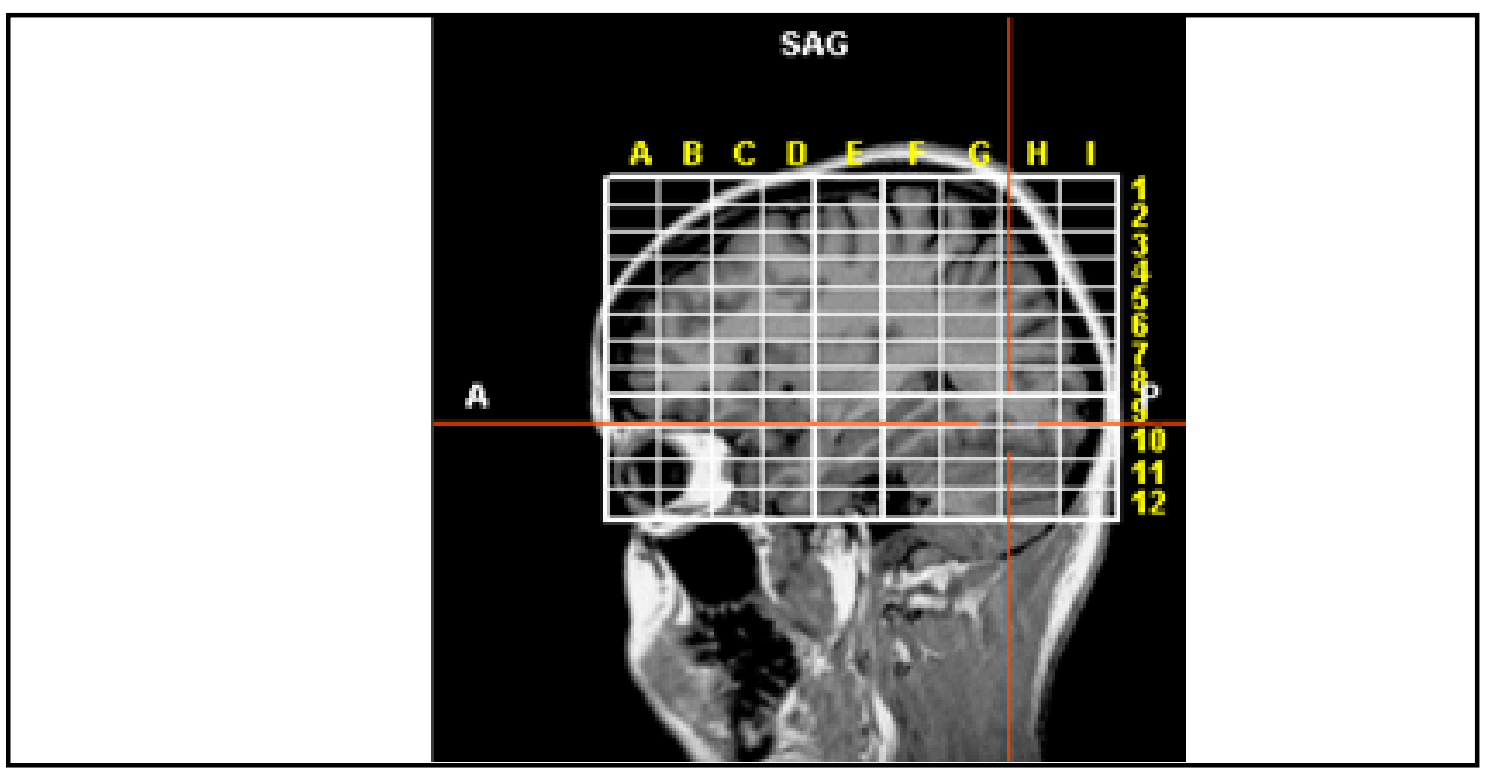

Figura 5.2. Representação das linhas utilizadas para definir o sistema de coordenadas Talairach. Também está representada a grade delimitada pelos seis pontos.

Após as dimensões máximas de cada cérebro serem demarcadas são realizadas contrações e expansões do cérebro para que ele preencha o sistema de grade Talairach. E então, podem-se extrair suas coordenadas $x, y, z$. Através desses processos consegue-se normalizar cada cérebro por uma estrutura padrão. 


\section{MATERial e Métodos}

\section{Voluntários e estímulo}

Esse trabalho foi constituído de duas fases. $\mathrm{Na}$ primeira, participaram 19 voluntários (9 homens e 10 mulheres) assintomáticos. Antes de iniciar os exames, os voluntários foram instruídos sobre os procedimentos a fim de evitar ansiedade e possíveis erros na execução do protocolo.

Durante a aquisição dos dados da fase um, os voluntários foram instruídos a inspirar e prender a respiração por intervalos de tempo de 14 ou 27 segundos. Previamente à aquisição das imagens, os mesmos foram treinados para saber se seriam capazes de prender a respiração durante o tempo necessário para os estudos. Durante o exame, as instruções eram reproduzidas por um $\mathrm{CD}$, que continha os comandos "prenda o ar" e "respire normalmente".

O protocolo utilizado para os exames foi do tipo bloco. Este foi constituído de 11 períodos de hipercapnia, intercalados com períodos de repouso, para o primeiro estudo (apnéia de 14s), e de 5 períodos de hipercapnia versus 6 de repouso, para o segundo estudo (apnéia de $27 \mathrm{~s}$ ).

Para aquisição das imagens, utilizou-se um scanner de 1.5 T Siemens (Magneton Vision) com uma bobina de quadratura transmissora/receptora de cabeça. Uma seqüência do tipo EPI foi utilizada para produzir continuamente 69 volumes de aquisição, para o primeiro estudo, e 66 para o segundo. Cada um foi constituído por 16 fatias axiais, com $6 \mathrm{~mm}$ de espessura $(\mathrm{TR}=4600 \mathrm{~ms}$; TE $=60 \mathrm{~ms}$; ângulo flip $90^{\circ}$; matriz $128 \times 128$; FOV $=220 \mathrm{~mm}$; dimensão do pixel $\left.=3.44 \times 3.44\right)$. As imagens anatômicas foram adquiridas, após as imagens funcionais, utilizando uma seqüência do tipo GRE, MPR, ponderada em T1 (TR = $9.7 \mathrm{~ms}$; TE $=4 \mathrm{~ms}$; ângulo flip 12; matriz $256 \times 256 ; \mathrm{FOV}=256 \mathrm{~mm}$; espessura da fatia $=1 \mathrm{~mm}$; dimensão dos voxels $=1 \times 1 \times 1 \mathrm{~mm})$. A duração média total do exame, para cada voluntário realizar os dois estudos, foi de 30 minutos.

Após a análise dos dados obtidos com o protocolo descrito acima, observouse que 14 s são suficientes para se obter um sinal global e uniforme no cérebro. Assim, na segunda fase do trabalho, foi utilizado apenas um protocolo de 15 segundos. 
Nessa segunda parte, desejando estudar a propagação temporal do sinal BOLD, em resposta à apnéia, adquiriram-se imagens de outros 10 voluntários com um TR mais curto, 2 segundos, e seguindo um desenho semelhante a um paradigma ER. Além disso, sabe-se que o sinal obtido em resposta à apnéia é dependente do protocolo, ou seja, se esta ocorre após uma inspiração ou uma expiração. Portanto, para se estudar essa diferença no sinal, este segundo protocolo foi dividido em dois estudos. No primeiro estudo, os voluntários eram instruídos a prender a respiração por 15s, após chegarem ao final da sua expiração normal. Ou seja, ao escutar o comando para prender o ar, o voluntário deveria continuar respirando normalmente até chegar ao final da expiração e só então prender a respiração. No segundo, os voluntários eram instruídos a prender a respiração após inspiração completa. Nesses dois estudos, após a apnéia, os voluntários voltavam a respirar normalmente por um período de 30 segundos, que constituiu o período de repouso. O protocolo foi constituído de 5 períodos de hipercapnia, intercalados com 6 períodos de repouso.

A seqüência utilizada foi, novamente, do tipo EPI, adquirindo continuamente 125 volumes, sendo cada volume constituído por 16 fatias axiais, cada uma com os seguintes parâmetros: $6 \mathrm{~mm}$ de espessura, TR $=2000 \mathrm{~ms}$, TE $=60 \mathrm{~ms}$, ângulo flip $90^{\circ}$, matriz 64 x 64, FOV $=220 \mathrm{~mm}$, dimensão do pixel $=3.44$ x 3.44. As imagens anatômicas foram adquiridas da mesma forma descrita anteriormente.

Por ter sido solicitado que os voluntários atingissem o final da inspiração/expiração antes de prender o ar, há um atraso entre o momento em que o comando é dado e o momento em que o voluntário prende a respiração, efetivamente. Para que esse atraso seja considerado, 4 voluntários foram instruídos a apertar um botão, conectado a um computador por um sistema de infravermelho, quando realmente prendessem o ar. Desse modo, tem-se o exato momento em que o estado de apnéia e de repouso são atingidos.

\section{Análise dos Dados}

Os mapas estatísticos foram processados no programa Brain Voyager $^{\mathrm{TM}} \mathrm{QX}$ 1.6 (Brain Innovation, Maastricht, Holanda), utilizando o método GLM. Na etapa de pré-processamento foram realizadas as correções de movimento, correção do tempo 
entre fatias, a filtragem temporal, com um filtro passa alta de $3 \mathrm{~Hz} / \mathrm{s}$, e a remoção de desvios lineares dos dados (Linear Drift). Após a análise dos dados individuais, os mapas estatísticos foram normalizados no espaço Talairach.

Gerou-se uma HRF, criada a partir da convolução de uma dupla gama (Equação. 3.12), com o tempo para o pico de 5 segundos e o tempo para o undershoot de 15 segundos, com a função do protocolo, para gerar a função preditora utilizada no GLM.

Como foi visto na seção 5.1, a correlação cruzada é capaz de quantificar a correspondência entre uma função hemodinâmica modelo e os dados adquiridos. Desta forma, criaram-se mapas de correlação cruzada (equação 5.1) entre dados e a função modelo convoluída, deslocada para a direita no eixo do tempo com o intuito de obter o atraso específico de diferentes regiões cerebrais. Ou seja, após a criação da função hemodinâmica (sinal apresentado em preto nas figuras (6.1)), esta é deslocada no eixo do tempo (o sinal apresentado em branco nas figuras 6.1 representa a função hemodinâmica deslocada uma vez no eixo do tempo). Em seguida, a correlação cruzada dos dados com a função resultante de cada deslocamento é calculada. Desta forma, obtêm-se as regiões que respondem com o atraso específico da função preditora. Como foram utilizados 3 protocolos distintos $27 \mathrm{~s}, 14 \mathrm{~s}$ e $15 \mathrm{~s}$ de inspiração/expiração, as funções hemodinâmicas resultantes da convolução da dupla gama com os protocolos, para os três casos, são diferentes (Ver figura (6.1)). Como as imagens foram geradas com um TR de 4.6s nos dois primeiros estudos e um TR de 2s nos dois últimos, a resolução temporal é limitada a este valor. Logo o deslocamento de cada função hemodinâmica no tempo é sempre feito em toda a função pelos respectivos TRs. 

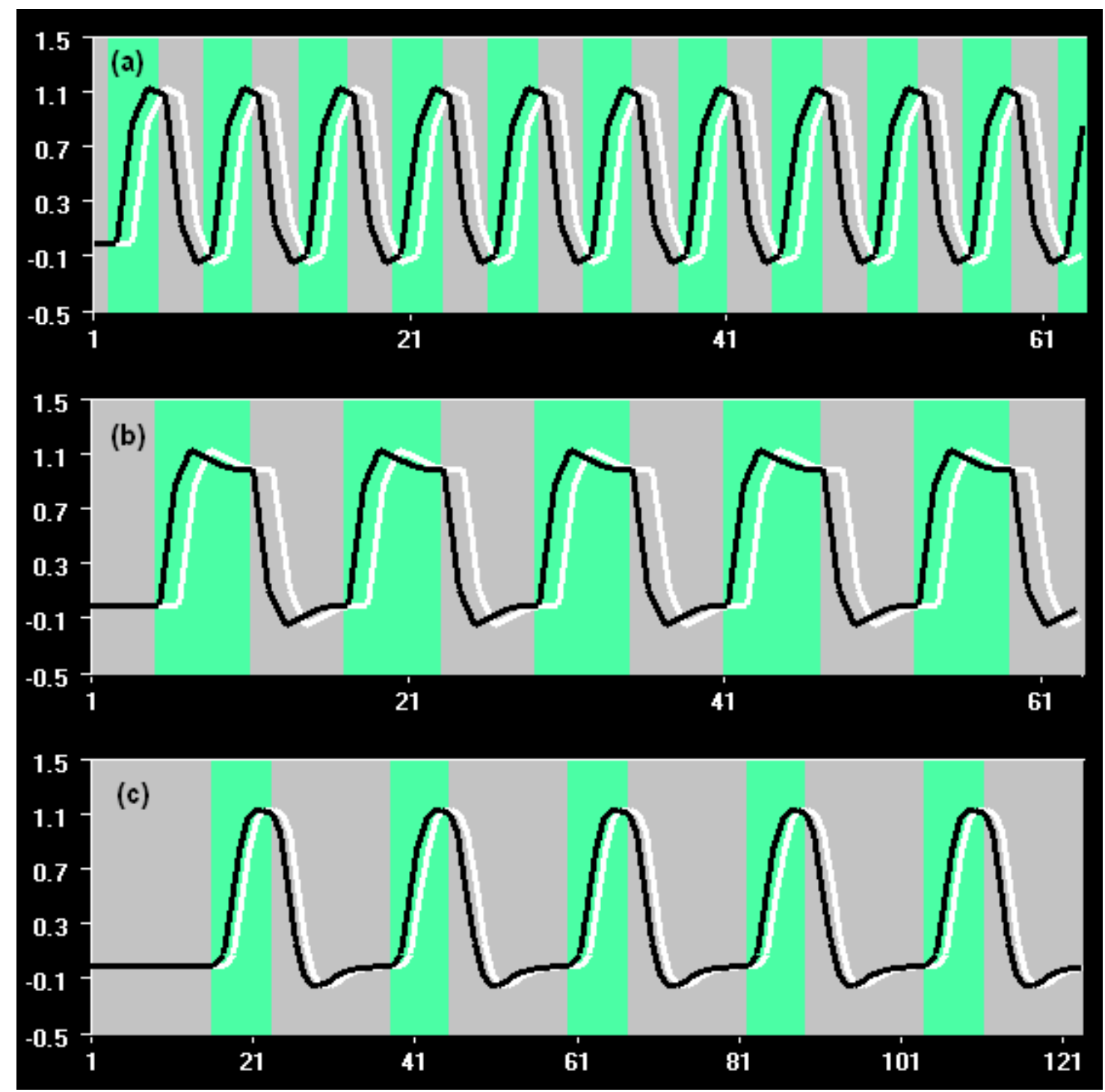

Figura 6.1. Função hemodinâmica para o protocolo de apnéia de (a) 14s; (b)27s; (c) 15s após inspiração/expiração. A linha preta representa a função hemodinâmica preditora utilizada no GLM. A linha branca representa a função hemodinâmica preditora deslocada 4.6s, para o caso da apnéia de 27 e 14s, e deslocada 2s pra o caso de apnéia de 15s após inspiração/expiração. As áreas que aparecem em verde representam os períodos em que os voluntários deveriam estar em apnéia, e as áreas em cinza os períodos de repouso.

Para se obter um efeito regional mais detalhado, dividiu-se o cérebro em três partes (Volume of Interest - VOI), correspondentes aos territórios de irrigação pelas três principais artérias cerebrais: Artéria Cerebral Anterior (ACA), Artéria Cerebral Média (ACM), Artéria Cerebral Posterior (ACP), como visto na figura (6.2). As VOIs da ACA, ACM e ACP foram constituídas de 260967, 312682, 155144 voxels, respectivamente. 


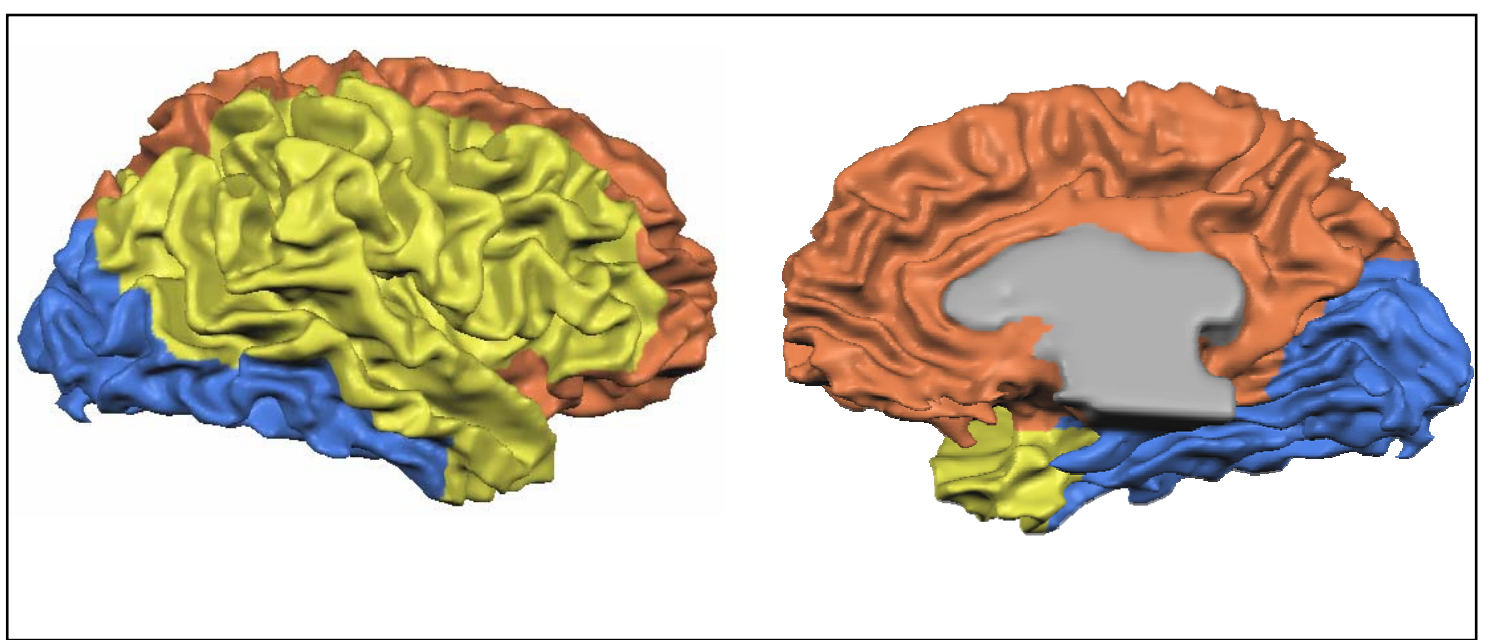

Figura 6.2. Figura representativa das VOIs dos territórios de irrigação pelas três principais artérias cerebrais. A área em azul representa o território da ACP, a área laranja o território da ACA e a área amarela a da ACM.

Aplicou-se o GLM para essas VOIs, utilizando os dados que foram obtidos durante apnéia de 15s após inspiração/expiração, a partir das funções hemodinâmicas, com diferentes atrasos (geradas da forma descrita acima). Em seguida quantificou-se quantos voxels apresentavam-se ativos em cada território, para saber qual a percentagem destes territórios apresentava resposta significativa, com um determinado atraso no sinal BOLD.

A resposta do CBF e do BOLD são atrasadas de, aproximadamente, 1-2s, com relação ao estímulo, e possuem uma largura de 4-6s (Bandettini et al., 1992). Portanto, foi feita uma análise das áreas que levaram 5s para atingir o pico da resposta hemodinâmica para os dados obtidos durante a apnéia de 15s, após expiração, com o intuito de associá-las com as áreas responsáveis pelo controle voluntário da respiração. As coordenadas Talairach que se apresentavam ativas com p<0.000109 foram associadas a uma região cerebral, através da utilização do programa Talairach DeamonClient. Posteriormente, essas informações foram analisadas no Excel, em que se verificou o número de voxels ativos para cada região cerebral.

Por fim, inspirados nos mapas de CBV que são gerados pelos dados obtidos com a técnica de DSC, em que o CBV é dado pela área abaixo da curva de concentração do agente de contraste normalizada pela a AIF, geraram-se mapas de cores em que foi calculada a área abaixo do sinal BOLD, normalizada por sua linha de base. O programa utilizado para gerar esses mapas foi o MATLAB 7.0 (Mathworks Inc.). 
O primeiro passo para a obtenção desses mapas, que aqui foi chamado de mapas de B-CBV, foi a normalização do sinal pela linha de base. Nosso experimento foi composto por um paradigma evento-relacionado de período igual a 22 imagens com um TR de 2s, ou seja, um período de 44s. A linha de base foi obtida fazendo-se uma média do primeiro bloco de repouso para cada pixel. Assim, a mudança de sinal entre a apnéia e a respiração normal pode ser calculada, de acordo com:

$$
\Delta S=\frac{S_{\text {apnéia }}-S_{\text {normal }}}{S_{\text {normal }}},
$$

sendo $\Delta S$ a mudança do sinal BOLD, entre o estado de apnéia e a respiração normal, $S_{\text {apnéia }}$ O sinal BOLD durante o estado de apnéia e $S_{\text {normal }}$ o sinal BOLD durante a respiração normal.

No caso da técnica DSC, as imagens são adquiridas apenas durante a primeira passagem do agente de contraste. Neste estudo, a tarefa é repetida várias vezes. Logo, o segundo passo, para a obtenção dos mapas de B-CBV, foi calcular um sinal médio da série temporal e em seguida o método do trapézio foi utilizado para calcular a área abaixo deste sinal médio. Portanto, tem-se o seguinte esquema para o cálculo dos mapas de B-CBV:

1. Normalizar o sinal pela linha de base;

2. Fazer média do sinal;

3. Calcular a área abaixo da média do sinal;

4. Gerar o mapa de cores.

Para eliminar o alto sinal encontrado no CSF, depois da obtenção dos mapas de B-CBV, um filtro que limitava a intensidade do sinal foi aplicado. 


\section{RESUlTADOS E DisCUSSÃO}

Dos 19 voluntários que realizaram a primeira parte do trabalho (apnéia de 14s e 27s), 6 tiveram que ser excluídos, devido a problemas na aquisição das imagens, em especial pela presença de artefatos de movimento. Os voluntários eram excluídos quando estes se movimentavam mais que $2 \mathrm{~mm}$, durante a aquisição das imagens funcionais. Outra análise que foi feita para garantir a qualidade dos exames foi uma inspeção visual dos dados através de um filme da série temporal, em que os volumes de aquisição são apresentados sequencialmente.

Quando o voluntário é submetido à apnéia, há um aumento de $\mathrm{CO}_{2}$ no sangue, que diminui a relação $\left[\mathrm{O}_{2}\right] /\left[\mathrm{CO}_{2}\right]$. Segundo a teoria proposta por Buxton (Buxton, 2004), a regulação do CBF é feita na tentativa de manter constante a relação entre $\mathrm{O}_{2}$ e $\mathrm{CO}_{2}$ na mitocôndria, para preservar a energia termodinâmica livre do metabolismo oxidativo da glucose. Pela equação (3.7), como o valor de $\mathrm{CMRO}_{2}$ permanece praticamente constante, a diminuição em $E$ (para aumentar o fluxo difusivo de $\mathrm{O}_{2}$ dos capilares para a mitocontria) provoca um aumento no CBF, ocasionando uma diminuição da deoxi-hemoglogina local e consequentemente um aumento no sinal de MR. Espera-se, ainda, que este sinal ocorra de forma geral no cérebro, já que o aumento de $\mathrm{CO}_{2}$ ocorre globalmente. Mas, em princípio, não se sabe quanto tempo essas duas variáveis levam para responder a este aumento global de $\mathrm{CO}_{2}$.

Para a aplicação do GLM, é necessária a suposição de uma função preditora. Portanto, para determinar a função que melhor modela o sinal BOLD, em resposta à apnéia, houve, primeiramente, a necessidade da criação de mapas de correlação cruzada entre os dados e várias funções hemodinâmicas, que possuíam a mesma forma e diferiam com relação à sua fase (figura 7.1). Esse atraso do sinal BOLD foi quantificado com relação ao tempo gasto para se atingir o pico da reposta hemodinâmica. Cada atraso é representado por uma escala de cores (figura 7.1) e representa 4.6s, que são acrescidos à função hemodinâmica, representada em preto na figura 6.1b. 


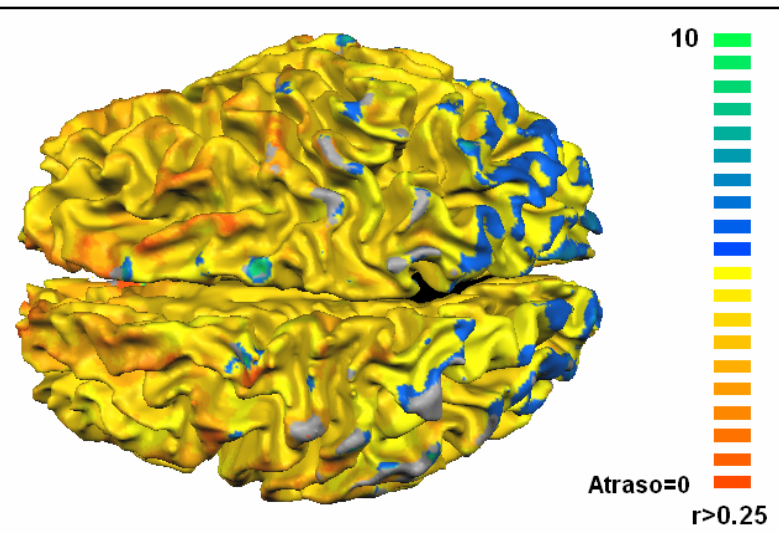

Figura 7.1. Mapas temporais da mudança do sinal BOLD durante o paradigma de apnéia de 27s, mostrando que seu atraso depende da região cerebral. $O$ mapa de cores corresponde a um atraso específico da resposta hemodinâmica: as regiões avermelhadas correspondem àquelas que responderam mais rapidamente, enquanto que as regiões esverdeadas àquelas que responderam mais lentamente.

Nesta primeira análise do atraso da resposta hemodinâmica, observou-se que a maior parte das regiões cerebrais respondia com uma resposta hemodinâmica atrasada, em média, de 22.94s e 19.15s, para a apnéia de 27 s e $14 \mathrm{~s}$, respectivamente. Sabendo, agora, qual função hemodinâmica usar para se obter um sinal na maioria das regiões cerebrais, em resposta à apnéia, aplicou-se o GLM, e os mapas estatísticos referentes a esse aumento global de rCBF foi construído (figura 7.2).
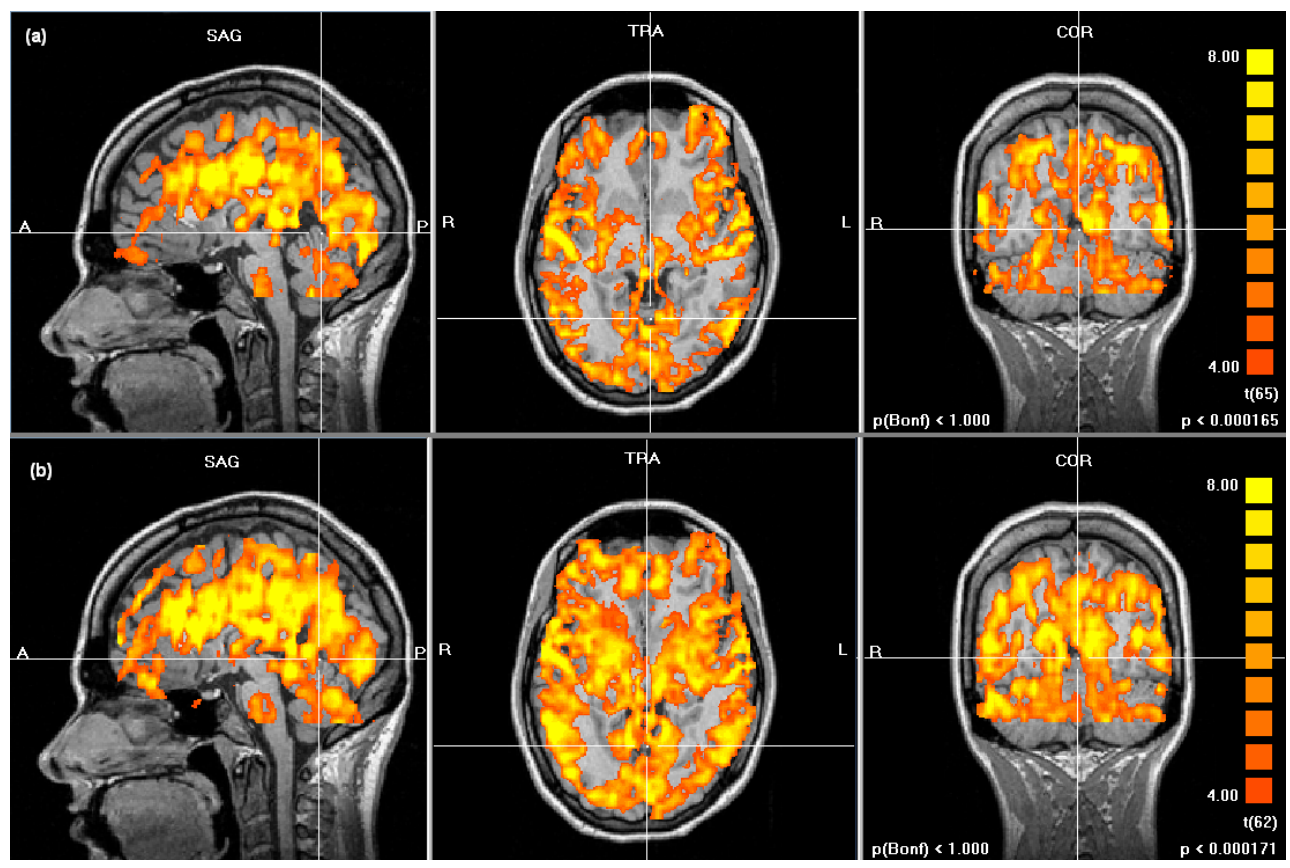

Figura 7.2. Mapas estatísticos da mudança do sinal BOLD induzida por apnéia, construídos durante o pico de atividade. (a) 14s e (b) $27 \mathrm{~s}$. Um aumento global na perfusão cerebral nos dois hemisférios pode ser observado. 
A figura 7.3 mostra a diferença de amplitude da média do sinal BOLD para as diferentes condições de apnéia, com duração de 14 s e 27 s, para uma mesma região do lobo parietal (Área de Bodmann 31). Os dados apresentados na figura 7.3 foram interpolados para que a resolução temporal fosse de $1 \mathrm{~s}$.

Neste estudo, o padrão de aumento do sinal BOLD está correlacionado com o tempo da apnéia: quanto maior o tempo de apnéia, maior a intensidade do sinal BOLD e maior seu tempo ao pico (figura 7.2 e 7.3). Isso era de se esperar, já que, quanto maior a duração da apnéia, maior a quantidade de $\mathrm{CO}_{2}$ na corrente sangüínea, o que provoca um aumento de fluxo sanguíneo para conservar a relação entre $\mathrm{O}_{2}$ e $\mathrm{CO}_{2}$. Ainda, essa alteração promove uma maior redução no $E$, e na quantidade total de deoxi-hemoglobina presente em um voxel, levando a um aumento mais pronunciado no sinal de MR.

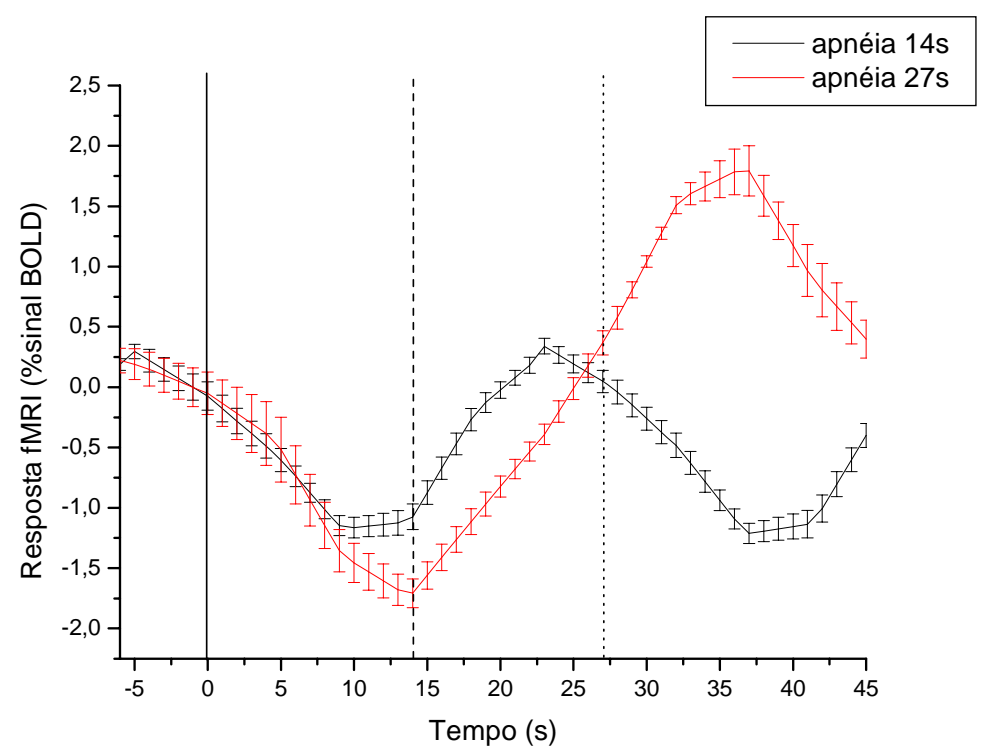

Figura 7.3. Média do sinal BOLD para apnéia de 14s (preto) e 27s (vermelho) para na coordenada Talairach (20, -74, 24) para um dos voluntários (Área de Brodmann 31). Quanto maior o tempo de apnéia, maiores o atraso e o aumento da resposta hemodinâmica. As linhas verticais sólida, tracejada e pontilhada, representam o inicio da apnéia, final da apnéia de 14s, e final da apnéia de 27s, respectivamente.

Esse resultado está em concordância com Kastrup et al. (1999), que observaram que a mudança no rCBF está relacionada ao tempo de apnéia. Ainda, Liu et al. (2002) detectaram que o número de voxels estatisticamente significativos, na substân- 
cia cinza, está diretamente relacionado com o período de apnéia, para durações entre 10 s e 20 s. Essa correlação atinge um limiar quando a apnéia dura mais que 20s.

Alguns trabalhos utilizaram a apnéia para analisar diferenças regionais da resposta BOLD (Kastrup et al., 1999b e Thomason et al., 2005), mas esta análise restringiu-se à verificação da intensidade do sinal BOLD e número de pixels ativados em diferentes regiões. Kastrup et al. (1999) verificaram que a mudança no sinal BOLD pode variar de 1.8 a 5.1\%, sendo as regiões de maior intensidade o cerebelo e o córtex visual, enquanto o córtex frontal apresentou menor sinal.

Diferenças regionais na forma ou no atraso da resposta hemodinâmica ao $\mathrm{CO}_{2}$, tanto intra quanto inter-regional, pode contribuir para a aparente diferença na sensitividade do BOLD ao $\mathrm{CO}_{2}$ (Wise et al., 2004). Posse et al. (1997) analisaram a dinâmica do sinal BOLD, durante a hiperventilação controlada, nos córtices frontal, occipital, parietoccipital e insular, cerebelo, tálamo, núcleo estriado e na matéria branca. Eles observaram que o atraso da resposta hemodinâmica à hipocapnia pode variar de 5 a 12 s.

Neste trabalho, ao procurar a função preditora que melhor representava o sinal BOLD em resposta ao aumento global de $\mathrm{CO}_{2}$ no sangue, observou-se que atraso da resposta hemodinâmica também dependia da região cerebral. Desse modo, para melhor compreender essa dinâmica desse processo, um segundo estudo foi idealizado. Para tanto, utilizaram-se dados adquiridos com um TR mais curto, melhorando, assim, a resolução temporal. Além disso, sobre esse segundo conjunto de dados, estudou-se a diferença ocasionada no sinal BOLD quando a apnéia era realizada após inspiração ou expiração.

Dos 10 voluntários que realizaram essa segunda tarefa, 9 foram incluídos na análise dos dados em que a apnéia era atingida ao final da expiração e 8 para o caso em que a apnéia era realizada após a inspiração.

\section{Inspiração x Expiração}

É de se esperar que haja diferenças do sinal BOLD quando este é ocasionado por um estado de apnéia precedido de inspiração ou expiração, já que as variações de $\mathrm{PaO}_{2}$ e $\mathrm{PaCO}_{2}$ ocorrem de forma específica em cada um desses casos. 
O gráfico que representa a média do sinal BOLD quando um dos voluntários realizou a apnéia após inspiração e expiração está ilustrado na figura 7.4. Esse sinal é referente a uma VOI na ACA.

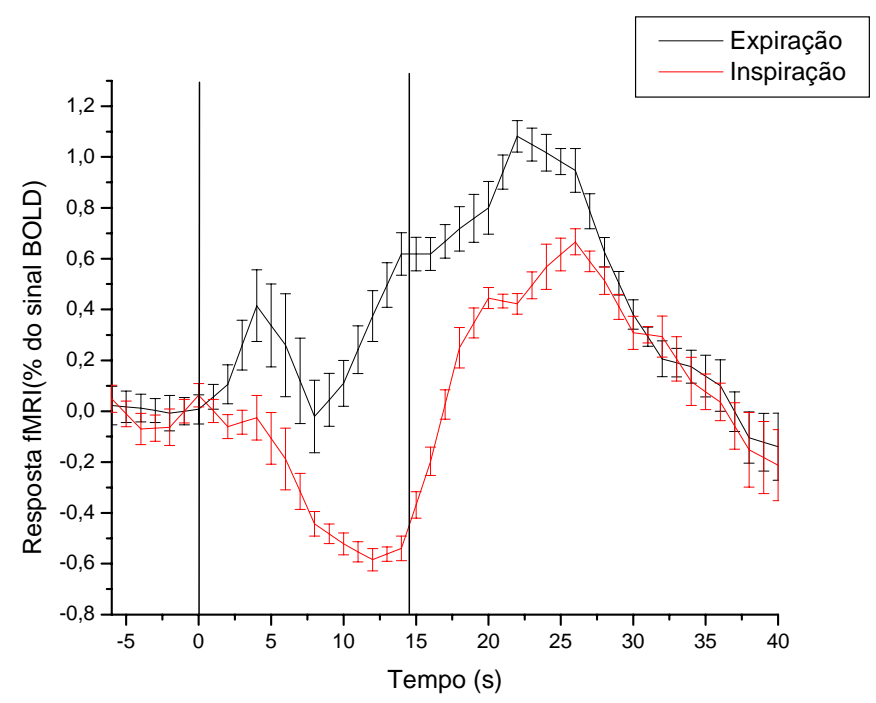

Figura 7.4. Evolução temporal da mudança do sinal BOLD em resposta à apnéia, após inspiração (linha vermelha) e expiração (linha preta). As duas retas verticais representam o inicio e o final do período de apnéia, respectivamente.

Pode-se observar que o sinal BOLD, quando a apnéia é precedida de expiração apresenta um aumento imediato. Isso ocorre porque a apnéia causará uma diminuição instantânea da $\mathrm{PaO}_{2}$ e um aumento da $\mathrm{PaCO}_{2}$. Como já foi mencionado, o fluxo é controlado para que essa relação permaneça constante, ou seja, ele aumenta com a intenção de restaurar a relação $\left[\mathrm{O}_{2}\right] /\left[\mathrm{CO}_{2}\right]$, E diminui (para aumentar ou manter $\mathrm{CMRO}_{2}$ ), e, assim, tem-se um aumento de sinal.

No caso da apnéia precedida de inspiração, o sinal decresce inicialmente e só depois cresce. Isso é observado porque a $\mathrm{PaCO}_{2}$, e a $\mathrm{PaO}_{2}$, exibem uma mudança bifásica. Com a inspiração, a $\mathrm{PaCO}_{2}$ reduz e a $\mathrm{PaO}_{2}$ aumenta e isso faz com que a relação entre $\left[\mathrm{CO}_{2}\right]$ e $\left[\mathrm{O}_{2}\right]$ aumente. Ou seja, a $\left[\mathrm{O}_{2}\right] /\left[\mathrm{CO}_{2}\right]$ aumenta e a regulação do fluxo e da $E$ deve ocorrer de maneira inversa para a restauração dessa relação. Assim, o fluxo diminui e a $E$ aumenta, causando um decréscimo no sinal. Depois, com o inicio da apnéia, a $\mathrm{PaO}_{2}$ começa a diminuir e a $\mathrm{PaCO}_{2}$ a aumentar causando o aumento de sinal já mencionado. 
Pela figura 7.4, pode-se notar, também, que a amplitude do sinal em resposta à apnéia precedida de expiração é maior que quando esta é precedida por expiração. Isso pode ser igualmente explicado pelo aumento imediato na $\mathrm{PaCO}_{2}$ e pela diminuição da $\mathrm{PaO}_{2}$, fazendo com que a variação entre a concentração de $\mathrm{CO}_{2}$ e $\mathrm{O}_{2}$ acabe sendo maior, ocasionando um maior aumento no fluxo, uma maior redução em E e, portanto, uma maior variação no sinal BOLD.

Esses resultados estão de acordo com o reportado por Li et al. (1998) que, também, verificaram que na apnéia precedida por expiração, há um aumento imediato do sinal BOLD. Enquanto que na apnéia precedida por inspiração o sinal BOLD e o fluxo cerebral sangüíneo irão decrescer inicialmente após inspiração e, se o tempo de apnéia for suficientemente longo, haverá um aumento posterior tanto do CBF quanto do BOLD.

\section{Análise do atraso da resposta hemodinâmica}

Para se quantificar alguns aspectos da resposta BOLD em função dos territórios arteriais anteriormente definidos, analisou-se o atraso da resposta hemodinâmica, de cada território, em relação ao início da apnéia. Para isso, em um primeiro momento, quantificou-se a área percentual de cada território arterial que se mostrou estatisticamente significativa $(\mathrm{p}<0.000109)$, quando processadas com uma função hemodinâmica de diferentes atrasos.

Tanto para a apnéia realizada após inspiração quanto após expiração, em todos os voluntários, essa percentagem é relativamente baixa, aumentando gradativamente com o atraso, chegando a um máximo, e diminuindo em seguida. A figura 7.5 mostra essa variação em função do tempo de atraso da resposta hemodinâmica para um voluntário. 

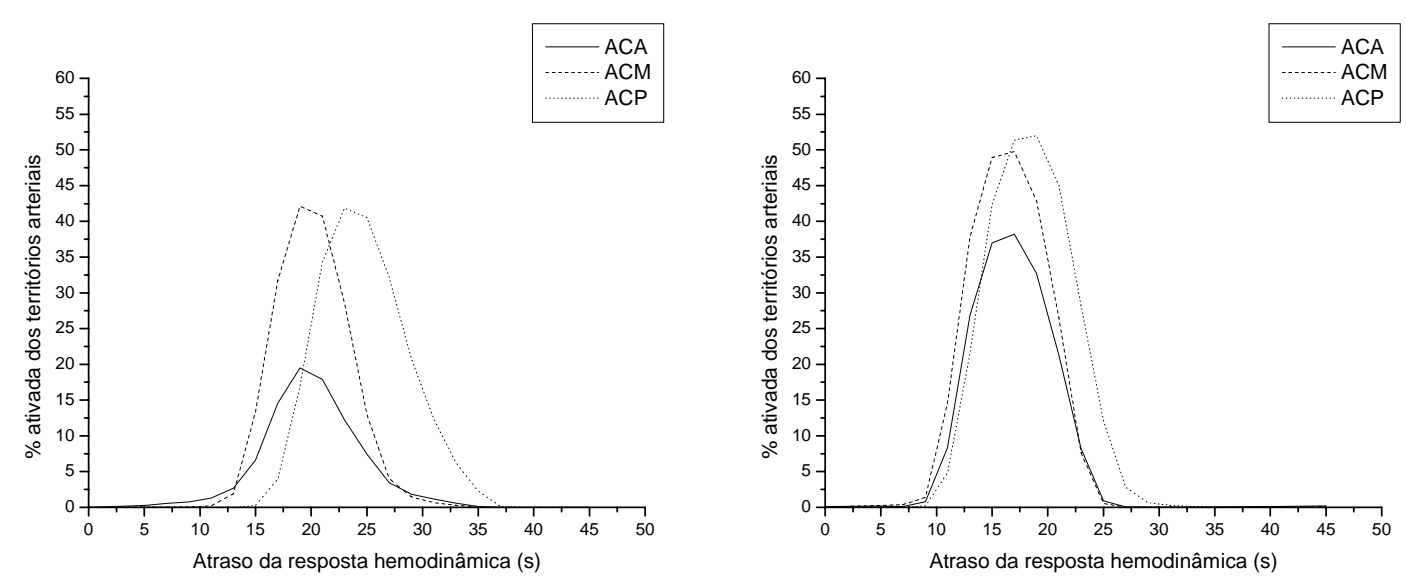

Figura 7.5. Evolução temporal da área percentual estatisticamente significativa $(p<0.000109)$, de cada território arterial, em resposta à apnéia. À esquerda observamos essa variação para a inspiração. À direita, para a expiração respectivamente.

Pela figura 7.5, pode-se observar que um maior número de regiões cerebrais mostrou-se estatisticamente significativa à apnéia, quando esta era realizada após expiração. $\mathrm{Na}$ média realizada entre os voluntários, a percentagem máxima que respondeu a esse estímulo na apnéia após a inspiração foi de $31.3 \%$, 37.8\%, 38.5\% para a ACA, ACM e ACP, respectivamente. Por outro lado, para a apnéia após a expiração, essa percentagem foi de 43.5\%, 57.7\%, 52.2\% para a ACA, ACM e ACP, respectivamente.

Sabe-se que a variação na $\left[\mathrm{O}_{2}\right] /\left[\mathrm{CO}_{2}\right]$ é maior quando a apnéia é precedida de expiração, pois, neste caso, a diminuição de $\mathrm{PaO}_{2}$ e o aumento da $\mathrm{PaCO}_{2}$ ocorre de forma imediata. Portanto o fato de um maior número de regiões cerebrais mostrarem-se estatisticamente significativas à apnéia após a expiração, mostra que algumas regiões precisam de uma maior alteração nas concentrações de $\mathrm{O}_{2}$ e $\mathrm{CO}_{2}$ para que mudanças no fluxo e na E sejam significativas, gerando um sinal BOLD detectável.

Outra observação interessante é que, quando a apnéia é realizada após a expiração, a máxima percentagem de voxels ativados no território irrigado pela ACA foi sempre menor se comparado aos territórios irrigados pela ACM e ACP (Ver tabela 7.1). Isso mostra que o sinal BOLD no território irrigado pela ACA é menos sensível a mudanças da $\mathrm{PaCO}_{2}$ e $\mathrm{PaO}_{2}$. Wise et al. (2004) propõe que essa diferença de sensibilidade pode ser devido a diferenças no atraso da resposta hemodinâmica. Contudo, no caso aqui apresentado, os dados foram analisados utilizando várias 
funções hemodinâmicas com diferentes atrasos e, apesar disso, observou-se a mesma diferença entre número de voxels.

\begin{tabular}{|l|l|l|l|l|l|l|l|l|l|l|}
\hline $\begin{array}{l}\text { Voluntário/ } \\
\text { Território arte- } \\
\text { rial }\end{array}$ & V1 & V2 & V3 & V4 & V5 & V6 & V7 & V8 & V9 & $\begin{array}{l}\text { Média en- } \\
\text { tre voluntá- } \\
\text { rios }\end{array}$ \\
\hline ACA $(\%)$ & 56.0 & 44.5 & 38.2 & 40.3 & 57.0 & 28.1 & 58.5 & 49.3 & 19.5 & 43.5 \\
\hline $\mathrm{ACM}(\%)$ & 72.3 & 65.0 & 49.0 & 62.6 & 68.0 & 32.5 & 74.6 & 69.9 & 25.5 & 57.7 \\
\hline $\mathrm{ACP}(\%)$ & 58.0 & 49.6 & 52.0 & 46.9 & 58.6 & 34.6 & 60.6 & 64.9 & 26.7 & 50.2 \\
\hline
\end{tabular}

Tabela 7.1. Máxima percentagem de voxels ativos para os 9 voluntários que realizaram apnéia após expiração com um $p<0.000109$. $O$ atraso na resposta hemodinâmica para a obtenção dessas percentagens encontra-se na tabela (7.2).

A tabela 7.2a mostra o tempo ao pico da função preditora para que a maior percentagem de cada território atingisse o máximo valor do sinal BOLD, tanto para a inspiração quanto para a expiração. Observa-se que esse pico ocorre sempre antes na apnéia realizada após a expiração se comparada à apnéia após a inspiração. Isto é de se esperar, pois como foi mostrado na discussão em que se comparam os protocolos de apnéia após a expiração e após a inspiração, a apnéia a após inspiração apresenta uma queda inicial do sinal, fazendo com que haja um atraso do tempo para o pico da resposta hemodinâmica.

Pode-se observar, ainda, que o território da ACP responde, de uma forma global, mais lentamente que outros dois territórios. Além disso, observou-se que o território da ACM responde, de uma forma global, mais rapidamente, em 4 dos 8 voluntários. Essa diferença está limitada pela resolução temporal utilizada, que é de 2 segundos.

\begin{tabular}{|l|l|l|l|}
\hline $\begin{array}{l}\text { Voluntários } \\
\text { (inspiração) }\end{array}$ & ACA(s) & $\mathrm{ACM}(\mathrm{s})$ & $\mathrm{ACP}(\mathrm{s})$ \\
\hline V1 & 19 & 17 & 19 \\
\hline V2 & 19 & 19 & 23 \\
\hline V3 & 19 & 17 & 19 \\
\hline V4 & 21 & 19 & 21 \\
\hline V5 & 23 & 23 & 25 \\
\hline V6 & 19 & 19 & 21 \\
\hline V7 & 21 & 21 & 25 \\
\hline V8 & 23 & 21 & 25 \\
\hline
\end{tabular}

\begin{tabular}{|l|l|l|l|}
\hline $\begin{array}{l}\text { Voluntários } \\
\text { (expiração) }\end{array}$ & ACA(s) & ACM(s) & ACP(s) \\
\hline V1 & 15 & 15 & 15 \\
\hline V2 & 17 & 17 & 19 \\
\hline V3 & 15 & 15 & 15 \\
\hline V4 & 17 & 17 & 19 \\
\hline V5 & 19 & 17 & 19 \\
\hline V6 & 17 & 17 & 17 \\
\hline V7 & 17 & 17 & 17 \\
\hline V8 & 19 & 17 & 19 \\
\hline V9 & 15 & 13 & 15 \\
\hline
\end{tabular}

Tabela 7.2. Tabelas do tempo para que cada território arterial atinja a maior percentagem ativa para um $\mathrm{p}<0.000109$. 
Essa diferença no atraso da resposta hemodinâmica entre os territórios foi mais visível quando a apnéia foi realizada após a inspiração. Em apenas 5 dos 9 voluntários que realizaram a apnéia após a expiração, pôde-se observar uma diferença no tempo necessário para que a maior percentagem de cada território respondesse à apnéia. Por outro lado, em todos os 8 voluntários que realizaram a apnéia após a inspiração pôde ser observado alguma diferença. Essa observação pode ser devido ao fato de que a evolução temporal do sinal BOLD, após a expiração, ocorre mais rapidamente, pois o tempo necessário para que cada território atinja uma porcentagem máxima é maior quando a apnéia é realizada após a inspiração. Contudo, a freqüência de amostragem utilizada neste estudo não é grande suficiente para captar essas diferenças temporais das respostas de cada território.

$\mathrm{Na}$ figura 7.6 apresenta-se a evolução temporal da média do sinal BOLD dos 8 voluntários acima, em resposta à apnéia após a inspiração. Para melhor visualização, destacaram-se os três territórios arteriais (ACA- Laranja, ACM- Cinza, ACPAzul). Os dados são apresentados em escala de cores, sendo as cores mais escuras representando melhor correlação nos dados para um $\mathrm{p}<0.003$ (foi feita a correção de Bonferroni para diminuir o erro do tipo I).

Pela evolução temporal dos dados (figura 7.6), pode-se confirmar o fato do território da ACM ser o primeiro a responder ao estímulo de apnéia de uma forma mais generalizada (Ver figura 7.6 (2) e 7.6 (3)) bem como do fato do território da ACP ser o último a responder de uma forma global (Ver figura 7.6 (3) e 7.6 (4)). 


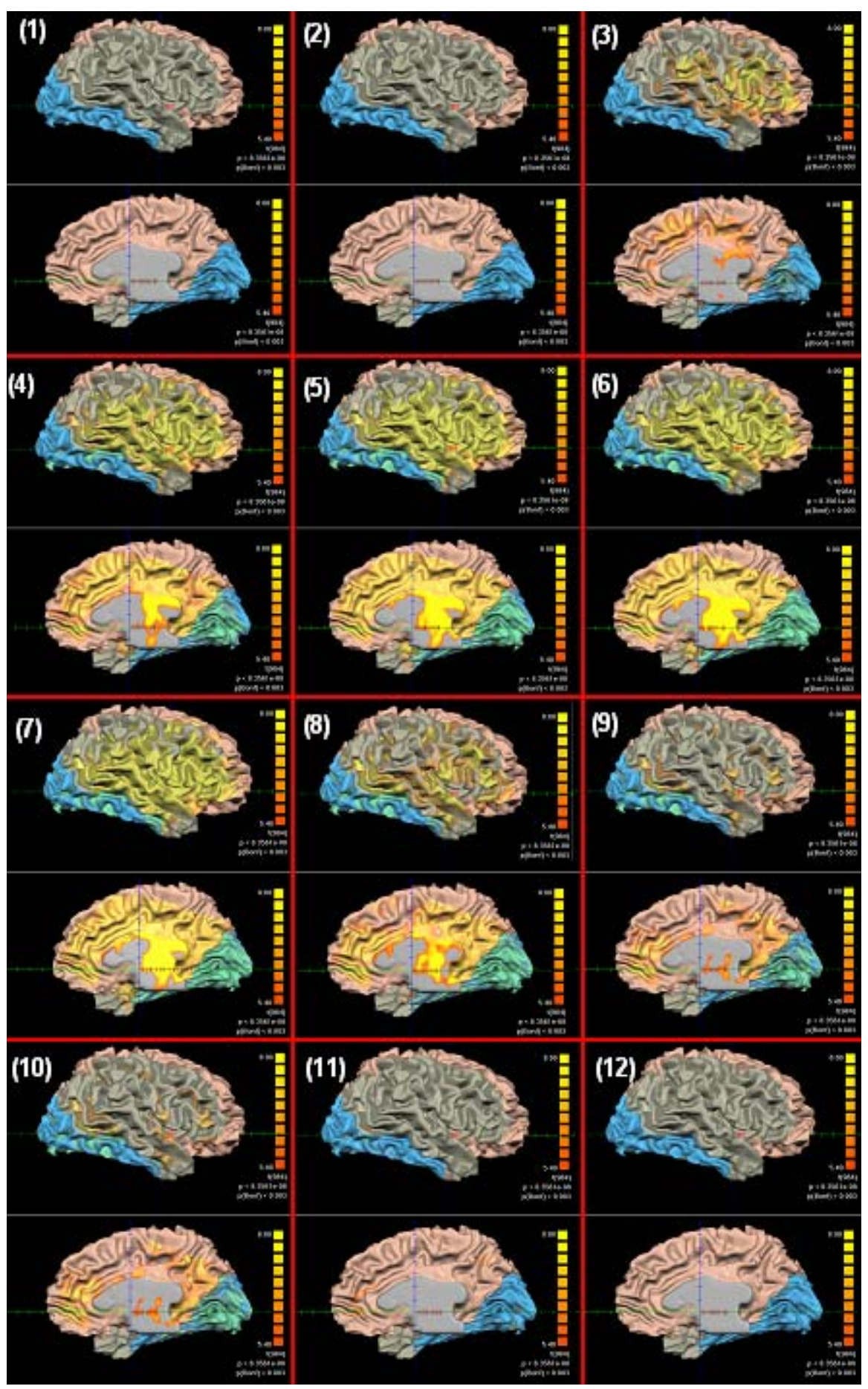

Figura 7.6 Territórios cerebrais, com seus respectivos atrasos ao estímulo de apnéia, após inspiração. (1) 0s; (2) 13s; (3) 15s; (4) 17s; (5) 19s; (6) 21s; (7) 23s; (8) 25s; (9) 27s; (10) 29s; (11) 31s; (12) 33s. Os territórios irrigados pelas três principais artérias foram destacados (ACA-Laranja, ACMcinza, ACP-Azul).

Diferenças regionais na sensibilidade do sinal BOLD ao $\mathrm{CO}_{2}$ na substância cinzenta, portanto, pode refletir diferenças regionais na atividade metabólica e na regulação vascular. Causas prováveis das diferenças regionais podem ser atribuídas à anatomia microvascular regional e ao volume cerebral sangüíneo (CBV) basal (Ban- 
dettini e Wong, 1997; Boxerman et al., 1995a, b). Davis et al. (1998) discutem que as mudanças do sinal BOLD relativamente elevadas observadas no córtex visual durante a ativação funcional poderiam ser, em parte, atribuída à anatomia microvascular da região, já que se sabe que esta região contém uma concentração elevada de vênulas. Já o valor do volume sangüíneo basal pode interferir no sinal, pois este está correlacionado com a quantidade total de deoxi-hemoglobina. Quanto mais deoxihemoglobina estiver presente durante o repouso, maior será a mudança no sinal BOLD, para uma mesma mudança no $C B V$ e E, durante a ativação (Buxton et al., 2004).

Rostrup et al. (2000) observaram uma grande mudança no sinal BOLD na matéria cinzenta do córtex temporal e occipital em resposta a mudanças no $\mathrm{CO}_{2}$. Posse et al. (1997) encontraram uma maior sensibilidade à hipocapnia nas regiões frontal, occipital e parietal e Kastrup et al. (1999) encontraram uma grande sensibilidade à apnéia nas áreas sensoriais-motoras e visuais e cerebelo.

Variabilidades regionais da reatividade podem diferir entre estudos porque a fonte e a natureza temporal da variação do $\mathrm{CO}_{2}$ e a magnitude do campo de cada medida podem ser diferentes. Nos presentes resultados, foi visto que o atraso da resposta hemodinâmica pode estar relacionado com a reatividade das artérias que irrigam cada território, ou seja, relacionado com a habilidade desta responder ao aumento da $\mathrm{PaCO}_{2}$. Essa diferença, também, pode estar relacionada ao volume basal do CBV em cada artéria.

\section{Áreas ativadas}

Além dos mecanismos de perfusão globais estudados até agora, os paradigmas de apnéia mexem com a ativação neural de áreas específicas, responsáveis pelo controle da respiração. Desse modo, buscou-se estudar possíveis áreas associadas a esse processo. Para tanto, utilizou-se dados do protocolo de apnéia após a expiração.

Já existe uma organização neural bem estabelecida que envolve o bulbo, a ponte, e o hipotálamo, e que controla a excitabilidade, quimicamente determinada, da necessidade de ar em resposta às mudanças do $\mathrm{CO}_{2}$ do sangue arterial. O reflexo 
motor não requer nenhuma entrada consciente e pode, claramente, ser observada durante o sono ou anestesia (McKay et al., 2003). Em contraste, a respiração pode ser modulada, durante o discurso e eventos emocionais, ou como no caso aqui apresentado, quando a pessoa é instruída a prender a respiração. O controle respiratório é requerido também para tarefas tais como cantar e tocar instrumentos de sopro. É de grande interesse, portanto, identificar as regiões corticais que são responsáveis pela consciência do impulso de respirar. Os mecanismos fisiológicos utilizados para monitorar os níveis de $\mathrm{CO}_{2}$ envolvem mudanças de $\mathrm{pH}$ do líquido intersticial dos neurônios da parte ventral do bulbo (Pappenheimer, 1965). Os neurônios hipotalâmicos funcionam também como quimioreceptores centrais que são sensíveis não somente à hipoxia, mas, também, à hipercapnia (Horn, E. M. et al., 1998).

A base neural para o controle corticomotor dos músculos respiratórios nos seres humanos foi investigada primeiramente durante uma neurocirurgia em que estímulos elétricos na superfície cortical induziam uma contração muscular do diafragma (Felder et al., 1936), indicando uma representação dos músculos respiratórios dentro do córtex motor primário. Subseqüentemente, um estudo usando estimulação magnética transcraniana (Murphy et al., 1990) identificou uma ligação entre o córtex motor e o diafragma. Cada hemisfério do diafragma é representado predominantemente no córtex motor contralateral (Maskill et al., 1991). Além disso, estudos através da tomografia por emissão do pósitron destacaram áreas do córtex motor, do tálamo e do cerebelo, associadas à respiração voluntária (Colebatch et al. (1991), Fink et al. (1996), Ramsay et al. (1993)).

Sabendo-se que a resposta do CBF e do BOLD são atrasadas de, aproximadamente, 1-2s, com relação ao estímulo, e possuem uma largura de 4-6s (Bandettini et al., 1992), analisou-se, aqui, as áreas que levaram 5s para chegar ao máximo do sinal BOLD. Utilizaram-se, para isso, os dados obtidos durante o protocolo de apnéia após expiração com um $\mathrm{p}<0.000109$.

Observou-se uma grande variabilidade tanto das áreas quanto do número de pixels ativados entre sujeitos. Essa variabilidade pode ser devido à presença de sinal causada, também, pela hipercapnia. Este sinal pode ocorrer de formas diferentes em cada voluntário, dependendo da capacidade respiratória de cada um. A figura 7.7 representa as áreas que se mostraram ativada na maioria dos voluntários. As barras 
representam o número de voxels em cada região e seu respectivo desvio padrão, entre os voluntários. A escala em tons de cinza representa o número de voluntários que tiveram determinada área ativada. No gráfico estão apenas representadas as áreas que em 8, 7, ou 6, dos 9 voluntários apareceram ativas.

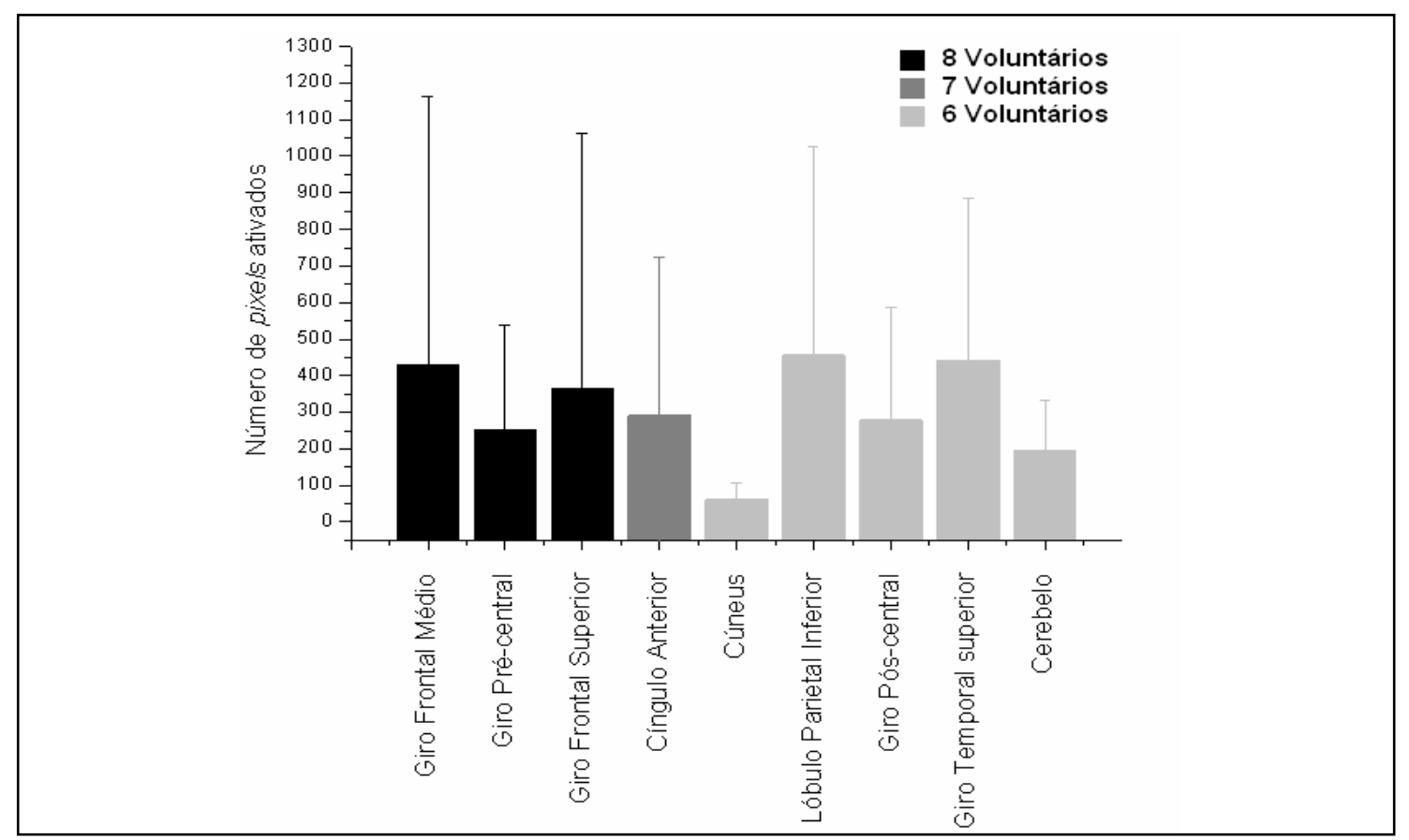

Figura 7.7. Número de voxels ativados em áreas que com um $\mathbf{p}<0.000109$, nos voluntários que realizaram o protocolo de apnéia após a expiração. A escala em tons de cinza representa o número de voluntários que ativaram determinada área.

Em 5 dos 8 voluntários havia atividade na área de Brodmann (AB) 10. Essa área é geralmente relacionada à recuperação de memórias e funções executivas (Ramnani et al., 2004). Koechlin et al. (1999) sugeriram que o córtex frontopolar regula funções cognitivas ou a habilidade humana de reter funções na mente enquanto processa objetivos secundários, um processo requerido geralmente no planejamento e no raciocínio. No presente experimento, essa área possivelmente aparece ativa pela tentativa dos voluntários de inibir o processo autônomo da respiração, ao tentar controlá-la.

Em 3 dos 8 voluntários a atividade estava associada às áreas de Brodmann 6 e 9. A AB9 também está associada a funções executivas, enquanto que a AB6 está associada ao planejamento do movimento.

Outra área que foi encontrada ativa foi o giro pré-central. Este é geralmente associado a funções motoras e está localizado no lobo frontal. Em 5 dos 8 voluntá- 
rios a atividade no giro pré-central apareceu nas áreas de Brodmann 4 e 6. A AB4 é localizada na parte posterior do giro pré-central, no córtex motor primário, e é responsável por movimentos voluntários, fazendo parte do sistema piramidal. Já a área AB6 faz parte do sistema extrapiramidal, localizada anteriormente ao córtex motor primário (AB4), e é, às vezes, referida como córtex pré-motor. A parte medial da AB6 é chamada área motora suplementar. Esta área é responsável pelos movimentos automáticos, regulação do tônus, postura, sucção e a deglutição.

McKay et al. (2003), estudando áreas associadas à respiração voluntária através de fMRI, também observaram uma atividade bastante significativa localizada no córtex motor suplementar. Observaram, também, clusters menores bilateralmente no núcleo anterior do tálamo, no globo pálido, núcleo caudal e no giro parietal inferior. No hemisfério direito foi observado atividade no córtex pré-motor, na porção média do giro do cíngulo, no giro frontal superior, no giro frontal médio anterior e no giro temporal superior. Também foram identificadas mudanças de sinal no cerebelo.

Embora McKay et al. (2003) tenham observado uma atividade do córtex prémotor unilateral no hemisfério direito, no presente trabalho, 2 voluntários apresentaram atividade bilateral e 1 apresentou atividade apenas no hemisfério esquerdo.

A tarefa de controlar a respiração executada pelos voluntários foi uma tarefa previamente instruída que requer o controle no planejamento de executar o movimento, explicando desse modo a ativação do na área motora suplementar.

O cerebelo, encontrado ativo também neste estudo, é considerado hoje como uma estrutura especializada na regulação de funções perceptivas, cognitivas e motoras, geradas em outras porções do sistema nervoso (Kandel 2000; Thach et al. 1992). O estudo das conexões do cerebelo mostra que cada hemisfério cerebelar controla os neurônios motores do seu lado, o que é uma importante diferença quando comprado aos hemisférios cerebrais, que controlam o neurônio motor do lado oposto. Outra importante diferença entre o cérebro e o cerebelo é que este funciona sempre em nível involuntário e inconsciente.

Já o cíngulo anterior é conhecido por ter um papel crucial na iniciação e na motivação dos movimentos com um objetivo específico (Devinsky et al., 1995). Um estudo utilizando PET (Ritchley et al., 2000) relatou que o cíngulo anterior pode ser 
importante em integrar mudanças cardiovasculares periféricas com esforços cognitivos, preparo motor, e estados emocionais. A ativação do cíngulo anterior a mudanças no estado emocional pode, portanto, ser devido ao esforço de controlar a respiração (McKay et al., 2003).

A atividade dentro dos córtices frontal e parietal pode representar componentes da rede frontoparietal associada ao planejamento motor e a atenção (Passingham, 1993), requeridos pelos voluntários para atender à tarefa instruída.

Observou-se também ativação na região do cúneus. Essa ativação estava presente na AB18, em 5 dos 6 voluntários. Le et al. (1998) relacionaram a ativação no cúneus com a atenção continuada, o que pode justificar também o aparecimento desta área ativa no presente trabalho, visto que os voluntários tinham que manter a atenção no processo da respiração.

É no giro pós-central onde está localizada a área de sensibilidade somática. Essa atividade observada no giro pós-central pode estar relacionada não à apnéia em si, mas sim à representação somatotópica da musculatura relacionada à respiração, bem como à mucosa que reveste o trato respiratório. Isso se deve ao estímulo sensitivo causado pelo fluxo de ar durante a expiração, já que os voluntários que participaram da análise das áreas ativadas foram instruídos a prender a respiração apenas quando chegassem ao final da expiração.

Obbott et al. (2005) estudando a influência de pequenos intervalos de apnéia durante exames de imagens funcionais encontraram ativação no cíngulo posterior e anterior (associando estas ao mecanismo de atenção), na ínsula (associando ao controle autonômico motor de funções associadas à respiração e engolir envolvendo a boca, a garganta, salivação) e regiões caudais (associando ao controle motor da respiração).

No presente trabalho, embora não apresentado na figura 7.7, 5 dos 9 voluntários apresentaram atividade na ínsula e nas regiões caudais.

\section{Influência do tempo de reação}

Por ter sido solicitado que os voluntários atingissem o final da inspiração/expiração para prender o ar, há um atraso entre o momento em que o comando 
é dado e o momento em que o voluntário prende a respiração de fato. Para que esse atraso seja considerado, 4 dos 10 voluntários, que realizaram os exames com TR mais curto, foram instruídos a apertar um botão, conectado a um computador, quando realmente prendessem o ar. Assim, o tempo real de início da apnéia pode ser verificado. Dos 4 voluntários, 3 foram incluídos na análise em que a apnéia foi realizada após se chegar ao final da expiração e 2 para a apnéia após a inspiração. Os critérios para a exclusão dos voluntários foram os mesmos já apresentados no inicio da discussão.

Para aplicar o GLM sobre esses dados, foram criadas funções preditoras específicas para cada voluntário. Agora, o início dessas funções acontece não mais quando o comando é dado, mas quando, realmente, se iniciava o período de apnéia. A figura 7.8 apresenta um exemplo da função preditora de um dos voluntários, durante o protocolo de apnéia após expiração. Note que a forma da função se altera ao longo do exame.

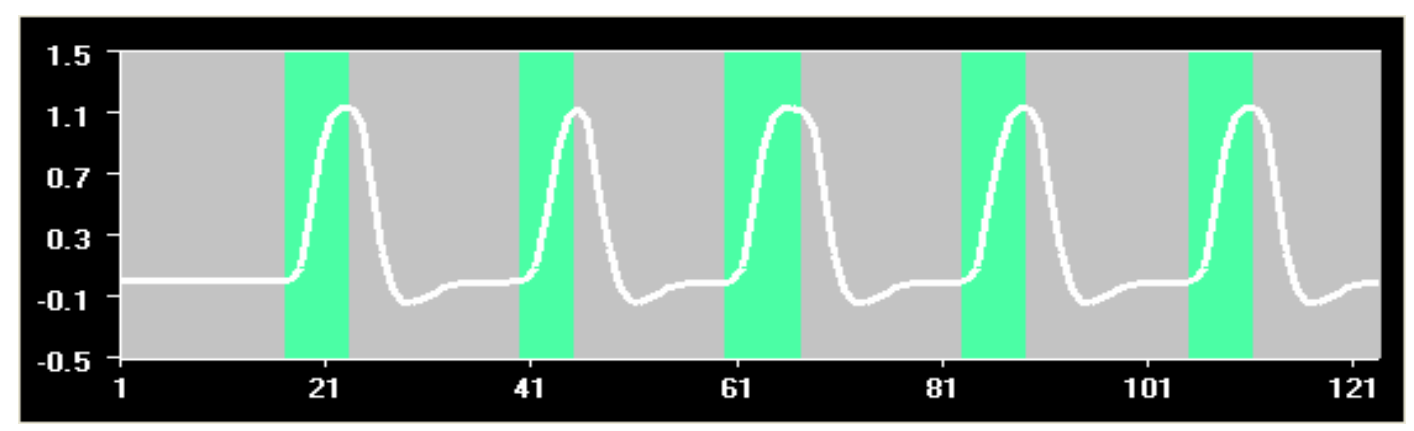

Figura 7.8. Exemplo de uma função preditora em que foi considerado o tempo real para o voluntário iniciar a apnéia. Os períodos apresentados em cor cinza representam o repouso, enquanto os períodos em verde representam o estado de apnéia. A linha branca representa a convolução entre os períodos de atividade e uma HRF modelo.

O tempo médio necessário para o início da apnéia após a expiração foi de 1.8s, já para iniciar a apnéia após a inspiração foi de 1.7s. Porém, foi observada uma grande variação desse tempo tanto entre indivíduos como ao longo do exame de um voluntário, como pode ser visto na figura 7.8.

Ao se analisar os dados, considerando esse tempo de reação, observou-se que o número de voxels ativos para um atraso na resposta hemodinâmica de $5 \mathrm{~s}$ foi me- 
nor, independentemente da apnéia ter iniciado antes da expiração ou da inspiração (Ver figura 7.9).

Essa variação no tempo necessária para iniciar a apnéia pode, também, justificar a grande variabilidade nas áreas ativadas entre os voluntários.

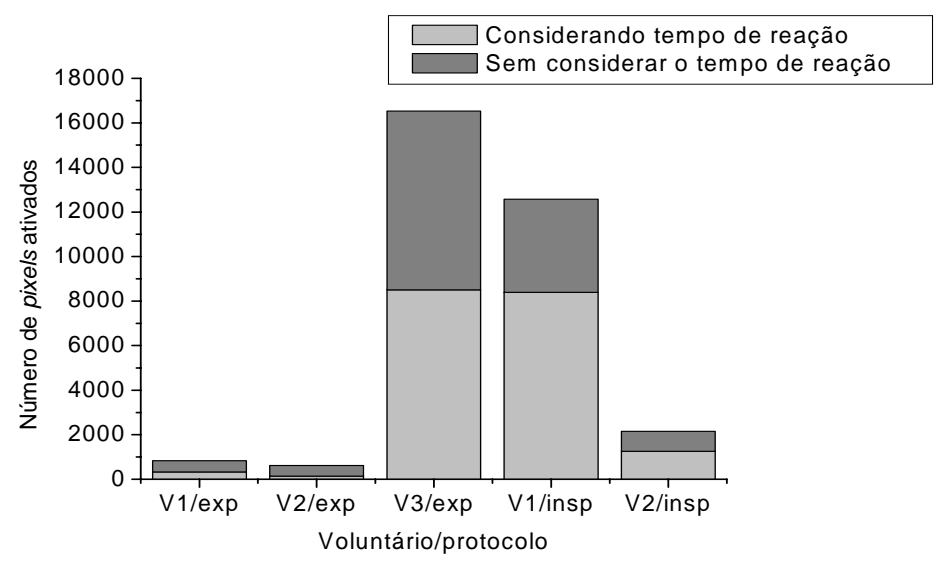

Figura 7.9. Gráfico com o número de pixels ativados. Comparação quando o GLM foi aplicado com a função preditora, considerando o tempo que o voluntário leva pra prender a respiração (cinza claro) e sem considerar esse tempo (cinza escuro).

\section{Mapas de B-CBV}

Uma vez que os mapas aqui observados fornecem uma informação global de perfusão, foi idealizado, ainda que de forma preliminar, a construção de mapas de CBV, semelhantes àqueles calculados a partir das técnicas de perfusão comuns, como a DSC. Esses mapas foram gerados na tentativa de trazer informações a respeito do volume cerebral sanguíneo, de todo o cérebro, de uma forma não-invasiva.

Lu et al. (2003) propuseram uma técnica não invasiva de fMRI baseada em mudanças de CBV durante a ativação do cérebro, utilizando imagens baseadas na ocupação do espaço vascular, associadas à ativação, que foi dado o nome de VASO (Vascular Space Occupancy). A imagem de VASO, embora com melhor especificidade espacial que imagens baseadas no contraste BOLD, devido à sua sensibilidade elevada aos microvasos, não pode obter informações quantitativas de CBV durante a ativação, sem informações adicionais sobre a linha de base do CBV.

A quantificação não-invasiva de CBV, e de sua mudança durante testes fisiológicos, promete melhorar nossa compreensão sobre mecanismos hemodinâmicos 
do cérebro e do sinal de fMRI, incluindo a avaliação de potenciais alterações do estado vascular em relação à ativação neuronal depois da administração de drogas (Salmeron e Stein, 2002). Imagens de CBV com injeções de agentes de contraste exógenos é um método invasivo e não é apropriado para estudos de fMRI com paradigmas complexos de estimulação (Belliveau et al., 1991) e imagens VASO detectam mudanças do sinal ponderado no CBV entre o repouso e os estados da ativação, mas não fornece valores absolutos de CBV nestes dois estados (Lu et al., 2003).

Recentemente, Gu et al. (2006) propuseram um método capaz de quantificar o CBV não-invasivamente no repouso e durante ativação. Essa quantificação foi obtida ajustando-se os dados de fMRI, provenientes de um paradigma visual, para vários tempos de inversão (TI, Inversion Time), a um modelo biofísico compreendido de vários componentes do tecido.

Os mapas de CBV gerados pela técnica de DSC, são obtidos pelo cálculo da área abaixo da curva de concentração do agente de contraste. De modo semelhante, neste trabalho, mapas de cores foram gerados através do cálculo da área abaixo das curvas de contraste BOLD, normalizadas pela linha de base do sinal, que foram chamados de B-CBV.

Embora interpretações fisiológicas do sinal BOLD sejam complexas, já que este envolve mudanças de volume sanguíneo, fluxo e consumo de oxigênio, esses mapas foram construídos baseados no fato que a taxa de relaxação é proporcional ao volume sanguíneo, ou seja, o aumento de sinal observado em resposta à apnéia pode refletir um aumento do rCBV.

$\mathrm{Na}$ figura 7.10 observa-se um exemplo dos mapas de cores encontrados (BCBV), em 16 fatias axiais, calculados a partir da resposta BOLD dos dados adquiridos durante um protocolo ER, em que períodos de respiração normal eram intercalados por períodos de apnéia. As áreas em vermelho são as que possuem maior volume sanguíneo enquanto as de azul, menor. 


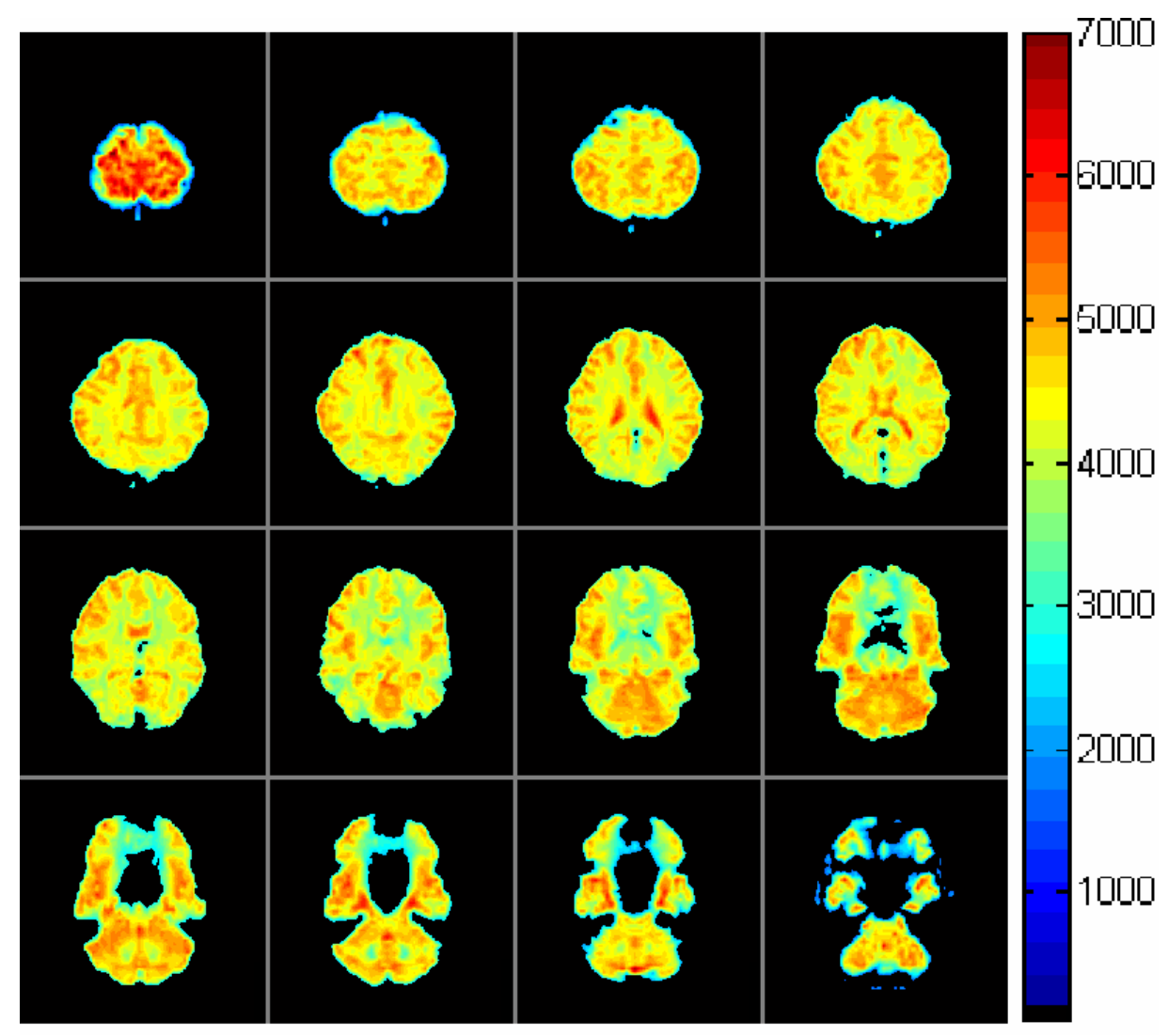

Figura 7.10. Mapas de B-CBV gerados a partir do cálculo da área abaixo da curva do contraste BOLD, obtido durante um protocolo de apnéia.

Pela figura 7.10, pode-se observar um maior volume sanguíneo na matéria cinzenta e no cerebelo. Observa-se, ainda, um alto sinal no CSF, que será discutida adiante. Em virtude desse sinal, há uma dificuldade de se visualizar outras estruturas no mapa acima. Portanto, aplicou-se uma máscara de filtro limiar, sobre as imagens originais, para retirar o sinal observado no CSF. Os mapas de B-CBV, após a aplicação desse filtro, são apresentados na figura 7.11. 


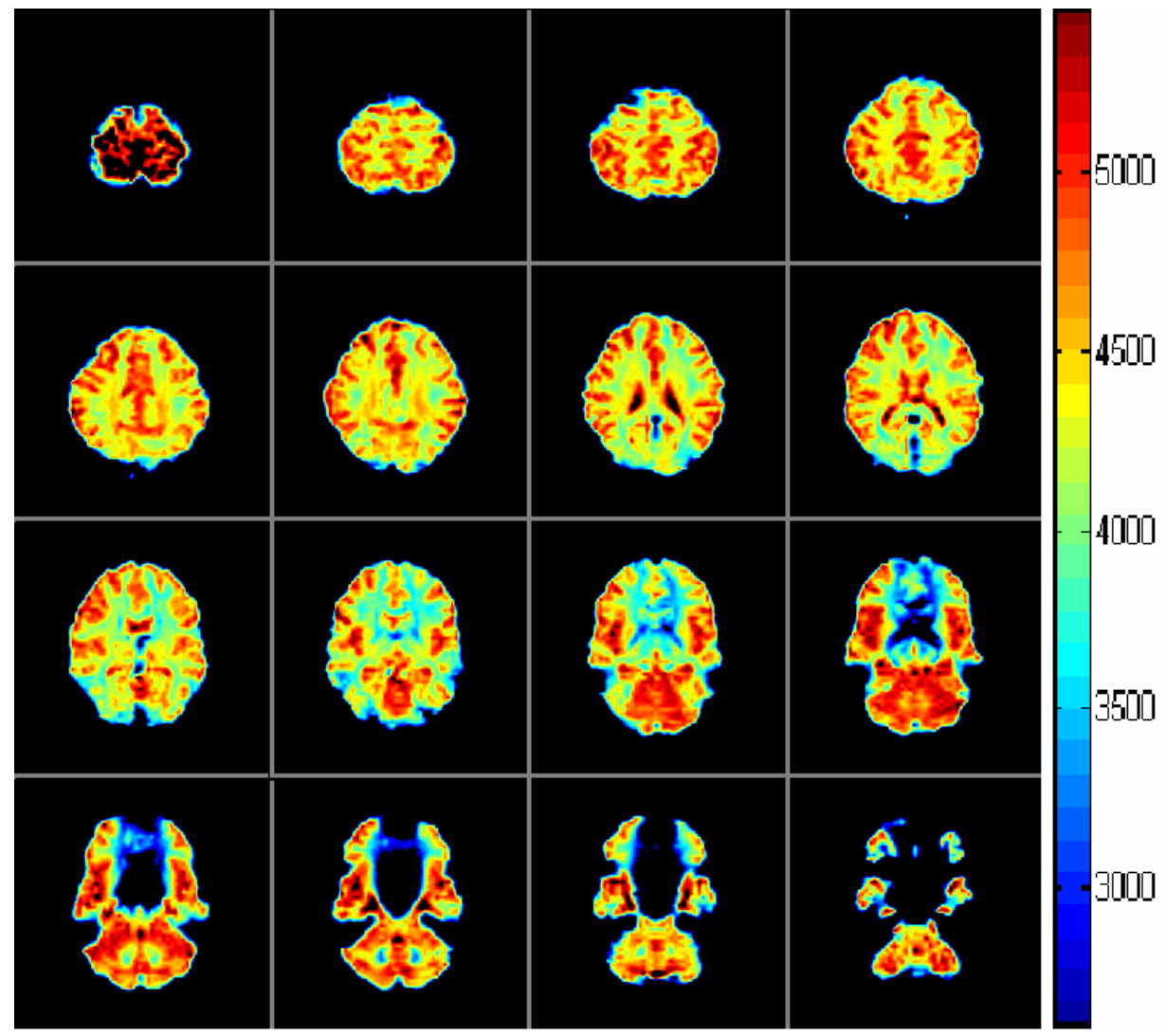

Figura 7.11. Mapas de B-CBV gerados a partir do cálculo da área abaixo da curva do contraste BOLD, obtido durante um protocolo de apnéia após a aplicação de um filtro para retirar o sinal do CSF.

Ao se comparar os mapas da figura 7.10 aos da figura 7.11, observa-se que a aplicação do filtro promove um bom delineamento entre a substância cinzenta e branca. Pelos mapas de B-CBV pode-se observar que estes refletem o volume sangüíneo local, embora, estudos para análise dos outros parâmetros que influenciam o sinal devam ser feitos.

\section{Sinal no CSF}

Outra observação interessante nos dados aqui obtidos foi a presença de ativação no líquido cérebroespinhal, Cerebral Spinal Fluid (CSF) (Figura 7.12). Esse sinal foi observado quando não se supôs nenhum atraso na resposta hemodinâmica.

Como já foi dito na introdução deste trabalho, a conformação espacial do CSF diminui com a vasodilatação cerebral durante hipercapnia. Czosnyka et al. (1999) observaram que o coeficiente de elasticidade cerebral aumenta, significando 
um aumento na rigidez do cérebro. Além disso, mudanças na resistência ao afluxo do CSF foram observadas durante diferentes manobras vasodilatatorias cerebrais. A reabsorção ou afluxo do CSF diminui com hipotensão, mas aumenta com a hipercapnia. Isso significa que os parâmetros cerebrovasculares, como a $\mathrm{PaCO}_{2}$, têm um limitado, mas significante, impacto na conformação do CSF.
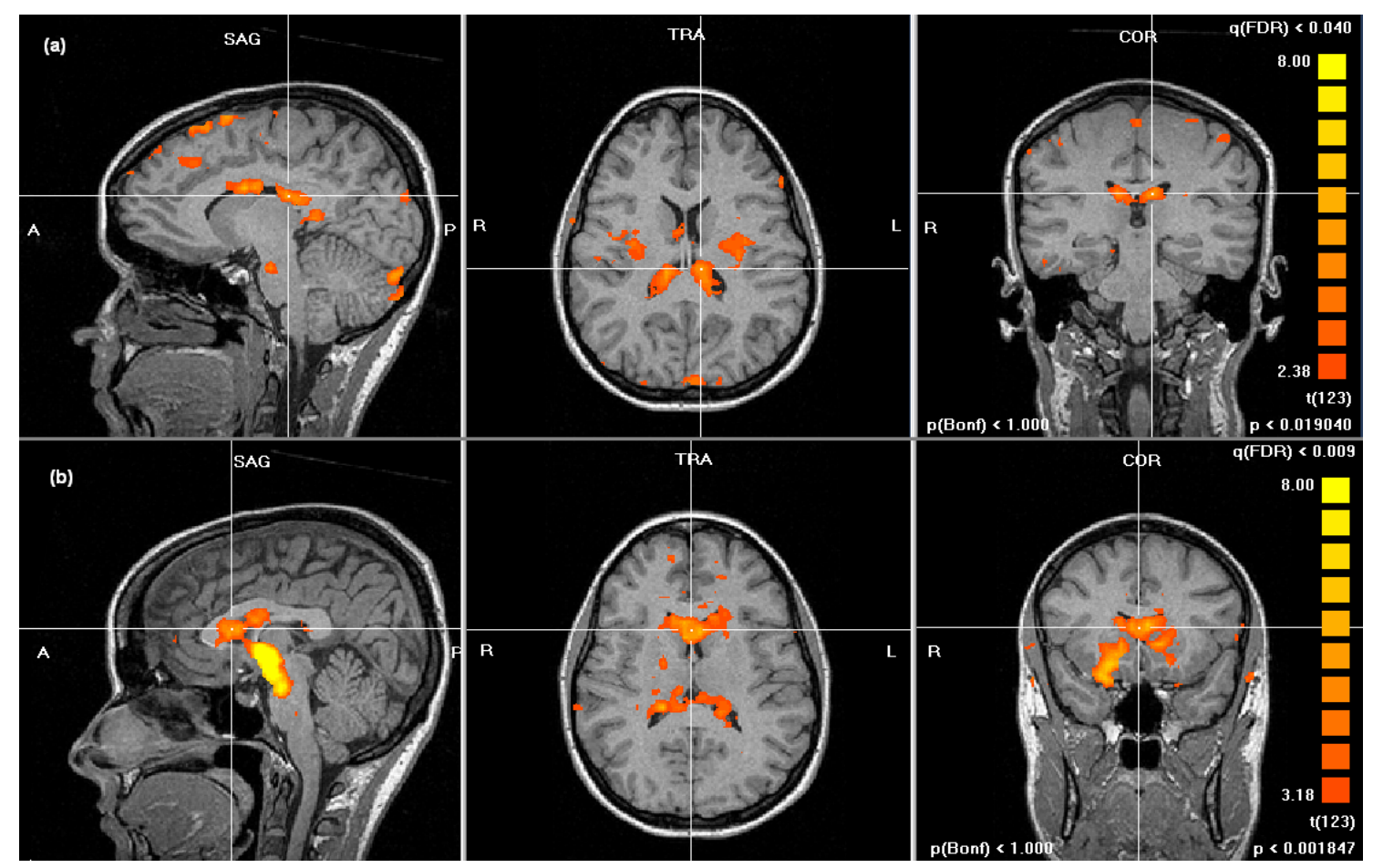

Figura 7.12. Sinal positivo no CSF, em resposta à apnéia (a) após inspiração (p<0.019040), (b) após expiração $(\mathbf{p}<0.001847)$. Pode-se ver claramente que o sinal no CSF é mais evidente quando a apnéia é iniciada após expiração.

Uma possível explicação para o aparecimento desse sinal positivo no CSF é o fato deste ser composto não apenas por água, mas por íons como $\mathrm{Na}^{+}, \mathrm{K}^{+}, \mathrm{Ca}^{++}$, $\mathrm{Mg}^{++}, \mathrm{Cl}^{-}$, que possuem propriedades magnéticas capazes de alterar o tempo de relaxação $\mathrm{T}_{2}{ }^{*}$. A alteração no volume do CSF, ocasionada pela hipercapnia, poderia mudar a concentração desses íons. Como essa mudança estaria correlacionada com o período de apnéia, causaria um aumento de sinal. Outro fato que sustenta essa hipótese é que o sinal no CSF foi bem maior quando a apnéia foi realizada depois da expiração, já que o aumento de volume sangüíneo, nesse caso, é maior do que quando a apnéia é realizada após a inspiração. Porém, no presente trabalho, não foram 
feitas medidas para saber se esta pequena variação de volume destes íons seria capaz de causar uma mudança significativa no tempo de relaxação $\mathrm{T}_{2}{ }^{*}$.

Gotman et al. (2005), estudando o aumento e o decréscimo do metabolismo durante descargas epiléptica em pacientes, através de medidas simultâneas de EEG e fMRI, observaram uma resposta positiva nos ventrículos laterais. Eles sugerem a hipótese de que este fenômeno seja apenas artefato, embora tenham verificado que o movimento durante o exame tenha sido mínimo, o que torna essa explicação menos provável. Eles sugerem, ainda, que o aumento de volume de sangue ocasionado pelas descargas poderia causar uma redução transitória no volume dos ventrículos e, portanto, alteraria as características magnéticas próximas ao mesmo, concordando com a hipótese levantada no presente trabalho.

Outro fato que pode contribuir para o sinal no CSF é a de que a tensão de oxigênio no CSF $\left(\mathrm{P}_{\mathrm{CSF}} \mathrm{O}_{2}\right)$ é correlacionada com a $\mathrm{PaO}_{2}$. O oxigênio possui dois elétrons desemparelhados, apresentando, assim, uma fraca característica paramagnética. Este efeito paramagnético do oxigênio foi observado em vários tecidos, incluindo artérias (Jankowska et al., 1979) e foi explorado como um potencial agente de contraste para a MRI no cérebro (Deliganis et al., 2001). Entretanto, o efeito do oxigênio no CSF tem sido menos estudado. Anzai et al. (2004) mostraram que a administração de oxigênio suplementar, através de máscaras faciais, resulta em um aumento na intensidade de sinal do CSF em imagens FLAIR para voluntários normais. Eles mostraram também que a exposição ao oxigênio de soluções salinas in vitro diminui o tempo de relaxação $T_{1}$ sendo este o mesmo mecanismo que causaria o aumento de sinal nas imagens FLAIR.

Normalmente, quando na presença do ar atmosférico, a saturação arterial da hemoglobina pelo oxigênio é aproximadamente de 100\%. No entanto, a pressão parcial do oxigênio dissolvido no sangue (no nível de mar) representa uma fração pequena da concentração de oxigênio total $(0,3 \%)$. Com a adição do oxigênio, a concentração do oxigênio dissolvido no sangue aumenta. $\mathrm{O}$ oxigênio dissolvido difundirá nos tecidos de acordo com o gradiente do oxigênio. Como o CSF não possui nenhuma molécula capaz de carrear oxigênio, como a hemoglobina ou a mioglobina, a concentração total do oxigênio no CSF será apenas de oxigênio dissolvido. A relação entre a pressão do oxigênio do CSF e a pressão parcial arterial de oxigênio 
foi estudada em coelhos em 1979 (Jankowska et al., 1979). Neste estudo, a pressão do oxigênio do CSF $\left(\mathrm{P}_{\mathrm{CSF}} \mathrm{O}_{2}\right)$ foi linearmente relacionada com a pressão parcial arterial de oxigênio, sendo a difusão do oxigênio do sangue na fronteira do CSF sugerido como o mecanismo principal de tal transferência (Yarnell et al., 1967).

Desta forma, como existe uma dependência entre a pressão $\mathrm{PaO}_{2}$ e $\mathrm{P}_{\mathrm{CSF}} \mathrm{O}_{2}$, durante a apnéia, a $\mathrm{PaO}_{2}$ diminui, sugerindo, dessa forma, uma diminuição na PCSF$\mathrm{O}_{2}$. Sendo o $\mathrm{O}_{2}$ livre paramagnético, a diminuição local desse causaria um aumento na homogeneidade de campo, aumentando, assim, o tempo de relaxação T2* e, conseqüentemente, aumentaria o sinal da EPI. A observação do sinal no CSF ser maior quando a apnéia é realizada após expiração também concorda com essa hipótese, já que, neste caso, a queda na $\mathrm{PaO}_{2}$ seria bem maior, se comparada com a apnéia após inspiração.

A $\mathrm{P}_{\mathrm{CSF}} \mathrm{O}_{2}$ foi proposta como um marcador da oxigenação do tecido do cérebro ou da medula espinhal, dado a natureza passiva da difusão do oxigênio (Venkatesh et al., 1999). Historicamente, investigadores mediam a $\mathrm{PCSF}_{2}$ analisando o líquido obtido por punção lombar ou utilizavam a implantação de microeleterodos para a detecção da concentração de oxigênio. Esses métodos são inconvenientes e invasivos, e são limitados com relação à resolução espacial. Além disso, os métodos que necessitam da remoção do líquido são passíveis de erros introduzidos pela exposição do CSF ao ar atmosférico antes que a análise seja executada (Grand et al., 1988). Desse modo, um método não-invasivo de imagem para determinar $\mathrm{P}_{\mathrm{csf}} \mathrm{O}_{2}$ permitiria a repetição de medidas com uma boa sensibilidade espacial durante manipulações fisiológicas.

Recentemente, Zaharchuk el al. (2005) quantificaram a pressão parcial de oxigênio no CSF em humanos enquanto o voluntário respirava ar atmosférico e durante inalação de ar com $100 \%$ de $\mathrm{O}_{2}$ através de medidas de $\mathrm{T}_{1}$ do CSF. Mas, algumas limitações foram apresentadas nesse trabalho. Devido à natureza invasiva para a medida do $\mathrm{PaO}_{2}$, esta não foi medida nos voluntários. Como eles respiravam 100\% de oxigênio através de máscaras que permitiam a entrada de ar ambiente, o nível de oxigênio era menor que 100\%. O movimento do paciente, também, pode causar grandes erros nas medidas $\mathrm{P}_{\mathrm{CSF}} \mathrm{O}_{2}$. Logo, o desenvolvimento de paradigmas mais 
rápidos de imagens, possivelmente usando imagens EPI ou técnicas de pulso único, poderia ser aplicado. 


\section{CONCLUSÕES}

Para que fosse possível observar um aumento global no rCBF, em resposta ao aumento da $\mathrm{PaCO}_{2}$, os dados obtidos durante o protocolo de apnéia, com duração de 27s e 14s, tiveram que ser processados utilizando uma função preditora com um tempo médio ao pico de 22,94s e 19.15s, respectivamente. Foi observado, também, que o padrão de aumento do sinal BOLD induzido pela apnéia está correlacionado com o tempo da apnéia, ou seja, quanto maior o tempo de apnéia, maior a intensidade do sinal BOLD.

No estudo do comportamento do sinal BOLD diante de diferentes manobras de apnéia, ou seja, se esta se iniciava antes de uma expiração ou inspiração, notou-se que o sinal BOLD para apnéia precedida pela expiração apresenta um aumento imediato. No entanto, para a apnéia precedida pela inspiração, o sinal decresce inicialmente e só depois cresce, mostrando a mudança bifásica na $\mathrm{PaO}_{2}$ e $\mathrm{PaCO}_{2}$ para este caso. Além disso, um maior número de regiões cerebrais respondeu à apnéia, quando esta é realizada após a expiração, indicando que algumas regiões precisam de uma maior alteração nas concentrações de $\mathrm{PaO}_{2}$ e $\mathrm{PaCO}_{2}$ para que mudanças no fluxo e na E sejam significantes, gerando um sinal BOLD detectável.

Outra observação interessante é que, quando a apnéia é realizada após a expiração, a máxima percentagem de voxels ativados no território irrigado pela ACA foi sempre menor se comparado com a dos territórios irrigados pela ACM e ACP. Como esses dados foram analisados a partir de diferentes atrasos das funções hemodinâmicas, as diferenças observadas de sensibilidade do sinal BOLD a mudanças na $\mathrm{PaCO}_{2}$ e $\mathrm{PaO}_{2}$ não deve ser devida à escolha de uma função preditora específica. Essa diferença, portanto, pode estar relacionada à reatividade dessas artérias ou devido aos seus volumes sangüíneos basais.

$\mathrm{Na}$ análise do atraso da resposta hemodinâmica, o território da artéria cerebral posterior respondeu, de forma global, mais lentamente que outros dois territórios. Por outro lado, o território da ACM respondeu, de forma global, mais rapidamente, em 4 dos 8 voluntários. A característica temporal da mudança do CBF para diferentes regiões do cérebro, em resposta à hipercapnia, é de interesse teórico e, 
potencialmente, de interesse clinico, já que pode ajudar a acessar diferenças regionais da regulação vascular.

Os dados obtidos durante apnéia após a expiração foram utilizados para correlacionar as regiões cerebrais que apresentavam um tempo para o pico do sinal BOLD de $5 \mathrm{~s}$ com a performance da apnéia. Nessa análise foi observada uma grande variabilidade nas regiões ativadas entre indivíduos. As áreas que apareceram com maior freqüência entre os voluntários foram: giro frontal médio, giro pré-central, giro frontal superior, cíngulo anterior, cúneus, lóbulo parietal inferior, giro póscentral, giro temporal superior e cerebelo.

Os dados foram processados, ainda, levando-se em consideração o tempo que os voluntários demoravam para, realmente, prender a respiração. O tempo médio após a expiração foi de 1.8s, e para a inspiração foi de 1.7s. Porém, foi observada uma grande variação tanto no tempo entre indivíduos como ao longo do exame de um mesmo voluntário. Quando esse tempo foi considerado, verificou-se que o número de voxels ativos para um atraso na resposta hemodinâmica de $5 \mathrm{~s}$ foi menor, independentemente da apnéia ter iniciado antes da expiração ou da inspiração. Essa variação no tempo necessária para iniciar a apnéia pode justificar a grande variabilidade nas áreas ativadas entre os voluntários. Outra possibilidade que justificaria essa variabilidade é a interferência do sinal causado pela hipercapnia. Essa interferência pode ocorrer de formas diferentes em cada voluntário, dependendo da capacidade respiratória de cada um.

Além disso, os mapas de B-CBV, obtidos utilizando o contraste BOLD, a partir de dados adquiridos durante um protocolo ER, foram capazes de refletir o volume sangüíneo local, com bom delineamento da substância cinza e branca. Embora, estudos para a análise de outros parâmetros que influenciam esse sinal devam ser feitos.

Por último, durante a realização dos protocolos de apnéia, observou-se uma alteração do sinal BOLD no CSF. Na discussão deste trabalho, foram propostas duas hipóteses para o aparecimento desse sinal. A primeira é que o CSF é composto por íons como $\mathrm{Na}^{+}, \mathrm{K}^{+}, \mathrm{Ca}^{++}, \mathrm{Mg}^{++}, \mathrm{Cl}^{-}$, que possuem propriedades magnéticas capazes de alterar o tempo de relaxação $\mathrm{T}_{2}{ }^{*}$. A alteração no volume do CSF, ocasionada pela hipercapnia, poderia mudar a concentração desses íons. Como esta mu- 
dança estaria correlacionada com o período de apnéia, causaria a presença deste aumento de sinal. Porém, no presente trabalho, não foram feitas medidas para saber se esta pequena variação de volume destes íons seria capaz de causar uma mudança significativa no tempo de relaxação $T_{2}{ }^{*}$. A segunda hipótese é que, como existe uma dependência entre a pressão $\mathrm{PaO}_{2}$ e $\mathrm{P}_{\mathrm{CSF}} \mathrm{O}_{2}$, durante a apnéia, a $\mathrm{PaO}_{2}$ diminui, sugerindo desta forma uma diminuição na $\mathrm{P}_{\mathrm{CSF}} \mathrm{O}_{2}$. Sendo o $\mathrm{O}_{2}$ livre paramagnético, a diminuição local desse causaria um aumento na homogeneidade de campo, aumentando, assim, o tempo de relaxação $\mathrm{T}_{2} *$ e, conseqüentemente, ocasionando um aumento de sinal da EPI. A observação do sinal no CSF ser maior quando a apnéia é realizada após a expiração concorda com as duas hipóteses. 


\section{Perspectivas}

A grande maioria dos métodos estatísticos utilizados para o processamento de fMRI utilizam uma função preditora para estudar o atraso da resposta hemodinâmica. Dessa forma, uma generalização natural do presente trabalho é o de utilizar outros métodos, que não necessitam de um modelo, como é o caso da análise de componentes independentes e de outros, desenvolvidos pelo nosso grupo. Isso é necessário uma vez que os métodos que necessitam de uma função preditora podem induzir a um erro na estimativa do atraso. Por exemplo, embora o sinal apresentado em cor branca na figura (9.1) esteja melhor correlacionado com a função preditora, apresentada em preto, a função que melhor representaria o tempo ao pico do sinal seria a função apresentada em vermelho, fazendo com que alguns valores de atraso sejam subestimados.

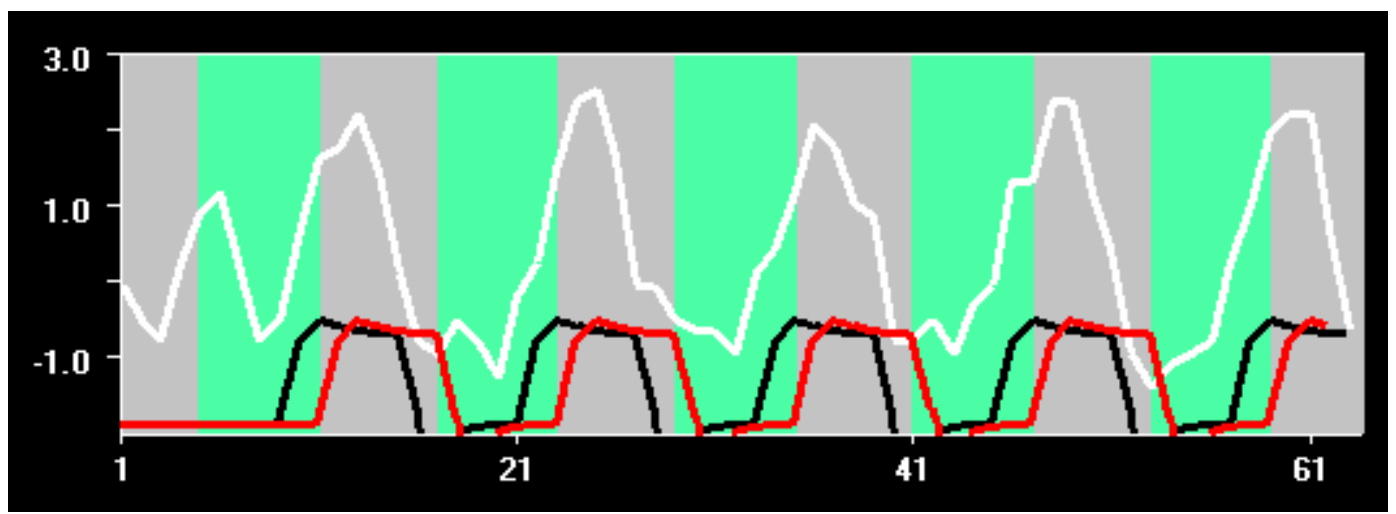

Figura 9.1 O sinal apresentado em branco é melhor correlacionado com a função preditora apresentada em preto. A função que melhor representa o tempo ao pico do sinal é a função apresentada em vermelho, indicando a necessidade de aplicação de outros métodos para a deteç̧ão do atraso da resposta hemodinâmica.

Este trabalho abre, ainda, a possibilidade de se fazer um estudo da reatividade vascular dos diferentes territórios, ACA, ACM e ACP, em resposta a alterações de $\mathrm{PCO}_{2}$ e $\mathrm{PO}_{2}$. Esse exame pode, ainda, ser complementado pela aquisição de angiografias, para confirmar se realmente as diferenças nas respostas dos diferentes ramos arteriais, observadas neste trabalho, são acompanhadas por alterações anatômicas. 
Ainda, o polígono de Willis, em alguns casos, permite a manutenção de um fluxo sangüíneo adequando em todo o cérebro, em caso de obstrução de uma ou mais das quatro artérias que o irrigam. Porém, o polígono possui muitas variações, que tornam imprevisível o comportamento diante de, por exemplo, um quadro de obstrução vascular. Em muitos indivíduos, o circuito é incompleto, faltando uma ou mais artérias comunicantes. Apesar disso, não há qualquer prejuízo funcional. Portanto, seria interessante verificar a circulação sangüínea no polígono que justifiquem, por exemplo, o fato de o território da ACP não ter aparecido como último território a responder a apnéia, após a inspiração, em alguns voluntários.

A variabilidade observada entre indivíduos também pode estar relacionada ao fato dos aumentos das $\mathrm{PaCO}_{2}$ e $\mathrm{PaO}_{2}$ ocorrerem diferentemente em cada voluntário, dependendo da capacidade respiratória de cada um. Por isso, seria interessante o acompanhamento, através de capinógrafos, das $\mathrm{PaCO}_{2}$ e $\mathrm{PaO}_{2}$ para poder quantificar esses aumentos durante o protocolo de apnéia.

Seria interessante, também, realizar um estudo de parâmetros que influenciam o sinal BOLD (CBF e metabolismo de oxigênio) para que esses possam ser incorporados no modelo para obtenção dos mapas de B-CBV. Assim, seria possível uma quantificação absoluta do volume sangüíneo. Essa quantificação não-invasiva de CBV, e de sua mudança durante testes fisiológicos, promete melhorar nossa compreensão de mecanismos hemodinâmicos do cérebro e do sinal da fMRI, incluindo a avaliação de potenciais alterações do estado vascular em relação à ativação neuronal.

Embora os mapas de B-CBV tenham sido obtidos de forma preliminar, os resultados demonstram uma boa delimitação de substância branca e cinza. Desse modo, abre-se a possibilidade de ampliar esses estudos a pacientes que possuam alterações perfusionais, para observar se esses são capazes de detectar tais alterações.

Para avaliar melhor o sinal observado no CSF, é necessária a produção de phantoms com a mesma composição de íons do líquido cerebroespinhal, contendo soluções salinas de composição próxima ao do CSF. Posteriormente, fazer medidas de MRI, ponderadas em $\mathrm{T}_{2}{ }^{*}$, para medir se pequenas variações de volume desses íons são capazes de causar uma mudança significativa no tempo de relaxação $T_{2}{ }^{*}$. Ainda, seria interessante determinar se as mudanças na intensidade do sinal do CSF, 
em imagens ponderadas em $\mathrm{T}_{2}{ }^{*}$, poderiam ser detectadas com a administração de $\mathrm{O}_{2}$ suplementar, em experiências com phantoms.

Por fim, é interessante o desenvolvimento de métodos para estabelecer a relação entre a $\mathrm{PaO}_{2}$ e a $\mathrm{P}_{\mathrm{CSF}} \mathrm{O}_{2}$, com o intuito de, posteriormente, aplicar essas relações para obter valores de tensão de oxigênio no CSF de forma não-invasiva, por meio de um protocolo de apnéia. 


\section{BIBLIOGRAFIA}

AGUIRRE, G.K., ZARAHN, E., D'ESPOSITO, M. The variability of human. BOLD hemodynamic responses. NeuroImage 8, 360-369, 1998.

ALLEN, G., BUXTON, R.B., WONG, E.C., \& COURCHESNE, E. Attentional activation of the cerebellum independent of motor involvement. Science. 275(5308):1940-1943, 1997.

ANCES, B.M., GREENBERG, J.H., DETRE, J.A. The effects of graded hypercapnia on the activation flow coupling response due to forepaw stimulation in alpha-chloralose anesthetized rats. Brain Res. 911: 82-88, 2001.

ANDRÄ, W., NOWAK,H. (EDS.) (1998) Magnetism in Medicine.(WILEY-VCH, Berlin), 1998.

ANZAI, Y., ISHIKAWA, M., SHAW, D. W. W, ARTRU, A., YARNYKH, V., MARAVILLA, K.R. Paramagnetic effect of supplemental oxygen on CSF hyperintensity on fluid-attenuated inversion recovery MR images. AJNR Am J Neuroradiol 2004;25:274279.

BANDETTINI, P.A., JESMANOWICZ, A., WONG, E.C., HYDE, J.S. Processing strategies for time-course data sets in functional MRI of the human brain. Magnetic Resonance in Medicine. 30: 161-173, 1993.

BANDETTINI, P.A., WONG, E.C., HINKS, R.S., TIKOFSKY, R.S., HYDE, J.S. Time course EPI of human brain function during task activation. Magn. Reson. Med. 25, 390397, 1992.

BANDETTINI, P.A., WONG, E.C. A. hypercapnia-based normalization method for improved spatial localization of human brain activation with fMRI. NMR Biomed. 10, 197203, 1997. 
BELLIVEAU, J.W., KENNEDY JR., D.N., MCKINSTRY, R.C., BUCHBINDER, B.R., WEISSKOFF, R.M., COHEN, M.S., VEVEA, J.M., BRADY, T.J., ROSEN, B.R., Functional mapping of the human visual cortex by magnetic resonance imaging. Science 254, 716- 719, 1991.

BERNINGER, W. H, AXEL, L., NORMAN, D., NAPEL, S., REDINGTON, R. W. Functional imaging of the brain using computed tomography. Radiology 138 711-16, 1981.

BETZ, A. L., GOLDSTEIN G. W. Specialized proprerties an solute transport in brain capillaries. Annu Rev Physiol 48:241-250, 1986.

BOXERMAN, J. L., HAMBERG, L M, ROSEN, B. R., WEISSKOFF, R. M. MR contrast due to intravascular magnetic susceptibility perturbations Magn. Reson. Med. 34 555-66, 1995b.

BOXERMAN, J.L., BANDETTINI, P.A., KWONG, K.K., BAKER, J.R., DAVIS, T.L., ROSEN, B.R., WEISSKOFF, R.M., The intravascular contribution to fMRI signal change: Monte Carlo modeling and diffusion-weighted studies in vivo. Magn. Reson. Med. 34: 4 - 10, 1995a.

BROWN, G.G., EYLER ZORRILlA, L. T., GEORGY, B., KINDERMANN, S.S., WONG, E.C., BUXTON, R. B. BOLD and perfusion response to finger -thumb apposition after acetazolamide administration: differential relationship to global perfusion. J. Cereb. Blood Flow Metab. 23: 829-837, 2003.

BUXTON, R. B., ULUDAG, K., DUBOWITZ, D. J., LIU, T.T. Modeling the hemodynamic response to brain activation. Neuroimage. 24: S220-S233, 2004.

BUXTON, R.B. A hypothesis for cerebral blood flow regulation and the origin of the BOLD effect. 12th ISMRM Scientific Meeting, Kyoto, Japan, 2004.

BUXTON, R.B. The elusive initial dip. NeuroImage 13: 953- 958, 2001. 
BUXTON, R.B., MILLER, K., FRANK, L.R., WONG, E.C., 1998. BOLD signal dynamics: the balloon model with viscoelastic effects. Sixth Meeting, International Society for Magnetic Resonance in Medicine, Sydney, Australia, 1401, 1998a.

BUXTON, R.B., WONG, E.C., FRANK, L.R.. Dynamics of blood flow and oxygenation changes during brain activation: the balloon model. Magn. Reson. Med. 39, 855- 864, 1998b.

CLARE, S. Functional MRI: methods and applications. Oxford, Tese ( Doutorado). John Radcliffe Hospital. Universidade de Oxford, 1998.

COLEBATCH, J. G, MURPHY, K, MARTIN, A. J., LAMMERTSMA, A. A., TOCHONDANGUY H. J., CLARK J. C., FRISTON K. J., GUZ A., ANDADAMS L. Regional cerebral blood flow during volitional breathing in man. J Physiol 443: 91-103, 1991.

CORFIELD, D.R., MURPHY, K., JOSEPHS, O., ADAMS, L., TURNER, R. Does hypercapnia-induced cerebral vasodilation modulate the hemodynamic response to neural activation? NeuroImage. 13:1207-1211, 2001.

CRITCHLEY, H. D, CORFIELD, D. R, CHANDLER, M. P, MATHIAS, C. J, DOLAN, RJ. Cerebral correlates of autonomic cardiovascular arousal: a functional neuroimaging investigation in humans. J Physiol 523: 259-270, 2000.

CZOSNYKA, M, RICHARDS ,H K, CZOSNYKA, Z, PIECHNIK, S, PICKARD J D. Vascular components of cerebrospinal fluid compensation. J. Neurosurg. 90 752-9, 1999.

CZOSNYKA, M., CZOSNYKA, Z., MOMJIAN, S., PICKARD, J. D. Cerebrospinal fluid dynamics. Physiol. Meas. 25: R51-R76, 2004.

DAVIS, T.L., KWONG, K.K., WEISSKOFF, R.M., ROSEN, B.R., Calibrated functional MRI: mapping the dynamics of oxidative metabolism. Proc. Natl. Acad. Sci. U. S. A. 95 : 1834-1839, 1998. 
DE ARAUJO D. B., ARAUJO D., ESCORSI-ROSSET S., WICHERT-ANA L., BAFFA O., SAKAMOTO A., SANTOS A. C. fMRI in Epilepsy and Recent Advances in Spatial Memory Mapping. Journal of Epilepsy and Clinical Neurophysiology 2003;9(4):213-219.

DE ARAÚJO, D.B. Sobre neuroimagens funcionais por magnetoencefalografia e ressonância magnética: novos métodos e aplicações. Tese (Doutorado). Universidade de São Paulo. FFCLRP, 2002.

DE BOORDER, M. J., HENDRIKSE, J., GROND J. V. D. Phase-contrast magnetic resonance imaging measurements of cerebral autoregulation with a breath-hold clallenge: A feasibility study. Stroke, 35: 1350-1354, 2004.

DE ZWART, J. A., SILVA, A. C., GELDEREN P. V., KELLMAN, P., FUKUNAGA, M., CHU, R., KORETSKY, A. P., FRANK, J., A., DUYN J. H. Temporal dynamics of BOLD fMRI impulse response. NeuroImage. 24: 667-677, 2005.

DELATORRE, J.C. Hemodynamic consequences of deformed microvessels in the brain in Alzheimer's disease. Cerebrovascular pathology in Alzheimer's disease. Annals of the New York academy of scence. 826: 75-91, 1997.

DELGADO-GARCIA, J. M. Structure and function of the cerebellum. Rev. Neurol. 33(7): 635-642, 2001.

DELIGANIS, A. V, FISHER, D. J., LAM, A. M., MARAVILLA, K. R. Cerebrospinal fluid signal intensity increase on FLAIR MR images in patients under generalanesthesia: the role of supplemental O2. Radiology. 218:152-156, 2001.

DELLA JUSTINA, H. M. Variabilidade da atividade cerebral em resposta a estímulos vestibular e oculomotor avaliada por fMRI. Dissertação (mestrado). Universidade de São Paulo. FFCLRP, 2005.

DEVINSKY O, MORRELL M. J, VOGT B.A. Contributions of anterior cingulate cortex to behaviour. Brain 118: 279-306, 1995. 
DEVINSKY, O, MORRELL, M. J., VOGT, B.A. Contributions of anterior cingulate cortex to behaviour. Brain 118: 279-306, 1995.

DEVOR, A., DUNN, A.K., ANDERMANN, M.L., ULBERT, I., BOAS, D.A., DALE, A.M. Coupling of total hemoglobin concentration, oxygenation, and neural activity in rat somatosensory cortex. Neuron. 39: 353- 359, 2003.

EDELSTEIN W.A., HUTCHISON J.M.S., JOHNSON G., REDPATH T. Spin warp NMR imaging and applications to human whole body imaging. Phys Med Biol, 25(4):7516, 1980.

FENG, C.M., LIU, H.L., FOX, P.T., GAO, J.H. Comparison of the experimental BOLD signal change in event-related fMRI with the balloon model. NMR Biomed. 14: 397-401, 2001.

FINK GR, CORFIELD DR, MURPHY K, KOBAYASHI I, DET'TMERS C, ADAMS L, FRACKOWIAK RSJ, AND GUZ A. Human cerebral activity with increasing inspiratory force: a study using positron emission tomography. J Appl Physiol 81: 1295-1305, 1996.

FISEL C. R., ACKERMAN J. L., BUXTON R. B., GARRIDO L., BELLIVEAU J. W., ROSEN B. R., BRADY T. J. MR contrast due to microscopically heterogeneous magnetic susceptibility: numerical simulations and applications to cerebral physiology. Magn. Reson. Med. 17: 336-47, 1991.

FOX, P. T, RAICHLE, M. E.. Focal physiological uncoupling of cerebral blood flow and oxidative metabolism during somatosensory stimulaton in human subjects. Proc. Natl. Acad. Sci. 83: 1140-1144, 1986.

FRISTON, K.J., Bayesian estimation of dynamical systems: an application to fMRI. NeuroImage. 16: 513-530, 2002.

FRISTON, K.J., MECHELLI, A., TURNER, R., PRICE, C.J. Nonlinear responses in fMRI: the Balloon model, Volterra kernels, and other hemodynamics. NeuroImage 12: 466- 477, 2000. 
FRISTON K. J., FLETCHER P., JOSEPHS O., HOLMES A. P., RUGG M. D., TURNER R. Event-Related: Characterizing diferential responses. Neuroimaging, 7: 3040, 1998.

FRISTON, K.J., WILLIAMS, S., HOWARD, R., FRACKOWIAK, R.S., TURNER, R. Movement-related effects in fMRI timeseries. Magnetic Resonance in Medicine. 35: 346$355,1996$.

GENOVESE, C. R., LAZAR, N. A., NICHOLS, T. thesholding of statistical maps in functional neuroimaging using the false discovery rate. Neuroimage. 15: 870-878, 2002.

GOTMAN, J., GROVA, C., BAGSHAw, A., KOBAYASHI, E., AGHAKHANI, Y., DUBEAU, F.. Generalized epileptic discharges show thalamocortical activation and suspension of the default state of the brain Source: Proceedings of the National Academy of science of the United States of America 102 (42): 15236-15240, 2005.

GRANT R, CONDON B, MOYNS S, PATTERSON J, HADLEY D, TEASDALE G. Temporal physiochemical changes during in vitro relaxation time measurements: the cerebrospinal fluid. Magn Reson Med. 6:397- 402, 1988.

GRUBB, R.L., RAICHLE, M.E., EICHLING, J.O., TER-POGOSSIAN, M.M., The effects of changes in PaCO2 on cerebral blood volume, blood flow, and vascular mean transit time. Stroke, 5: 630-639, 1974.

GU H., LU H. , YE F. Q., STEIN E. A., YANG Y. Noninvasive quantification of cerebral blood volume in humans during functional activation. NeuroImage 30377 - 387, 2006.

GU H., STEIN E. A., YANG Y.H. Nonlinear responses of cerebral blood volume, blood flow and blood oxygenation signals during visual stimulation. Magn. Reson Imag. 23 (9): 921-928,2005.

GUYTON, A. C., HALL, J. E. Tratado de fisiologia médica. Guanabara Koogan, 9 a ed, 1996, Philadelphia. 
HANDWERKER, D. A., OLLINGER, J. M, D'ESPOSITO M. Variation of BOLD hemodynamic response across subjects and brain regions and their effects on statistical analyses. NeuroImage. 21: 1639-1651, 2004.

HEDEHUS M., STEENSGAARD .A, ROSTRUP E., LARSSON H. B. W. Investigation of the linear relation between $\mathrm{R} * 2$ and gadolinium concentration in vivo Proc. ISMRM 5th Annu. Meeting 1792, 1997.

HOFMANN E., BECKER T., MEIXENSBERGER J., JACKEL M., SCHNEIDER M., REICHMANN H. Disturbance of cerebrospinal-fluid (CSF) circulation- Neurophychiatric syntpms and neuropsychiatric symptoms and neuroradiological contribuition. Journal of Neural Transmission-Geral section 99 (1-3): 79-88 1995.

HOGE, R.D., ATKINSON, J., GILL, B., CRELIER, G.R., MARRETT, S., PIKE, G.B., Linear coupling between cerebral blood flow and oxygen consumption in activated human cortex. Proc. Natl. Acad. Sci. U. S. A., 96: 9403- 9408, 1999.

HORN, E. M., WALDROP, T. G. Suprapontine control of respiration Respir. Physiol. 114: 201-211, 1998.

HUETTEL, S.A., SONG, A.W., \& MCCARTHY, G. Functional Magnetic Resonance Imaging. $1^{\text {st }}$ ed. Sunderland: Sinauer Associates, 2004.

IIDAKA T., MATSUMOTO A., HANEDA K., OKADA T., SADATO N. Hemodynamic and electrophysiological relationship involved in human face processing: Evidence from a combined fMRI-ERP study Brain and Cognition 60 (2): 176-186, 2006

JANKOWSKA L, GRIEB P. Relationship between arterial and cisternal CSF oxygen tension in rabbits. Am J Physiol. 236:F220-225, 1979.

JONES, M., BERWICK, J., JOHNSTON, D., MAYHEW, J. Concurrent optical imaging spectroscopy and laser-Doppler flowmetry: the relationship between blood flow, oxygenation, and volume in rodent barrel cortex. NeuroImage. 13: 1002-1015, 2001. 
KANDEL, E.R., SCHWARTZ, J.H., JESSELL, T. M. Principles of neural science. $4^{\text {th }}$ ed. New York: McGraw-Hill, 2000.

KASTRUP A, LI T. Q., GLOVER G. H., MOSELEY M. E., cerebral blood flow related signal changes during breath holding. AJNR Am J Neuroradiol 20: 1233-1238, 1990.

KASTRUP A, LI T-Q, GLOVER G. H., MOSELEY M. E. Cerebral Blood Flow-Related Signal Changes during Breath-Holding American Journal of Neuroradiology. 20 (7): 1233-1238, 1999a.

KASTRUP A., KRÜGER G., GLOVER G. H., NEUMANN-HAEFELIN T., MOSELEY M. E. Regional variability of cerebral blood oxygenation response to hypercapnia. NeuriImage. 10: 675-681, 1999b.

KASTRUP, A., KRÜGER, G., HAEFELIN-NEUMANN, T., MOSELEY, M. E., Assesment of cerebrovascular reactivity with functional magnetic resonance imaging: comparison of $\mathrm{CO}_{2}$ and breath holding. Magn. Reson. Imag. 19: 13-20, 2001.

KASTRUP, A., KRUGER, G., NEUMANN-HAEFELIN, T., GLOVER, G.H., MOSELEY, M.E., Changes of cerebral blood flow, oxygenation, and oxidative metabolism during graded motor activation. NeuroImage 15: 74- 82, 2002.

KENMA L. J., POSSE S. Effect of Respiratory CO2 changes on the temporal dynamics of the hemodynamic response in functional MR imaging. Neuroimage. 14: 642-649, 2001.

KENNAN R. P., ZHONG J., GORE J. C. Intravascular susceptibility contrast mechanisms in tissues Magn. Reson. Med. 31 9-21, 1994.

KIM, J.J. \& THOMPSON, R.F. Cerebellar circuits and synaptic mechanisms involved in classical eyeblink conditioning. Trends Neurosci. 20(4): 177-181, 1997.

KIM, S.G., RICHTER, W., UGURBIL, K., Limitations of temporal resolution in functional MRI. Magn. Reson. Med. 37, 631- 636,1997. 
KIM, S.G., ROSTRUP, E., LARSSON, H.B.W., OGAWA, S., PAULSON, O.B. Determination of relative $\mathrm{CMRO} 2$ from $\mathrm{CBF}$ and BOLD changes: significant increase of oxygen consumption rate during visual stimulation. Magn. Reson. Med. 41: 1152-1161, 1999.

KOECHLIN, E., BASSO, G., PIETRINI, P., PANZER, S., GRAFMAN, J. The role of the anterior prefrontal cortex in human cognition. Nature 399, 148-151,1999.

KRUGGEL, F., VON CRAMON, D.Y., Temporal properties of the hemodynamic response in functional MRI. Hum. Brain Mapp. 8, 259-271, 1999.

KUWABARA, H., OHTA, S., BRUST, P., MEYER, E., GJEDDE, A. Density of perfused capillaries in living human brain during functional activation. Prog. Brain Res. 91: 209-215, 1992.

LE DOUX, J. The Emotional Brain (Simon \& Schuster, New York), 1998.

LE, T. H., PARDO J. V., HU X. 4 T-fMRI study of nonspatial shifting of selective attention: Cerebellar and Parietal Contributions. J Neurophysiol 79: 1535-1548, 1998

LEE, A.T., GLOVER, G.H., MEYER, C.H., Discrimination of large venous vessels in time-course spiral blood-oxygen-level-dependent magneticresonance functional neuroimaging. Magn. Reson. Med. 33, 745- 754, 1995.

LENT, R. Cem Bilhões de Neurônios: Conceitos fundamentais de neurociência. Atheneu $2^{a}$ ed, 2004, São Paulo.

Li T-Q, Kastrup A., Takahashi M. A., Moseley M. E. Functional MRI of human brain during breath holding by BOLD and FAIR techniques. Neuroimage 9 (2): 243-249,1998.

LI, T.Q., KASTRUP, A., MOSELEY, M.E., GLOVER, G.H. Changes in baseline cerebral blood flow in humans do not influence regional cerebral blood flow response to photic stimulation. J. Magn. Reson. Imaging 12: 757- 762, 2000. 
LI, T.Q., MOSELEY, M.E., GLOVER, G. A FAIR study of motor cortex activation under normo- and hypercapnia induced by breath challenge. NeuroImage. 10: 562-569, 1999.

LIAO, C. H., WORSEY, K. J., PILINE, J. B., ASTON A. D., DUNCAN, G. H., EVANS A. C. Estiming the delay of the fMRI response. Neuroimage. 16: 593-606, 2002.

LIU, H-L., HUANG J-C., WU, C-T., HSU Y-Y. Detectability of blood oxygentation leveldependent signal changes during short breath hold duration. Magnetic Resonance Imaging. 20: 643-648, 2002.

LOGOTHETIS, N. K., The neural basis of the blood-oxygen-level-depenent functional magnetic resonance imaging signal. Philosophical Transactions of the Royal Society of London Series B-Biological Sciences 357 (1424): 1003-1037, 2002.

LU, H., GOLAY, X., PEKAR, J.J., VAN ZIJL, P.C., Functional magnetic resonance imaging based on changes in vascular space occupancy. Magn. Reson. Med. 50, 263- 274, 2003.

LYTHGOE DJ, WILLIAMS SC, CULLINANE M, MARKUS HS. Mapping of cerebrovascular reactivity using BOLD magnetic resonance imaging. Magn Reson Imaging, 17:495-502, 1999.

MACHADO A., Neuroanatomia Funcional. Livraria Atheneu, 1991.

MALONEK, D., GRINVALD, A. Interactions between electrical activity and cortical microcirculation revealed by imaging spectroscopy: implications for functional brain mapping. Science, 272: 551- 554, 1996.

MANDEVILLE, J.B., MAROTA, J.J.A., AYATA, C., MOSKOWITZ, M.A., WEISSKOFF, R.M., ROSEN, B.R. MRI measurement of the temporal evolution of relative CMRO2 during rat forepaw stimulation. Magn. Reson. Med. 42: 944- 951, 1999a.

MANDEVILLE, J.B., MAROTA, J.J.A., AYATA, C., ZAHARCHUK, G., MOSKOWITZ, M.A., ROSEN, B.R., WEISSKOFF, R.M. Evidence of a cerebrovascular post- 
arteriole Windkessel with delayed compliance. J. Cereb. Blood Flow Metab. 19: 679-689, 1999b.

MANDEVILLE, J.B., MAROTA, J.J.A., KOSOFSKY, B.E., KELTNER, J.R., WEISSLEDER, R., ROSEN, B.R., WEISSKOFF, R.M. Dynamic functional imaging of relative cerebral blood volume during rat forepaw stimulation. Magn. Reson. Med. 39: 615-624, 1998.

MARRETT, S., GJEDDE, A., Changes of blood flow and oxygen consumption in visual cortex of living humans. Adv. Exp. Med. Biol., 413: 205- 208, 1997.

MASKILL D, MURPHY K, MIER A, OWEN M, AND GUZ A. Motor cortical representation of the diaphragm in man. J Physiol. 443:105-121, 1991.

MCKAY L. C., EVANS K. C., FRACKOWIAK R. S. J., CORFIELD D. R. Neural correlates of voluntary breathing in humans. J Appl Physiol 95: 1170-1178, 2003.

MIEZIN, F.M., MACCOTTA, L., OLLINGER, J.M., PETERSEN, S.E., BUCKNER, R.L. Characterizing the hemodynamic response: effects of presentation rate, sampling procedure, and the possibility of ordering brain activity based on relative timing. NeuroImage 11, 735-759, 2000.

MILDNER, T., NORRIS, D.G., SCHWARZBAUER, C., WIGGINS, C.J. A qualitative test of the balloon model for BOLD-based MR signal changes at 3T. Magn. Reson. Med. 46: 891- 899, 2001.

MURPHY K, MIER A, ADAMS L, AND GUZ A. Putative cerebral cortical involvement in the ventilatory response to inhaled CO2 in conscious humans. J Physiol. 420: 1-18, 1990.

OBATA, T., LIU, T.T., MILLER, K.L., LUH, W.M., WONG, E.C., FRANK, L.R., BUXTON, R.B. Discrepancies between BOLD and flow dynamics in primary and supplementary motor areas: application of the balloon model to the interpretation of BOLD transients. NeuroImage 21: 144-153, 2004. 
OGAWA, S., MENON, R.S., TANK, D.W., KIM, S.-G., MERKLE, H., ELLERMAN, J.M., UGURBIL, K., Functional brain mapping by blood oxygenation level-dependent contrast magnetic resonance imaging: a comparison of signal characteristics with a biophysical model. Biophys. J. 64: 803-812, 1993.

OSTERGOORD L, WEISSKOFF R. M., CHESLER D. A., GLYDENSTED C, ROSEN B. R., High resolution measuremtne of cerebral blood flow using intravascular tracer blous passages. Part I: mathematical approach and statistical analysis. Mag. Reson. Med. 36:726-36, 1996b.

PAPPENHEIMER, J. R. Harvey Lect. 71-94: 1965.

PASSINGHAM RE. The Frontal Lobes and Voluntary Action. Oxford, UK: Oxford University Press, 1993.

PASSINGHAM, R. E. The Frontal Lobes and Voluntary Action. Oxford, UK: Oxford University Press, 1993.

PENFIELD, W. E BOLDREY, E. Somatic motor and sensory representations in the cerebral cortex of man as studied by electrical stimulation. Brain, 60: 389-443, 1937.

PFEUFFER, J., VAN DE MOORTELE, P.F., YACOUB, E., SHMUEL, A., ADRIANY, G., ANDERSEN, P., MERKLE, H., GARWOOD, M., UGURBIL, K., HU, X. Zoomed functional imaging in the human brain at 7 Tesla with simultaneous high spatial and high temporal resolution. NeuroImage 17, 272-286, 2002.

POSSE, S. OLTHOFF, U., WECKESSER, M., JÄNCKER L., GÄRTNER, H-W. M-G., DAGER S. R. Regional dynamic signal changes during controlled hyperventilation assessed with blood level-dependent functional MR. AJNR Am J Neuroradiol. 18: 17631770, 1997.

RAMNANI N., OWEN, A. M. Anterior prefrontal cortex: Insights into function from anatomy and neuroimaging. Nature Reviews Neuroscience 5 (3): 184-194, 2004 
RAMSAY SC, ADAMS L, MURPHY K, CORFIELD DR, GROOTOONK S, BAILEY DL, FRACKOWIAK RSJ, AND GUZ A. Regional cerebral blood flow during volitional expiration in man: a comparison with volitional inspiration. J Physiol 461: 85-101, 1993.

RIECKER, A. GRODD, W., KLOSE, U., SHULZ, J., GRÖSCHEL K., ERB, M., ACKERMANN H., KASTRUP A. Relation between regional functional MRI activation and vascular reactivity to carbon dioxide during normal aging. Journal of Cerebral Blood Flow \& Metabolism. 23: 565-573, 2003.

ROC, A. C, WANG, J. J, ANCES, B. M, LIEBESKIND, D. S, KASNER, S. E, DETRE, J. A. Altered hemodynamics and regional cerebral blood flow in patients with hemodynamically significant stenoses Stroke 37 (2): 382-387, 2006.

ROSEN B. R., BELLIVEAU J. W., VEVEA J., MAND BRADY T. J. Perfusion imaging with NMR contrast agents Magn. Reson. Med. 14 249-65, 1990.

ROSTRUP E, LARSSON HB, TOFT PB, GARDE K, THOMSEN C, RING P, SEITZ, R.J., ROLAND, P.E., Vibratory stimulation increases and decreases the regional cerebral blood flow and oxidative metabolism: a positron emission tomography (PET) study. Acta Neurol. Scand. 86: 60-67, 1992.

ROSTRUP E., LARSSON H. B. W., TOFT P. B., GARDE K., THOMSEN C., RING P., SONDERGAARD L., HENRIKSEN O. Functional MRI of CO2 induced increase in cerebral perfusion. NMR in Biomedicine 7 (1-2): 29-34, 1994.

ROSTRUP, E., LAW, I., BLINKENBERG, M., LARSSON, H.B., BORN, A.P., HOLM, S., PAULSON, O.B. Regional differences in the CBF and BOLD responses to hypercapnia: a combined PET fMRI study. NeuroImage 11, 87-97, 2000.

SALMERON, B. J., STEIN, E. A. Pharmacological applications of magnetic resonance imaging. Psychopharmacol. Bull. 36, 102- 129, 2002. 
SCHETTINI A., ANDWALSH E. K., CSF dynamics and cerebral hemodynamics in ATPinduced hypotension Intracranial Pressure VIII. ed C J Avezaat, J H M Eijndhoven, A I R Maas and J T J Tans (Berlin: Springer) 738-43, 1993

SCHETTINI A., WALSH E. K. Brain tissue elastic behavior and experimental brain compression Am. J. Physiol. 255 R799-805, 1988.

SEITZ, R.J., ROLAND, P.E. Vibratory stimulation increases and decreases the regional cerebral blood flow and oxidative metabolism: a positron emission tomography (PET) study. Acta Neurol. Scand. 86: 60-67, 1992.

SILVESTRINI M, TROISI E, MATTEIS M, CUPINI LM, CALTAGIRONE C. Transcranial Doppler assessment of cerebrovascular reactivity in symptomatic and asymptomatic severe carotid stenosis. Stroke, 27:1970-3, 1996.

SONDERGAARD L, HENRIKSEN O. Functional MRI of CO2 induced increase in cerebral perfusion. NMR Biomed, 7:29 -34, 1994.

STARMER C. F., CLARK D. O. Computer computations of cardiac output using the gamma function J. Appl. Phys. 28 219-20, 1970.

TALAIRACH, J., TOURNOUX, P. Co-plannar stereotaxic Atlas of the human brain. Thieme Medical Publishers, New York., 1988

THACH, W.T., GOODKIN, H.P.., \& KEATING, J.G. The cerebellum and the adaptive coordination of movement. Annu. Rev. Neurosci. 15: 403-442, 1992.

THIERRY, G., BOULANOUAR, K., KHERIF, F., RANJEVA, J.P., DEMONET, J.F. Temporal sorting of neural components underlying phonological processing. NeuroReport 10, 2599-2603, 1999.

THOMAS C., COUNSELL C., WOOD P., ADAMS G. E. Use of F-19 Nuclear-MagneticResonance spectroscopy and hydraline for measuring for measuring dynamic changes in 
blood perfusion volume in tumor mice. JOURNAL OF THE NATIONAL CANCER INSTITUTE 84 (3): 174-180,1992.

THOMAS D. L, LYTHGOE M. F., PELL G S., CALAMANTE F., ORDIDGE R. J The measurement of diffusion and perfusion in biologicalsystems using magnetic resonance imaging Phys. Med. Biol. 45 R97-R138,2000

THOMASON, M. E., BURROWS B. E., GABRIELI, J. D. E., GLOVER G. H. Breath holding reveals difference in fMRI BOLD signal in children and adults. NeuroImage. 25: 824-837, 2005.

TORONOV, V., WALKER, S., GUPTA, R., CHOI, J.H., GRATTON, E., HUEBER, D., WEBB, A. The roles of changes in deoxyhemoglobin concentration and regional cerebral blood volume in the fMRI BOLD signal. NeuroImage 19: 1521-1531, 2003.

VARGHA-KHADEM, F., GADIAN, D.G.; WATKINS, K.E., CONNELLY, A, VAN PAESSCHEN, W., MISHKIN, M. Differentialeffects of early hippocampal pathology on episodic and semantic memory. Science, 227, 376-380, 1997.

VENKATESH B, BOOTS RJ, TOMLINSON E, JONES RDM. The continuous measurement of cerebrospinal fluid gas tensions in critically ill neurosurgical patients: a prospective observational study. Intensive Care Med. 25:599-605, 1999.

VENKATESH, B, BOOTS, R. J., TOMLINSON, E., JONES, R. D. M. The continuous measurement of cerebrospinal fluid gas tensions in critically ill neurosurgical patients: a prospective observational study. Intensive Care Med. 25:599-605, 1999.

VILLRINGER A, ROSEN B. R., BELLIVEAU J. W. Dynamic imaging with lanthanide chelates in normal brain: contrast due to magnetic susceptibility effects Magn. Reson. Med. 6 164-74, 1988

WEISSKOFF R. M., ZUO C. S., BOXERMAN J. L., ROSEN B. R. Microscopic susceptibility variation and transverse relaxation: theory and experiment Magn. Reson. Med. 31 601-10, 1994. 
WISE, R. G., IDE, K., POULIN M. J., TRACEY. Rsting Flutuation in arterial carbon dioxide induce significant low frequency variation in BOLD signal. NeuroImage. 21: 16521664, 2004.

WOODS, R.P., CHERRY, S.R., MAZZIOTTA, J.C. Rapid automated algorithm for aligning and reslicing PET images. Journal of Computer Assisted Tomography. 16: 620-633, 1992.

WORSLEY, K. J., MARRETT, S., NEELIN, P., VANDAL, A. C., FRISTON, K. J., EVANS, A. C. A unified statistical approach for determining significant signal in images of cerebral activation. Hum. Brain Mapping. 4: 58-73, 1995.

YABLONSKY, D.A., HAACKE, E.M., Theory of NMR signal behavior in magnetically inhomogeneous tissues: the static dephasing regime. Magn. Reson. Med. 32: 749- 763, 1994.

YANG G; CHEN G; EBNER T. J; IADECOLA C. Nitric oxide is the predominant mediator of cerebellar hyperemia during somatosensory activation in rats American Journal of Physiology-Regulatory integrative and comparative Physiology. 277 (6): R1760-R1770, 1999.

YARNELL P, MERRIL CR, CHARLTON G, OMMAYA AK. Oxygen tension dynamics in the cerebrospinal fluid. Trans Am Neurol Assoc. 92:295-296, 1967.

ZAHARCHUK, G., MARTIN, A. J., ROSENTHAL, G., MANLEY, G. T., DILLON, W. P. Measurement of Cerebrospinal Fluid Oxygen Partial Pressure in Humans Using MRI Magnetic Resonance in Medicine 54:113-121, 2005.

ZIYER, S., RICK J., REINHARD, M., HETZEL, A., MADER, I., SPECK, O. Blood oxygen level-dependent MRI of cerebral CO2 reactivity in severe carotid stenosis and occlusion. Stroke. 36: 751-756, 2005. 


\section{ApÊNDice A}

\section{Ressonância Magnética Nuclear (Nuclear Magnetic Resonance - NMR)}

Na técnica de Ressonância Magnética (MR) aplicada à medicina trabalha-se principalmente com as propriedades magnéticas do núcleo de hidrogênio $\left({ }^{1} \mathrm{H}\right)$, que é o menor núcleo que existe e consta de um próton. Todas as partículas elementares exibem uma propriedade quântica denominada spin (que é um momento angular intrínseco). Além do spin, os prótons, por serem eletricamente carregados, possuem um momento magnético associado a eles. A imagem de ressonância magnética baseia-se no sinal proporcionado pelo núcleo de hidrogênio ${ }^{1} \mathrm{H}$, por duas razões: o sinal magnético do núcleo do ${ }^{1} \mathrm{H}$ é bem superior ao de outros núcleos magnéticos, e, o hidrogênio é o átomo mais abundante no corpo humano, principalmente devido à concentração da água.

Normalmente os prótons encontrados no corpo possuem orientações completamente aleatórias, fazendo com que o momento magnético total seja zero. No entanto, quando colocados na presença de um campo magnético estático, os prótons tendem a se orientar com o mesmo, fazendo com que haja um momento magnético diferente de zero.

\section{A.1 Teoria quântica da NMR}

Pela física quântica, o diagrama dos níveis de energia para um núcleo de spin I, na presença de um campo magnético, será dado por $(2 \mathrm{I}+1)$ níveis discretos de energia. Assim, o diagrama de níveis de energia para o hidrogênio $(I=1 / 2)$ irá consistir de dois níveis. Isso indica duas possíveis orientações do momento magnético nuclear, paralela e antiparalela ao campo magnético externo, sendo a orientação paralela a de mais baixa energia. Como é comum na natureza se buscar estados de mais baixa energia, quando os prótons são colocados na presença de um campo magnético estático, o número de prótons paralelos será maior que o número de prótons antiparalelos. Particularmente, na situação de equilíbrio térmico, a proporção 
entre entes paralelos e antiparalelos ao campo aplicado é governada pela equação de Boltzmann, ou distribuição de Boltzmann (Andrä et al., 1998):

$$
\frac{N_{\text {par }}}{N_{\text {antipar }}}=e^{\frac{-\Delta E}{K_{b} T}} .
$$

Sendo $\mathrm{N}_{\text {par }}$ e $\mathrm{N}_{\text {antipar }}$ Os números de prótons paralelos e antiparalelos respectivamente, $\Delta \mathrm{E}$ é a diferença de energia entre o estado paralelo e o antiparalelo, $\mathrm{T}$ é a temperatura e $K_{b}$ é a constante de Boltzmann.

Devido a esta maior quantidade de prótons paralelos, um vetor magnético $\vec{M}$ é criado. É este vetor magnetização que, através de algumas manipulações irá induzir uma corrente em uma bobina receptora e produzir um sinal de ressonância magnética.

Pela lei da indução de Faraday, para que o momento magnético seja capaz de induzir uma corrente na bobina, ele tem que produzir um campo magnético variável dentro da bobina. E para isso, deve-se mudar a orientação do vetor $\vec{M}$. No equilíbrio térmico, o vetor magnetização criado pelos prótons na presença do campo magnético estático é constante em módulo e em direção (paralelo ao campo magnético) e assim não pode induzir uma corrente na bobina receptora. Para ser capaz de induzir um sinal, a magnetização deve mover-se desta posição, isto quer dizer que o equilíbrio entre as populações de prótons paralelos e antiparalelos deve ser perturbado.

O modelo quântico simplificado, que aqui foi utilizado, não é útil para explicar o movimento do vetor magnetização, mas explica como o equilíbrio entre os prótons paralelos e antiparalelos pode ser perturbado. Esta perturbação pode ser feita dando-se energia para os prótons do tecido, fazendo com que haja mais transições do estado de mais baixa energia para o de mais alta do que transições do de mais alta para o de mais baixa energia. Isso pode ser feito se os prótons forem irradiados com ondas de rádio, de determinada freqüência.

Ondas de rádio são um tipo de radiação eletromagnética. A radiação eletromagnética, além de possuir características ondulatórias, também possui características corpusculares. A radiação eletromagnética teria, então, uma natureza dual, sen- 
do composta por corpúsculos sem massa denominados fótons, cuja energia, E, depende unicamente da freqüência da radiação:

$$
E=h v .
$$

Em que $h$ é a constante de Planck e $v$ é a freqüência da radiação.

Se prótons, que estão na presença de um campo magnético, forem irradiados com radiação eletromagnética, alguns destes irão ser induzidos a absorver energia desta radiação e sair de um estado de mais baixa energia para um de mais alta energia. Mas isso, só irá ocorrer se a condição de ressonância for satisfeita. Essa condição diz que a energia do fóton que compreende a radiação deve ser exatamente igual à diferença de energia $(\Delta \mathrm{E})$ entre os dois estados de energia que o próton quer transitar. Isto é:

$$
\Delta E=h v .
$$

Para um ente de spin $1 / 2$ a diferença de energia entre os dois níveis é dada por:

$$
\Delta E=\hbar \gamma B_{0}
$$

Sendo $\gamma$ a razão giromagnética, $\mathrm{B}_{0}$ o módulo do campo magnético aplicado e $\hbar$ a constante de Planck dividida por $2 \pi$. Portanto, se substituindo o valor de $\Delta \mathrm{E}$ na equação (A.3), obtém-se:

$$
v=\frac{\gamma B_{0}}{2 \pi}=\frac{\omega_{L}}{2 \pi} \Rightarrow \omega_{L}=\gamma B_{0} .
$$

Em que, $\omega_{\mathrm{L}}$ é a freqüência angular do fóton.

A ressonância é, pois, o fenômeno pelo qual spins em estados de energia mais baixa, submetidos à aplicação de um campo magnético $\vec{B}$, são levados a ocupar estados de energia mais alta, pela absorção de fótons cuja freqüência é igual a $\omega_{\mathrm{L}}$.

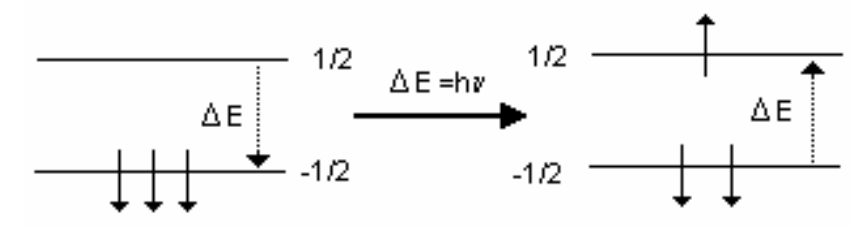

Figura A.1. Diagrama da transição de um próton entre dois estados quânticos através da absorção de um fóton de energia hv. 
O modelo quântico simplificado vê a interação entre fótons e prótons como troca de energia. Isso permite explicar a mudança de posição dos spins paralelos e antiparalelos, mas não explica como esse momento magnético pode induzir uma corrente na bobina e produzir um sinal MR. Para isso é preciso utilizar um modelo clássico.

\section{A.2 Modelo clássico da ressonância magnética}

Pela física clássica, quando prótons são colocados na presença de um campo magnético estático, este irá exercer um torque sobre o momento magnético fazendo com que ele tente se alinhar com o campo. Contudo, como os prótons exibem a propriedade de spin, o torque não irá alinhar os dois vetores coincidentemente, mas provocará o aparecimento de um movimento de precessão em torno do campo.

E sabido que a relação existente entre o momento magnético de uma carga e o seu momento angular associado $(L)$ é dada por:

$$
\mu=\gamma L
$$

sabendo, também, que:

$$
\tau=\frac{d \vec{L}}{d t}=\vec{\mu} \times \vec{B} \Rightarrow \frac{d \vec{\mu}}{d t}=\gamma \vec{\mu} \times \vec{B}
$$

em que $\vec{\tau}$ é o torque que o campo magnético, $\vec{B}$, exerce sobre o momento magnético.

A equação (A.7) diz que a razão com que o núcleo precessiona em um campo magnético depende da magnitude de $\vec{\mu}$ e de $\vec{B}$.

Em qualquer experimento de ressonância magnética nuclear os módulos de $\vec{\mu}$ e $\vec{B}$ são constantes. Como conseqüência, o momento magnético macroscópico irá precesionar com freqüência constante em torno da direção do campo magnético.

A taxa de variação temporal de um vetor genérico $\vec{\varphi}$ pode ser escrita como:

$$
\frac{d \vec{\varphi}}{d t}=\Omega x \vec{\varphi}
$$


em que $\Omega$ é a velocidade angular ou freqüência instantânea de $\vec{\varphi}$.

Assim, sendo $\omega_{\mathrm{L}}$ a freqüência de precessão de $\vec{\mu}$, pode-se escrever:

$$
\frac{d \vec{\mu}}{d t}=\overrightarrow{\omega_{L}} \times \vec{\mu}=-\vec{\mu} \times \overrightarrow{\omega_{L}}=\gamma(\vec{\mu} \times \vec{B}),
$$

e, portanto:

$$
\overrightarrow{\omega_{L}}=-\gamma \vec{B} \Rightarrow \omega_{L}=\gamma B_{0}(\mathrm{rad} / \mathrm{s})
$$

em que, $\omega_{\mathrm{L}}$ e $\mathrm{B}_{0}$ são os módulos de $\overrightarrow{\omega_{L}}$ e $\vec{B}$ respectivamente. Essa é a equação fundamental da ressonância e recebe o nome especial de equação de Larmor. Se o valor de $\gamma$ para um próton é conhecido, então, pode-se calcular a freqüência de ressonância, $\omega_{L}$, para qualquer campo magnético. O sinal negativo significa que o movimento esta na direção indicada na Figura A.2.

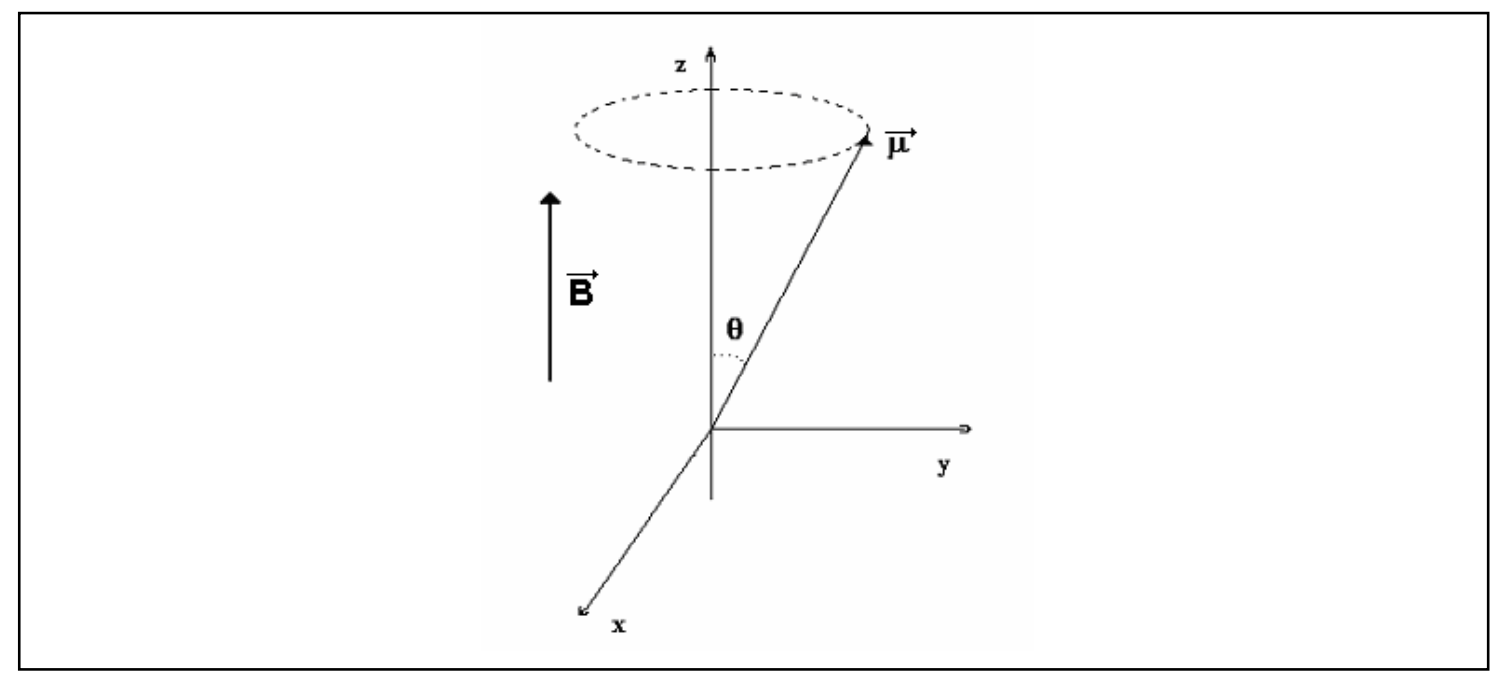

Figura A.2. Apresentação esquemática do momento magnético em relação a um campo magnético aplicado.

Até agora, foi descrito o movimento de um único próton. Porém, devido aos efeitos da interação do próton com outros prótons e moléculas, este movimento é bastante complicado. Além disso, as medidas realizadas em NMR são feitas normalmente sobre quantidades de matéria que contêm uma quantidade de núcleos da ordem do número de Avogadro. Portanto, o valor médio de $\vec{\mu}$ sobre um elemento de matéria é efetivamente o valor medido no laboratório. A esse valor médio é dado o nome de magnetização, e é representado pelo vetor $\vec{M}$,cujo movimento é bem mais simples. 
Quando $\vec{M}$ está na presença de um campo magnético, esse também exibirá um movimento de precessão análogo, que será governado pela equação:

$$
\frac{d \vec{M}}{d t}=\gamma(\vec{M} \times \vec{B}) .
$$

Supondo um campo estático aplicado, no tempo, e constante na direção z, de acordo com a Figura A.3 pode-se escrever $\vec{M}$ como:

$$
\begin{aligned}
& \vec{M}=M_{r}[\sin (\theta) \cos (\varphi) \hat{i}+\sin (\theta) \sin (\varphi) \hat{j}+\cos (\theta) \hat{k}] \\
& \vec{B}=B_{0} \hat{k},
\end{aligned}
$$

substituindo (A.12) em (A.11) obtém-se um conjunto de equações dado por:

$$
\begin{aligned}
& \cos (\theta) \cos (\varphi) \frac{d \theta}{d t}+\operatorname{sen}(\theta) \operatorname{sen}(\varphi) \frac{d \varphi}{d t}=\gamma B_{0} \operatorname{sen}(\theta) \operatorname{sen}(\varphi), \\
& \cos (\theta) \operatorname{sen}(\varphi) \frac{d \theta}{d t}+\operatorname{sen}(\theta) \cos (\varphi) \frac{d \varphi}{d t}=\gamma B_{0} \operatorname{sen}(\theta) \cos (\varphi), \\
& \frac{d \theta}{d t}=0 .
\end{aligned}
$$

Cuja solução é dada por:

$$
\begin{aligned}
& \frac{d \varphi}{d t}=-\gamma B_{0} \Rightarrow \omega_{L}=\gamma B_{0}, \\
& \frac{d \theta}{d t}=0 .
\end{aligned}
$$

Essa solução diz que, dado a aplicação de um campo constante, sem levar em consideração a interação com a vizinhança, a velocidade angular é constante e tem módulo igual à freqüência de Larmor, com ângulo $\theta$ constante.

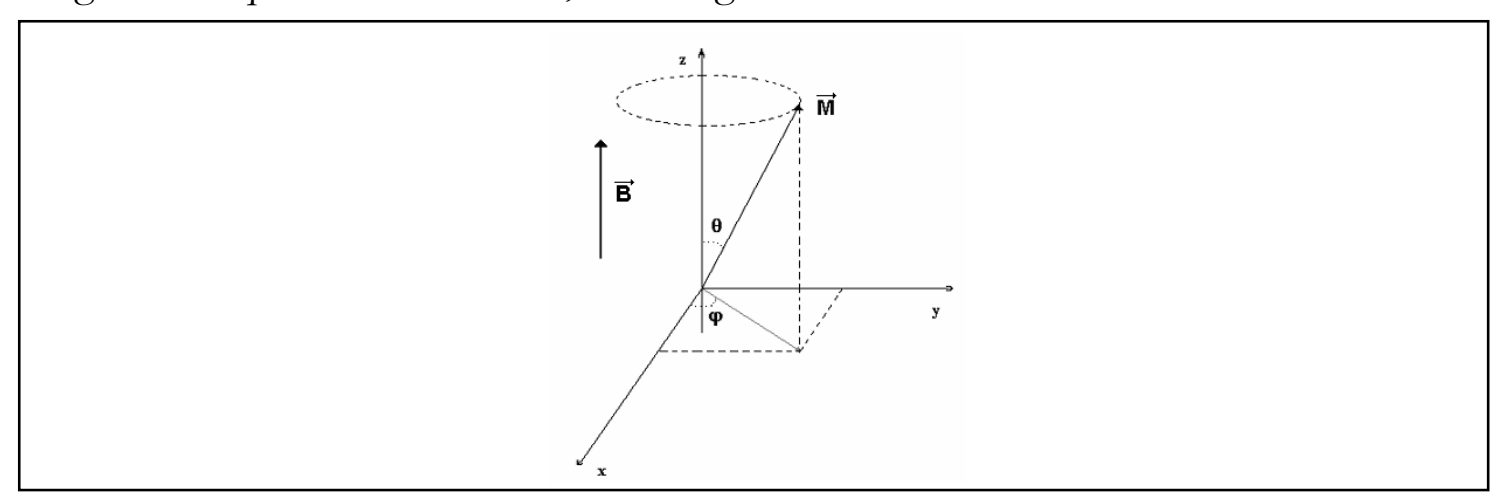

Figura A.3. Apresentação esquemática da magnetização em relação a um campo magnético aplicado.

Com já foi dito, para que o momento magnético seja capaz de induzir uma corrente na bobina, ele tem que produzir um campo magnético variável dentro da 
bobina. E para isso deve-se mudar a orientação do vetor $\vec{M}$, isto é, encontrar situações em que $\frac{d \theta}{d t} \neq 0$. Para que isso ocorra é necessário a aplicação de um segundo campo $\overrightarrow{B_{1}}$, circularmente polarizado no plano x-y e com freqüência de oscilação $\omega$, de modo que:

$$
\overrightarrow{B_{1}}=B_{1}[\cos (\omega t) \hat{i}-\operatorname{sen}(\omega t) \hat{j}]
$$

Acrescentando $\overrightarrow{B_{1}}$ em (A.11) obtém-se a seguinte equação:

$$
\frac{d \vec{M}}{d t}=\gamma \vec{M} x\left(\vec{B}+\overrightarrow{B_{1}}\right)
$$

Cuja solução é:

$$
\frac{d \varphi}{d t}=-\gamma\left[B_{1} \cos (\omega t+\varphi)-B_{0}\right], \mathrm{e}
$$

$$
\frac{d \theta}{d t}=-\gamma B_{1} \operatorname{sen}(\omega t+\theta)
$$

No caso em que $\overrightarrow{B_{1}}$ oscila com freqüência de Larmor, $\omega_{L}=\gamma B_{0}$ :

$$
\varphi=-\gamma B_{0} t-\frac{\pi}{2}
$$

Em adição $\frac{d \theta}{d t}$ apresenta valor máximo quando $\operatorname{sen}(\omega t+\theta)=1$, e nesse caso tem-se:

$$
\frac{d \theta}{d t}=\gamma B_{1} \text { ou } \theta=\gamma B_{1} t^{\prime}
$$

em que $t$ 'é o tempo de aplicação do campo $\overrightarrow{B_{1}}$.

As equações (A.18) e (A.19) perfazem a base da ressonância. A aplicação de um campo magnético $\overrightarrow{B_{1}}$ circularmente polarizado provoca a alteração no estado de magnetização do sistema. Sendo que a rotação induzida no vetor de magnetização depende da intensidade do campo $\overrightarrow{B_{1}}$ e do tempo de aplicação do campo $t$ '. Na prática esse tempo é muito curto de modo a ser denominado, por um pulso de rádio freqüência. Se o ângulo $\theta=\pi / 2$ ou $90^{\circ}$ denomina-se esse pulso por pulso de $90^{\circ}$. 
Esse pulso de rádio freqüência é aplicado através de uma bobina que circunda a amostra, introduzindo um campo ortogonal ao eixo principal do magneto. Muito freqüentemente essa bobina é utilizada também para a detecção do sinal.

\section{A.3 Processo de relaxação}

Depois de desligado o campo de RF, a magnetização tende a retornar para o estado de mais baixa energia, no qual os spins estão orientados paralelos ao campo. Esse efeito é descrito fenomenologicamente por dois fatores os quais dão origem a duas constantes de relaxação distintas $\mathrm{T}_{1}$ e $\mathrm{T}_{2}$.

\section{A.3.1 Relaxação $T_{1}$}

Da mesma forma que um campo magnético de radio freqüência, externamente aplicado, pode alterar o estado dos spins, as flutuações aleatórias dos momentos magnéticos das moléculas vizinhas também podem afetar a orientação dos spins. Mesmo que o resultado dessas flutuações aleatórias seja pequeno, ele pode conter componentes de movimento que estão na freqüência de Larmor, que envolve a energia característica $(\Delta \mathrm{E}=\mathrm{h} v)$, dos núcleos no campo magnético estático. É esse movimento aleatório das moléculas (translacional, rotacional e modos de vibração do movimento) que promove a flutuação no campo magnético necessária para que os spins possam alterar seus estados de energia para, preferencialmente, orientaremse ao longo da direção longitudinal (z).

Geralmente, existe um amplo espectro de movimentos moleculares em torno de uma extensa banda de freqüências. O módulo dessas flutuações aleatórias do campo magnético na freqüência correta (Larmor) determina a eficiência com que a magnetização nuclear pode mudar seu valor. Isso explica como diferentes tecidos possuem diferentes tempos de relaxação $\mathrm{T}_{1}$. Assim, por exemplo, dipolos magnéticos de pouca mobilidade, como aqueles presentes em ossos ou cartilagens, cuja faixa de freqüência possui valores baixos no espectro, influenciam pouco sobre os tempo de relaxação $T_{1}$. Nesses tecidos, os tempos de relaxação $T_{1}$ característicos são habitualmente longos. No outro extremo, moléculas que se movem com velocidades mais altas têm características espectrais bastante largas, contribuindo pouco na faixa 
que engloba $\omega_{\mathrm{L}}$. Nesse caso, os tempos $\mathrm{T}_{1}$ característicos também são longos. Em uma situação intermediária, moléculas de água ligadas a macromoléculas de proteínas, por exemplo causam a redução do movimento da água e favorecem a relaxação $\mathrm{T}_{1}$.

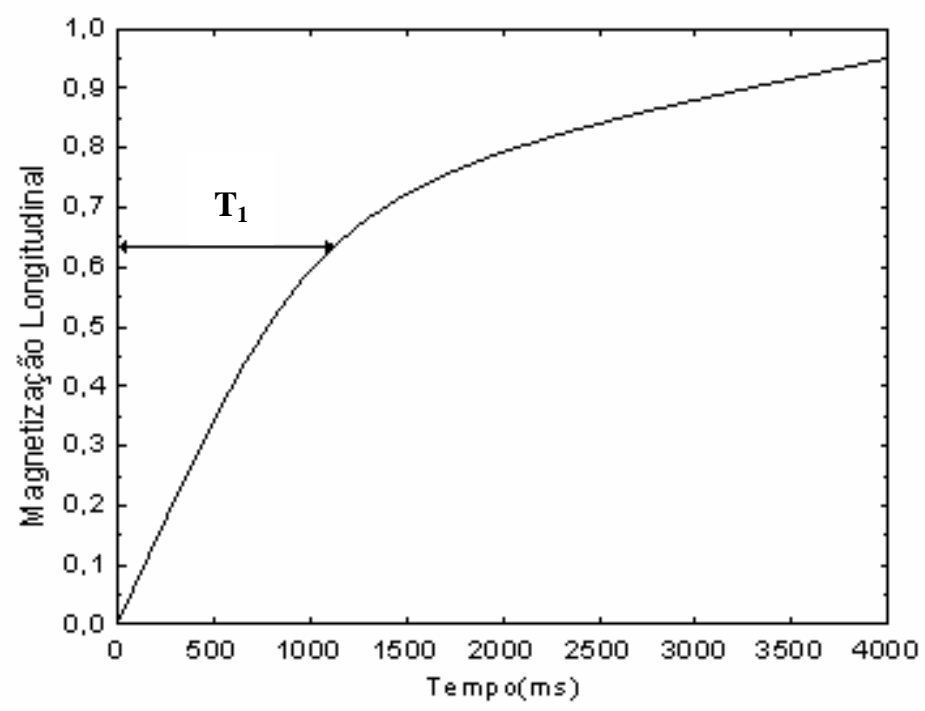

Figura A.4. Recuperação da magnetização longitudinal $M_{\mathrm{z}}$ depois de um pulso de $90^{0}$. É um processo exponencial, cuja constante de tempo é descrita pela constante de relaxação longitudinal $T_{1}$. A curva mostrada é para o caso de $\mathrm{M}_{\mathrm{z}} \mathrm{em} \mathrm{t}=0$.

A relaxação $T_{1}$ é um processo exponencial. Sempre que o vetor magnetização é tirado do equilíbrio, a componente- $Z$ da magnetização irá recuperar-se de forma exponencial, como mostrado na figura A.4. Esse gráfico mostra a recuperação da magnetização longitudinal em função do tempo no caso em que a magnetização longitudinal é zero em $t=0$. O tempo de relaxação é definido através de um conjunto de equações, conhecidas como equações de Bloch. A equação relevante para o processo de $\mathrm{T}_{1}$ é:

$$
\frac{d M_{z}}{d t}=-\frac{M_{z}-M_{0}}{T_{1}}
$$

Em que, $M_{z}$ é a projeção da magnetização no eixo $z$ e $M_{0}$ a magnetização inicial.

No caso em que a magnetização longitudinal é zero em $t=0$, a equação acima pode ser simplificada por:

$$
M_{z}(t)=M_{0}\left(1-e^{-t / T_{1}}\right)
$$


T 1 será o tempo necessário para $63 \%$ da magnetização $\mathrm{M}_{0}$ voltar para o equilíbrio (ou seja, paralela ao campo $\vec{B}$ ). Na tabela A.1, valores típicos da relaxação $T_{1}$ para alguns tecidos do corpo humano são apresentados.

\begin{tabular}{|l|l|l|}
\hline Tecido & $\mathrm{T}_{1}(\mathrm{~s})$ & $\mathrm{T}_{2}(\mathrm{~ms})$ \\
\hline CSF & $0.8-20$ & $110-2000$ \\
\hline Matéria Branca & $0.76-1.08$ & $61-100$ \\
\hline Matéria Cinzenta & $1.09-2.15$ & $61-109$ \\
\hline Meninges & $0.5-2.2$ & $50-165$ \\
\hline Músculos & $0.95-1.82$ & $20-67$ \\
\hline Gordura & $0.2-0.75$ & $53-94$ \\
\hline
\end{tabular}

Tabela A.1. Tempos de relaxação característicos de alguns tecidos do corpo humano.

\section{A3.2 Tempo de relaxação $T_{2}$ e $T_{2}{ }^{*}$}

Enquanto a relaxação $T_{1}$ é o processo de recuperação da magnetização longitudinal, a relaxação $\mathrm{T}_{2}$ e $\mathrm{T}_{2} *$ são processos de decaimento da magnetização transversal.

Após a aplicação de um pulso de $90^{\circ}$, toda a magnetização que estava orientada ao longo do eixo-Z irá ser jogada para o plano transverso. Para um ímã perfeito e uma amostra ideal, todos os núcleos iriam experimentar o mesmo campo magnético aplicado e a magnetização transversa iria permanecer forte e coerente, rotacionando com freqüência de Larmor enquanto o processo de relaxação $T_{1}$ estivesse ocorrendo. Em uma amostra real, a perturbação aleatória dos núcleos da vizinhança e imperfeições do campo magnético principal irão afetar a coerência através de flutuações aleatórias de baixa freqüência do campo local ao nível molecular fazendo com que a freqüência de Larmor de diferentes núcleos varie. No decorrer do tempo, esse aumento ou diminuição da freqüência de Larmor faz com que haja uma perda de coerência dos spins e, portanto, uma perda de magnetização transversal e de sinal.

Com relação às perturbações aleatórias dos núcleos da vizinhança que causam variações locais do campo estático $\vec{B}$, estas são provocadas por processos semelhantes aos descritos anteriormente para $\mathrm{T}_{1}$. Contudo, somente flutuações de baixa freqüência têm efeito preponderante sobre $T_{2}$. Além disso, fica claro que flu- 
tuações em torno da freqüência de Larmor, que induzem $T_{1}$, também resultam numa perda da magnetização transversal, provocando, indiretamente, um encurtamento de $\mathrm{T}_{2}$. Por esse motivo simples, $\mathrm{T}_{2}$ é sempre menor ou igual a $\mathrm{T}_{1}$.

O tempo de relaxação $T_{2}$ é uma medida da taxa de decaimento da magnetização transversal, e também é governada por um processo exponencial. A equação de Bloch relevante para o decaimento $\mathrm{T}_{2}$ é:

$$
\frac{d M_{x y}}{d t}=-\frac{M_{x y}}{T_{2}},
$$

que resolvendo, encontra-se uma equação exponencial simples $M_{x y}(t)=M_{x y}(0) e^{-t / T_{2}}$. A tabela A.1 também mostra valores típicos de $\mathrm{T}_{2}$ para alguns tecidos humanos.

Com relação à não homogeneidade do campo magnético principal, muito embora o efeito de ressonância dependa de um campo magnético estático $\vec{B}$, as imperfeições instrumentais são inevitáveis. São essas imperfeições que causam as variações locais, as quais dependem diretamente do aparelho em uso. O que motiva a definição de um tempo de relaxação $\mathrm{T}_{2}{ }^{*}$, que reflete os dois processos: flutuações locais e inomogeneidade de campo. Pode-se definir $\mathrm{T}_{2}{ }^{*}$ como:

$$
\frac{1}{T_{2} *}=\frac{1}{T_{2}}+\frac{1}{T_{2}^{\text {inom }}}
$$

Em que $T_{2}$ inom está ligado a não homogeneidade de campo. Pode-se notar, então, que $\mathrm{T}_{2}{ }^{*}$ quantifica não só as propriedades da matéria em questão, mas também propriedades do equipamento de medida.

\section{A.4 Free Induction Decay (FID)}

Foi visto que o vetor magnetização alinha-se com o campo magnético estático (que por convenção está na direção z), quando há um equilíbrio térmico. Se um pulso de $90^{\circ}$ é aplicado, a orientação deste vetor, imediatamente após o pulso, estará no plano-xy. O vetor magnetização irá, agora, precessionar no plano transversal. Se existir uma bobina receptora posicionada convenientemente no plano x-y, à medida que o vetor magnetização cruza a seção transversal da bobina, pode-se medir a voltagem nela induzida. Uma corrente elétrica é, então, induzida na bobina devido a 
essa variação no tempo da componente da magnetização ao longo do seu eixo. Essa corrente é detectada como um sinal chamado de Free Induction Decay ou FID.

A corrente induzida na bobina receptora produz um sinal oscilante que tem a mesma freqüência da precessão do vetor magnetização (freqüência de Larmor). Devido aos processos de relaxação $\mathrm{T}_{1}$ e $\mathrm{T}_{2}{ }^{*}$ o vetor de magnetização no plano x-y é amortecido, perdendo coerência de fase e redirecionando-o no sentido da conformação original, i.e., paralelo ao campo. Desse modo, observa-se um padrão de decaimento da magnetização, na bobina receptora, demonstrado na figura A.5. O sinal medido no plano transversal x-y é proveniente de toda a amostra e varia no tempo, e tem a forma:

$$
S(t) \propto e^{i \omega t} e^{-t / T_{2}^{*}}
$$

Note-se que, na expressão anterior, os dois tempos de relaxação aparecem. Muito embora $T_{1}$ não esteja explícito, ele está embutido na distribuição de $\mathrm{S}_{0}$, que, no fundo, reflete a magnetização que, por sua vez, reflete a densidade de spins.

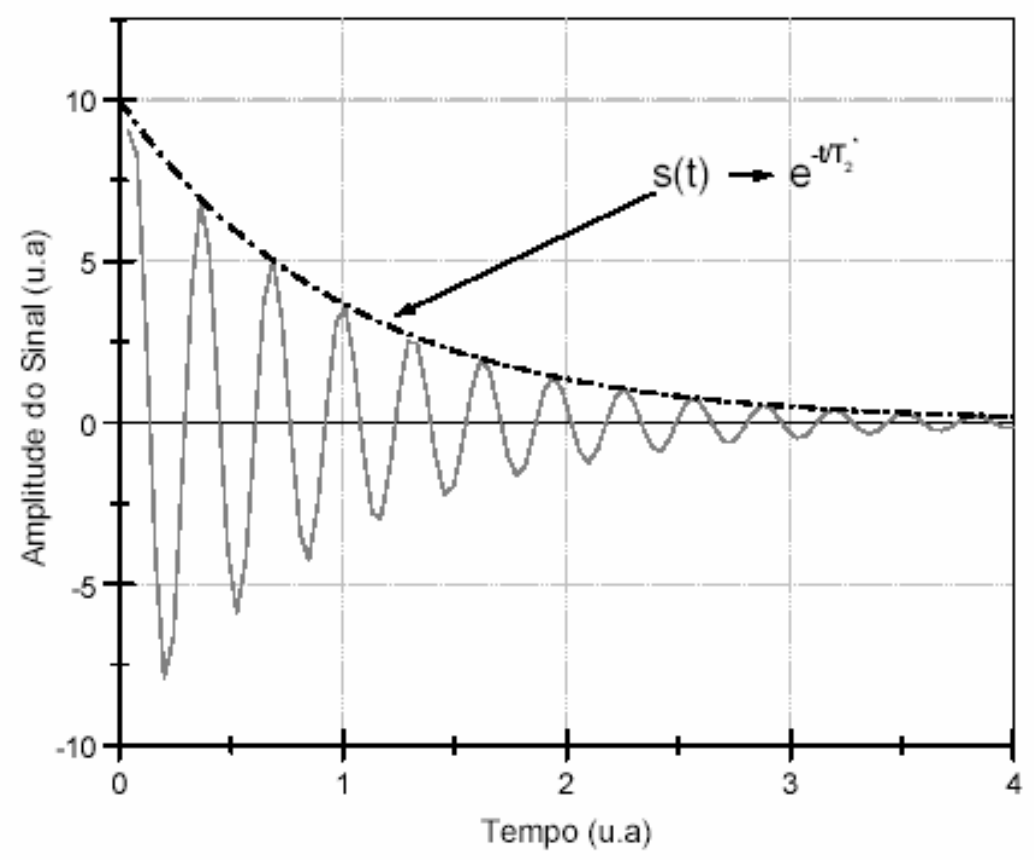

Figura A.5. Diagrama que representa o sinal detectado por bobinas de indução localizadas sobre o plano $x$-y em função do tempo. Esse padrão de sinal é conhecido por FID, e retrata o efeito de $T_{2}{ }^{*}$ na amplitude do sinal detectado. 


\section{A.5 Spin echo}

Uma simples variação do sinal FID pode ser obtida se, após o pulso de $90^{\circ}$, for aplicado um pulso capaz de refocalizar de $180^{\circ}$. Isso pode ser visto na figura A.6.

Após a aplicação de um pulso de $90^{\circ}$ (fgura A.6a), os spins começarão a precessionar no plano $\mathrm{x}-\mathrm{y}$. Devido à relaxação $\mathrm{T}_{2}$, os spins perdem coerência temporal (figura A.6c), ou seja, precessionam com velocidades ligeiramente diferentes, ocasionando uma diferença de fase relativa entre eles.

Decorrido um tempo $\tau$, aplica-se um pulso de $180^{\circ}$ (figura A.6d) cuja intenção é gira todos os spins em torno do eixo y. Isso faz com que aqueles spins que estão girando mais rapidamente fiquem em posição atrasada com relação aos que estão girando mais lentamente (figura A.6e). Porém, a velocidade de precessão dos spins não foi alterada, fazendo com que em um tempo $2 \tau$ acorra um eco (figura A.6f), isto é, os spins voltam a se aliarem em fase. Esse tempo de refocalização é conhecido como tempo ao eco, TE.

Se o campo fosse perfeitamente homogêneo, a amplitude do sinal de eco detectado seria idêntica ao do primeiro FID, que segue o pulso de $90^{\circ}$. Porém, como já foi dito, a perda de coerência de fase (que corresponde neste caso, a perda de magnetização transversal) não é devida exclusivamente à falta de homogeneidade de campo, mas também às interações naturais entre os spins. Como conseqüência da natureza aleatória desse segundo processo, ele é irreversível, não podendo ser refocalizado. Desse modo, a amplitude do eco decairá no tempo, seguindo a constante característica $\mathrm{T}_{2}$.

Purcell desenvolveu, a partir da idéia de aplicação de pulsos de $180^{\circ}$, um método para medir $\mathrm{T}_{2}$ independente de $\mathrm{T}_{2}{ }^{*}$, conhecido como método de CarrPurcell (figura A.7). Esse método consiste na aplicação de pulsos de $180^{\circ}$ seqüencialmente em $3 \tau, 5 \tau, 7 \tau \ldots$ sem a aplicação do pulso refocalizador de $90^{\circ}$, o que causa o reaparecimento dos padrões de eco em $4 \tau, 6 \tau, 8 \tau \ldots$ e permite uma medida efetiva do tempo $\mathrm{T}_{2}$. 


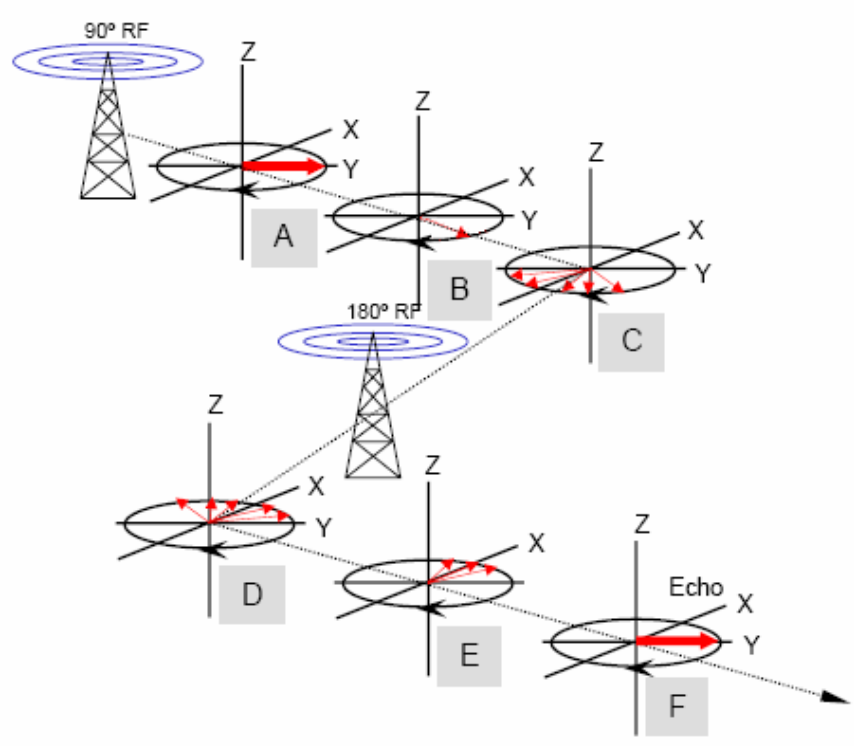

Figura A.6. Seqüência temporal dos pulsos aplicados e influencia desses sobre o spin. (a) Aplicação do pulso de 900. (b) Precessão em fase. (c) Efeito da relaxação longitudinal. (d) Aplicação do pulso de 1800. (e) Posição dos vetores de magnetização após o pulso. (f) Efeito de eco dos spins. Figura tirada Blinck E. J. MRI principle, 2004)

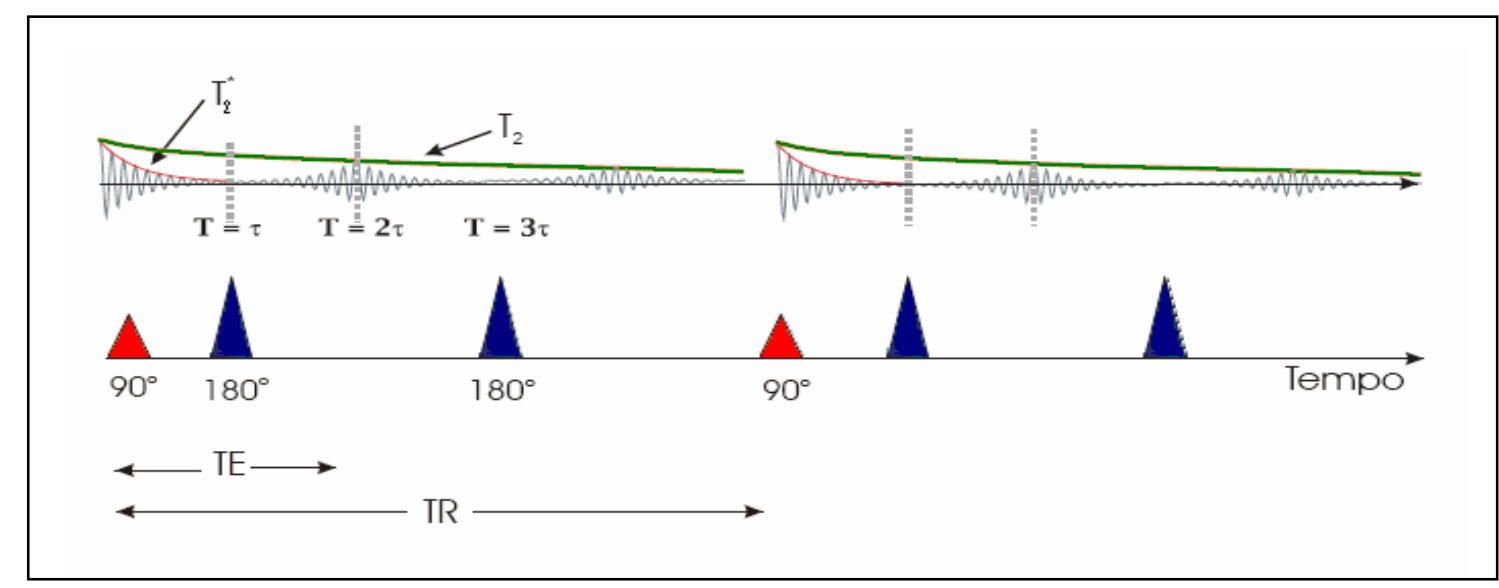

Figura A.7. Seqüência de pulsos Spin-echo (Método de Carr-Purcell). A aplicação de sucessivos pulsos de 1800 faz aparecerem múltiplos padrões de eco. Observa-se a separação entre T2 (linha verde) e T2* (linha vermelha). TR é o tempo de repetição do pulso excitatório de $90^{\circ}$.

\section{A.6 Localização espacial}

Um fato importante da MRI é que a resolução espacial do sinal NMR pode ser obtida variando-se o campo magnético espacialmente. Considere a equação de Larmor (equação (A.10)). Se o campo magnético na direção-Z for variável, por exemplo, a equação de Larmor ficará da seguinte forma:

$$
\omega_{L}(z)=\gamma B_{0}(z)
$$


Em outras palavras, a freqüência de Larmor do spin irá depender da posição z. A variação espacial mais simples do campo magnético é uma variação linear, na qual o campo magnético na direção $\mathrm{z}$ é diretamente proporcional à coordenada $\mathrm{z}$. Essa variação linear pode ser facilmente conseguida tendo-se corrente passando por duas bobinas paralelas como mostra a Figura A.8. No ponto central $(z=0)$, o campo magnético adicional gerado pelas duas bobinas se cancelam e, portanto, $\omega_{L}(0)=\gamma B_{0}$. Na direção $+z$, no entanto, a bobina direita irá aumentar o campo magnético local fazendo com que $\omega_{L}(+z)=\gamma B_{0}+\gamma G_{z} z$, na qual $G_{Z}$ o gradiente de campo gerado pelas bobinas. Inversamente, na direção $-Z$, a bobina diminui o campo magnético local, assim: $\omega_{L}(-z)=\gamma B_{0}-\gamma G_{z} z$.

Se um gradiente de campo na direção $z, B_{z}$, variar $\operatorname{com} x, y$ e $z$, ou seja $G_{x}=\frac{\partial B_{z}}{\partial x}$; $G_{y}=\frac{\partial B_{z}}{\partial y} ; G_{z}=\frac{\partial B_{z}}{\partial z}$ pode-se escrever:

$$
\omega_{L}(\vec{r})=\gamma\left(B_{0}+\vec{G} \cdot \vec{r}\right)
$$

em que $\vec{G}=\left(\overrightarrow{G_{x}}, \overrightarrow{G_{y}}, \overrightarrow{G_{z}}\right)$.

Assim, é possível iden-

tificar a posição $\vec{r}$ através da freqüência de precessão $\omega_{L}(\vec{r})$.

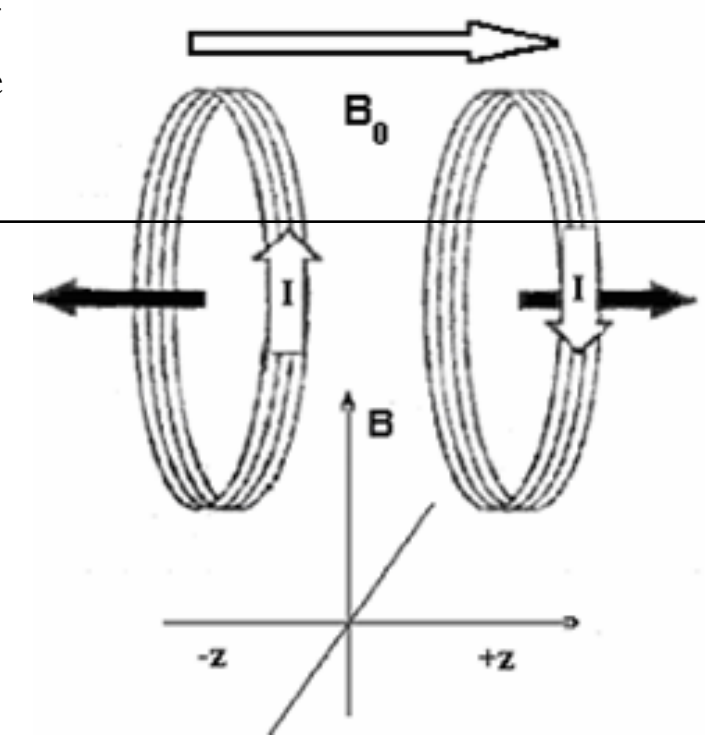

Figura A.8. Par de bobinas que geram um gradiente de campo que varia na direção do eixo da\$ bobinas. 


\section{A.6.1 Seleção da fatia}

Nas imagens por MR, primeiro, geram-se imagens 2D obtidas de fatias préselecionadas, para depois poder ser feito a reconstrução de todas estas fatias e assim, obter uma imagem 3D.

Para a seleção de uma fatia da amostra, aplica-se um gradiente Gz, fazendo com que os núcleos dos átomos desta fatia precessionem a uma dada freqüência. Em seguida pode-se girar a magnetização dos núcleos dessa fatia pela aplicação de um pulso de RF contendo uma faixa de freqüências e excitar prótons com freqüência de Larmor dentro desta faixa.

Para que cada fatia tenha uma largura, um grupo de núcleos deve ser excitado pelo pulso. Essa largura está ligada diretamente com a inclinação do gradiente selecionador $G_{z}$. Gradientes com inclinação elevada geram fatias finas enquanto gradientes moderados geram fatias grossas como pode ser visto na figura A.9.

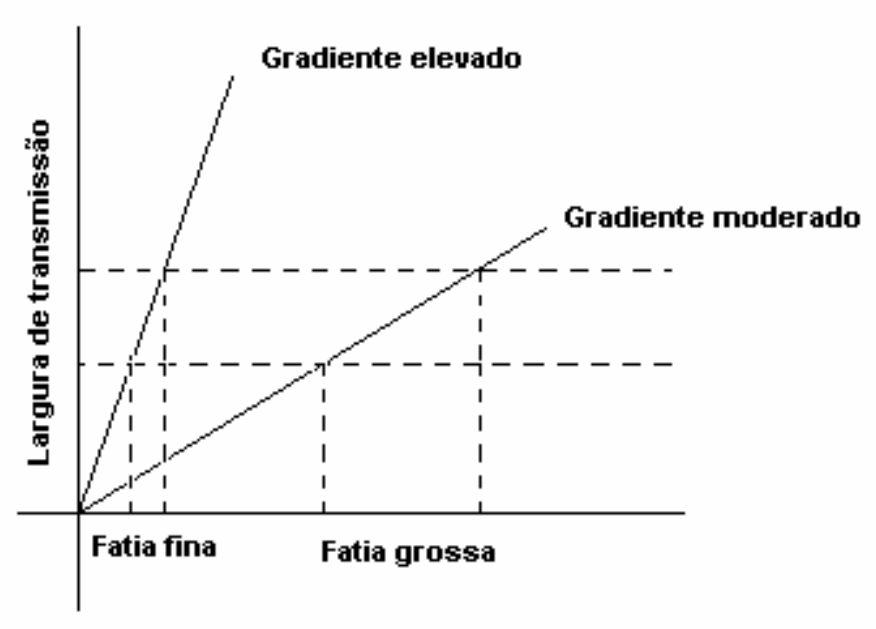

Figura A.9. Relação entre o gradiente e a largura da fatia.

\section{A.6.2 Imageamento de Fourier}

O método de seleção de fatia descrito na seção A.6.1 é raramente utilizado em seqüências de imagens modernas por ser bastante propenso a artefatos na imagem. O método escolhido pela maior parte dos scanners modernos é o método de 
Imageamento de Fourier, que foi inicialmente proposto por Edelstein (Edelstein et al., 1980).

O imageamento de Fourier baseia-se na transformada de Fourier. Transformada de Fourier de um sinal é a decomposição deste sinal na soma de termos puros de senos e cossenos de diferentes amplitudes e freqüências. Isto pode ser visto esquematicamente na figura A.10, na qual um sinal unidimensional foi decomposto em termos puros de senos e cossenos. Para se representar corretamente uma imagem de $\mathrm{N}$ pontos é necessária a soma de pares de senos e cossenos com $\mathrm{N}$ freqüências, dadas por $\mathrm{n} 2 \pi / \mathrm{FOV}$, com $\mathrm{n}$ variando de $-\mathrm{N} / 2$ até $\mathrm{N} / 2$ e o FOV (do inglês, field of view) é o campo de visão de um objeto.

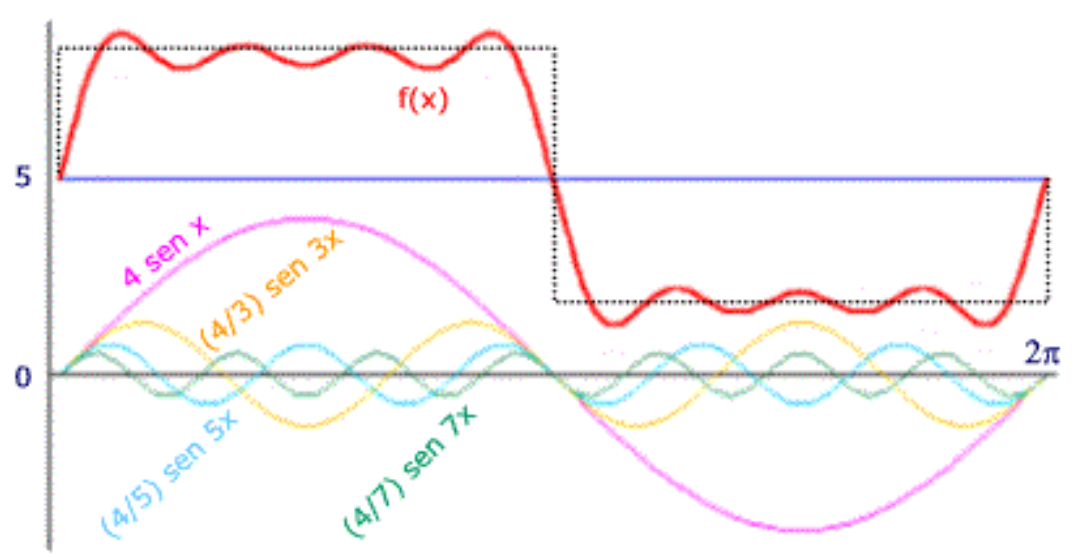

Figura A.10. A curva vermelha é a função $f(x)$ resultante de: $f(x)=5+4$ sen $x+(4 / 3)$ sen $3 x+(4 / 5)$ sen $5 x+(4 / 7)$ sen $7 x+\ldots$ (só com as 5 parcelas explicitadas na equação). Esta série é a representação de uma onda quadrada. Notar que, com 5 parcelas, já ocorre uma certa aproximação. Se infinitas parcelas fossem somadas, o resultado seria uma forma perfeita conforme indicado pela linha tracejada. Para a reconstrução da imagem é necessário que, primeiramente, determine-se os coeficientes de Fourier, como será mostrado a seguir.

\section{A.6.3 Espaço-K}

A maneira de se adquirir as componentes de Fourier deve seguir uma seqüência de pulsos e gradientes apropriada. Será mostrada, brevemente, a base matemática entre a obtenção dos coeficientes de Fourier e a reconstrução da imagem.

A freqüência de precessão de Larmor para um elemento de volume na posição $(\mathrm{x}, \mathrm{y})$ de uma fatia previamente excitada é dada por:

$$
\omega_{L}(x, y)=\gamma B_{0}+\gamma G_{x} x+\gamma G_{y} y .
$$

Assim, após a excitação por um pulso de RF, a magnetização de um elemento de volume terá um aumento de fase relativa ao eixo $\mathrm{x}$ dada por 
$\phi(x, y, t)=\omega_{L}(x, y) t$, sendo t o tempo após a excitação. $\mathrm{O}$ sinal induzido na bobina receptora devido a precessão desta magnetização é um vetor com magnitude igual a densidade de spins $\rho(x, y)$ na posição $(\mathrm{x}, \mathrm{y})$ multiplicada pelo tamanho do pixel ${ }^{4}$, dxdy, cuja fase é igual a $\phi(x, y, t)$.

A contribuição do sinal da posição $(\mathrm{x}, \mathrm{y}), \mathrm{dS}(\mathrm{x}, \mathrm{y})$, pode ser escrita por:

$$
\begin{aligned}
d S(x, y, t)= & \rho(x, y)\left\{\cos \left[\left(\gamma B_{0}+\gamma G_{x} x+\gamma G_{y} y\right) t\right]+\right. \\
& \left.i \operatorname{sen}\left[\left(\gamma B_{0}+\gamma G_{x} x+\gamma G_{y} y\right) t\right]\right\} d x d y
\end{aligned}
$$

Se for feita uma rotação de coordenadas na equação (A.28) pode-se ignorar a contribuição dada pelo campo magnético estático e o sinal que realmente é armazenado pelo scanner pode ser dado por:

$$
\begin{array}{r}
S(t)=\iint \rho(x, y)\left\{\cos \left[\left(\gamma G_{x} x+\gamma G_{y} y\right) t\right]+\right. \\
\left.i \operatorname{sen}\left[\left(\gamma G_{x} x+\gamma G_{y} y\right) t\right]\right\} d x d y
\end{array}
$$

Em que se somou a contribuição de todos os elementos em x e y, do plano selecionado resultando em um sinal total dado por $\mathrm{S}(\mathrm{t})$.

Fazendo $k_{x}(t)=\gamma G_{x} t$ e $k_{y}(t)=\gamma G_{y} t$ e substituindo na equação (A.29):

$$
S(t)=\iint \rho(x, y)\left\{\cos \left(k_{x}(t) x+k_{y}(t) y\right)+i \operatorname{sen}\left(k_{x}(t) x+k_{y}(t) y\right)\right\} d x d y .
$$

Com base na teoria de Fourier, nota-se que a equação (A.30) é uma equação de Fourier com o sinal $\mathrm{S}(\mathrm{t})$ e $\rho(x, y)$ formando um par de Fourier. Portanto, considerando-se um tempo fixo, obtém-se um a partir do outro e vise versa de acordo com as equações abaixo:

$$
S\left(k_{x}, k_{y}\right)=\iint \rho(x, y)\left\{\cos \left(k_{x} x+k_{y} y\right)+i \operatorname{sen}\left(k_{x} x+k_{y} y\right)\right\} d x d y,
$$

$$
\rho(x, y)=\iint S\left(k_{x}, k_{y}\right)\left\{\cos \left(k_{x} x+k_{y} y\right)-i \operatorname{sen}\left(k_{x} x+k_{y} y\right)\right\} d k_{x} d k_{y} .
$$

O valor de $\rho(x, y)$ é exatamente o necessário para se criar a imagem, mostrando assim, a ligação direta entre o sinal medido $\mathrm{S}(\mathrm{t})$ com a imagem gerada e os gradientes de campo.

\footnotetext{
${ }^{4} \mathrm{~A}$ imagem é formada por pequenos elementos de área ou pixels, cada pixel corresponde a um elemento de volume ou voxel.
} 


\section{$\rightarrow$ Representação esquemática do espaço $k$}

O processo de imageamento é, portanto, o modo de se adquirir ou varrer o espaço dos k's, dado pelas equações $k_{x}(t)=\gamma G_{x} t$ e $k_{y}(t)=\gamma G_{y} t$, em toda a área da amostra. A figura A.11. apresenta, esquematicamente, a passagem do espaço de $\mathrm{S}\left(\mathrm{k}_{\mathrm{x}}, \mathrm{k}_{\mathrm{y}}\right)$ para o espaço de $\rho(\mathrm{x}, \mathrm{y})$.
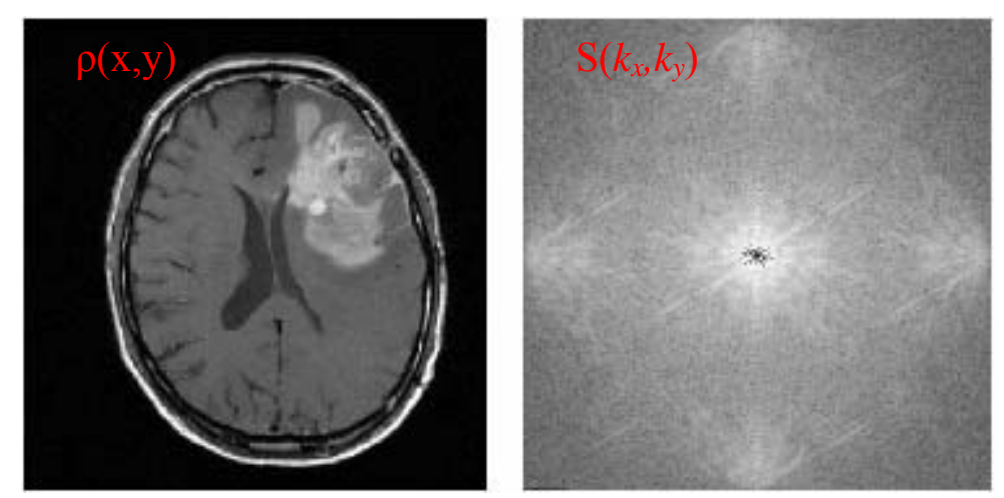

Figura A.11. A figura da direita apresenta a transformada de Fourier da imagem da esquerda.

O objetivo de cada seqüência de pulso é adquirir o espaço k de modo mais rápido. O tempo de aquisição depende do tempo de aplicação e a intensidade dos gradientes e pulsos de RF.

Como exemplo da varredura do espaço k será apresentado a seqüência de EPI (do inglês, Echo Planar Imaging) por ser muito utilizada na obtenção de imagens funcionais por ressonância magnética (Funcional Magnetic Resonance Imaging- fMRI) devido a sua grande rapidez.

\section{A.6.4 EPI}

Enquanto seqüências habituais têm sua resolução temporal limitada a alguns segundos, para a formação de um volume de imagens, a EPI alcança a ordem de alguns milisegundos.

Para reduzir o tempo de aquisição por imagem, a EPI captura todas as linhas do espaço k em um único TR. Uma maneira bastante conveniente de apresentar uma seqüência de pulsos é através dos diagramas de seqüências de pulso (DSP), geralmente utilizados para descrever a implementação de uma seqüência particular. Na figura A.12 observa-se a evolução temporal da seqüência EPI: aplicação de pul- 
sos de RF acompanhados dos diferentes gradientes ( $\mathrm{Gx}, \mathrm{Gy}, \mathrm{Gz})$. A forma dos gradientes apresentados nos diagramas define o tempo e intensidade de sua aplicação.

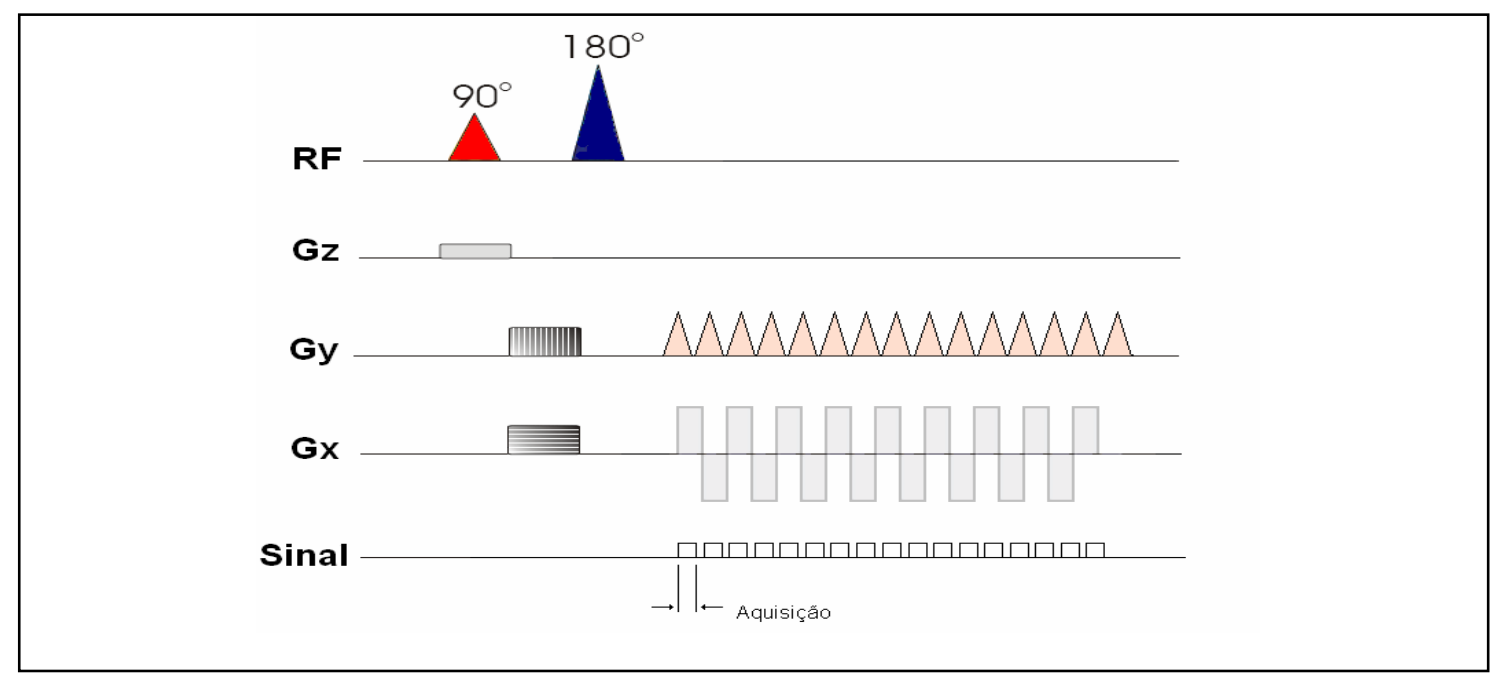

Figura A.12. Representação esquemática de uma seqüência de pulsos EPI, em que se apresenta a varredura das posições através da aplicação dos gradientes. Na linha em que se representa o sinal, os quadrados representam o tempo em que se realiza a aquisição.

Podemos resumir a seqüência EPI da seguinte forma:

1. Aplica-se um pulso excitatório de $90^{\circ}$ e, simultaneamente, um gradiente selecionador de fatias $\mathrm{Gz}$;

2. Através da aplicação de gradientes $G x$ e $G y$, os spins são levados para a posição inferior do espaço k (primeira linha);

3. Aplica-se um pulso de $180^{\circ}$;

4. Um gradiente codificador em $x, \mathrm{Gx}$, é aplicado em conjunto com um gradiente codificador em y, Gy, e o sinal é lido simultaneamente adquirindo assim, uma linha no espaço $k$.

5. O gradiente codificador em $x$ é invertido e aplicado em conjunto com o outro gradiente de fase e o sinal é novamente lido, adquirindo assim a linha seguinte do espaço $k$, porém em direção invertida com relação à primeira.

A respectiva varredura no espaço ke está representada na figura A.13. 


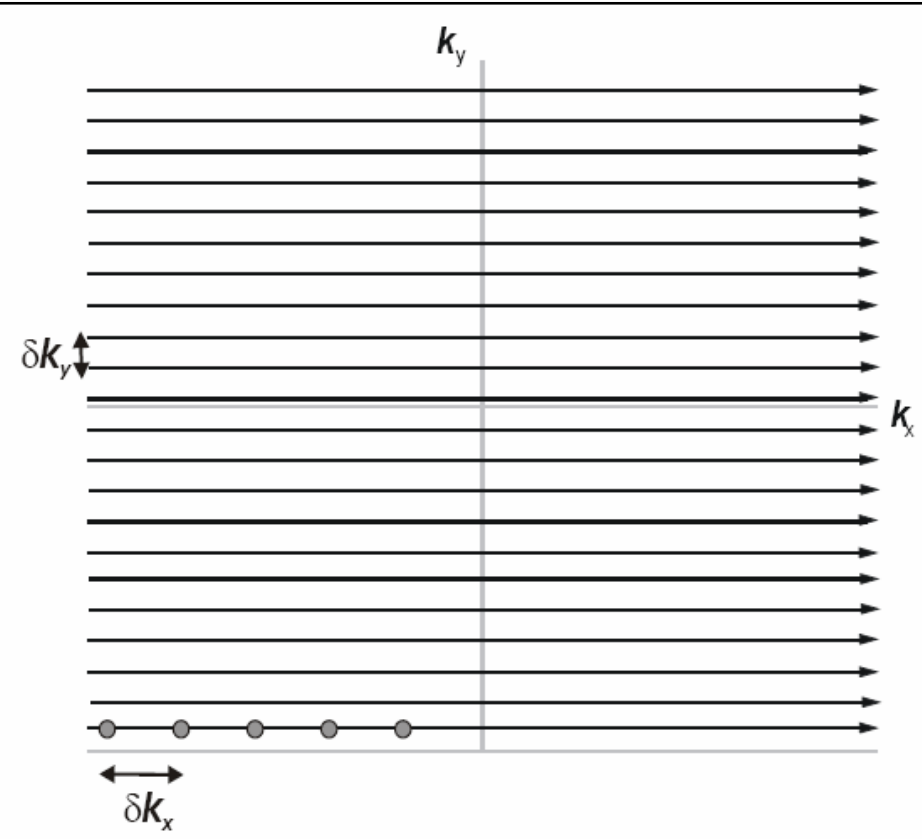

Figura A.13. Figura de preenchimento do espaço-k para uma seqüência de pulsos simples do tipo eco de spin. A freqüência é codificada na direção $x$, e a fase, na direção y.

Além de sua aplicação em imagens cardíacas, de abdômen e de fluxo, nos últimos anos essas seqüências de pulso vieram servir a um outro propósito: a obtenção de imagens capazes de mapear o cérebro em tempos relativamente curtos. Dentre as principais aplicações, podemos destacar as imagens por difusão e a fMRI.

Embora a EPI seja muito utilizada para obtenção de imagens funcionais por possuir boa resolução temporal, ela exige muito do aparelho e não permite obtenção de imagens com matrizes maiores que 256x256 o que, muitas vezes, não é suficiente para imagens anatômicas. 